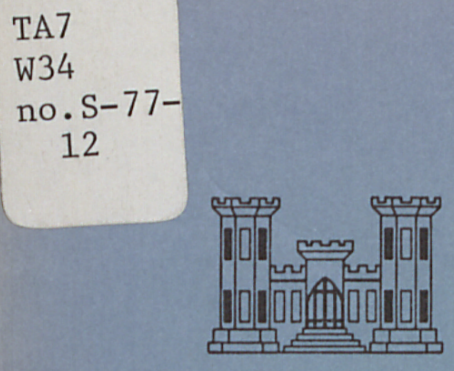

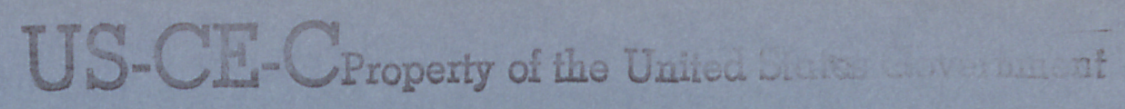

TECHNICAL REPORT S-77-12

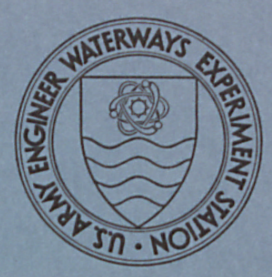

\title{
AIRFIELD PAVEMENT SMOOTHNESS REQUIREMENTS
}

\author{
by \\ Walter J. Horn \\ Soils and Pavements Laboratory \\ U. S. Army Engineer Waterways Experiment Station \\ P. O. Box 63I, Vicksburg, Miss. 39180
}

November 1977

Final Report

Approved For Public Release; Distribution Unlimited

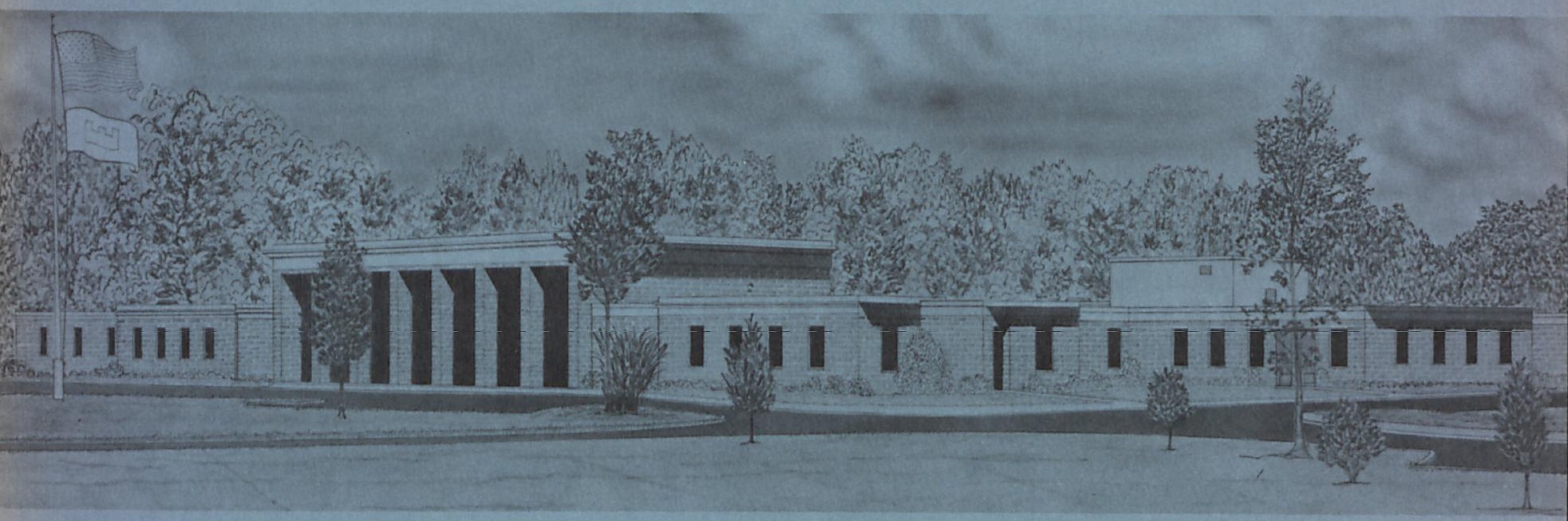

Prepared for Office, Chief of Engineers, U. S. Army

Washington, D. C. 20314 


\begin{tabular}{|c|c|}
\hline REPORT DOCUMENTATION PAGE & $\begin{array}{l}\text { READ INSTRUCTIONS } \\
\text { BEFORE COMPLETING FORM }\end{array}$ \\
\hline \begin{tabular}{l|l} 
1. REPORT NUMBER & 2. GOVT ACCESSION NO. \\
Technical Report S-77-12 &
\end{tabular} & 3. RECIPIENT'S CATALOG NUMBER \\
\hline \multirow[t]{2}{*}{$\begin{array}{l}\text { 4. TITLE (and Subtitı) } \\
\text { AIRFIELD PAVEMENT SMOOTHNESS REQUIREMENTS }\end{array}$} & $\begin{array}{l}\text { 5. TYPE OF REPORT \& PERIOD COVERED } \\
\text { Final report }\end{array}$ \\
\hline & 6. PERFORMING ORG. REPORT NUMBER \\
\hline $\begin{array}{l}\text { 7. AUTHOR(口) } \\
\text { Walter J. Horn }\end{array}$ & 8. CONTRACT OR GRANT NUMBER(ด) \\
\hline $\begin{array}{l}\text { 9. PERFORMING ORGANIZATION NAME AND ADDRESS } \\
\text { U. S. Army Engineer Waterways Experiment Station } \\
\text { Soils and Pavements Laboratory } \\
\text { P. O. Box 631, Vicksburg, Miss. } 39180\end{array}$ & $\begin{array}{l}\text { 10. PROGRAMELEMENT, PROJECT, TASK } \\
\text { AREA Q WORK UNIT' NUMBERS }\end{array}$ \\
\hline $\begin{array}{l}\text { 11. CONTROLLING OfFICE NAME AND ADDRESS } \\
\text { Office, Chief of Engineers, U. S. }\end{array}$ & $\begin{array}{l}\text { 12. REPORT DATE } \\
\text { November } 1977\end{array}$ \\
\hline Washington, D. C. 20314 & $\begin{array}{l}\text { 13. NUMBER OF PAGES } \\
\text { I } 32\end{array}$ \\
\hline 14. MONITORING AGENCY NAME \& ADDRESS(II difforene from Controlline Oflico) & $\begin{array}{l}\text { 1S. SECURITY CLASS. (of thie roport) } \\
\text { Unclassified }\end{array}$ \\
\hline 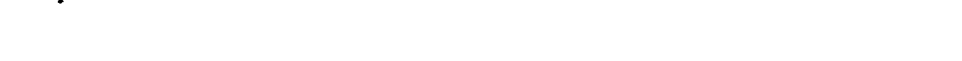 & $\begin{array}{l}\text { 15.. DECLASSIFICATION/DOWNGRADING } \\
\text { SCHEDULE }\end{array}$ \\
\hline
\end{tabular}

16. DISTRIBUTION STATEMENT (ol thie Roport)

Approved for public release; distribution unlimited.

17. DISTRIBUTION STATEMENT (ol the abatract entored In Block 20, Il dilforent froen Roport)

18. SUPPLEMENTARY NOTES

19. KEY WORDS (Continue on reverae elde It noceceary and identlty by block number)

Airfield pavements

Roughness measurements

Runway profiles

Surface smoothness

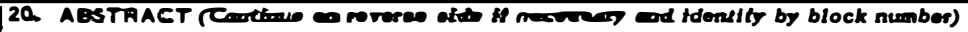

This investigation was undertaken to determine the influence of airfield pavement surface roughness upon aircraft operations and to develop more realistic airfield pavement surface smoothness criteria for the construction of new airfield pavements based upon aircraft and aircraft crew operational requirements. Based upon a literature review of previous efforts in the area of pavement roughness, the human response criteria to whole body vibration were selected as the criteria for assessing the severity of aircraft response (continued) 
20. ABSTRACT (Continued).

resulting from ground operations. Field tests were conducted using instrumented aircraft to measure the acceleration response of the aircraft at three locations within the fuselage during a series of ground operations. The profiles of the test site runways were also measured. The results of these tests provided a direct measure of the influence of a known runway surface on the response of the aircraft system and information for the verification of the computer code used during the subsequent analytical phase of the investigation. Aircraft response data were measured for both the $B-52$ and the Boeing 727 aircraft.

Runway surface measurements were also made at a number of civil airports where slip-form pavers had been used during construction of the pavement systems. These measurements were used to evaluate the level of roughness that might be anticipated when slip-form pavers are used.

An analytical investigation of runway roughness was conducted using an aircraft simulation computer code developed by the Air Force Flight Dynamics Laboratory, and hypothetical runway profiles as the forcing function. Profiles were varied in amplitude, frequency, and form. The results of analytical parametric study were analyzed with respect to the vibration tolerance level of humans to evalyate the current Corps of Engineers (CE) runway smoothness criteria for the construction of new runway pavements. Based upon the results of this investigation, minor modifications of the current CE criteria are recommended. 
THE CONTENTS OF THIS REPORT ARE NOT TO BE USED FOR ADVERTISING, PUBLICATION, OR PROMOTIONAL PURPOSES. CITATION OF TRADE NAMES DOES NOT CONSTITUTE AN OFFICIAL ENDORSEMENT OR APPROVAL OF THE USE OF SUCH COMMERCIAL PRODUCTS. 
The work reported herein was conducted by the personnel of the Soils and Pavements Laboratory (S\&PL), U. S. Army Engineer Waterways Experiment Station (WES), by the authority of the Office, Chief of Engineers, in support of Project 4A762719AT40, "Pavement Structural Capabilities and Functional Requirements Analysis, Smoothness Analysis."

The study was conducted under the general supervision of Messrs. James P. Sale, Chief of the S\&PL, Ronald L. Hutchinson, Pavement Program Manager, and Harry H. Ulery, Jr., Chief of the Pavement Design Division (PDD). Dr. Walter J. Horn of the PDD conducted the investigation and prepared the report.

Acknowledgment is made to the personnel of the Air Force Weapons Laboratory for conducting the instrumented B-52 field tests. Dr. Frazier Parker was responsible for the interpretation of the straightedge measurements related to slip-form pavers. Messrs. Robert C. Gunkel and Harry G. Brown assisted during the reduction of data and the preparation of the figures and graphs contained in the report. Computer programing assistance was provided by Mr. Harry R. Austin.

Directors of WES during this program and the preparation and publication of this report were BG E. D. Peixotto, CE; COL G. H. Hilt, $\mathrm{CE}$, and COL J. L. Cannon, CE. The Technical Director during this period was Mr. F. R. Brown. 
TABLE OF CONTENTS

Page

PREFACE . . . . . . . . . . . . . . . . . . . . 2

CONVERSION FACTORS, U. S. CUSTOMARY TO METRIC (SI)

UNITS OF MEASUREMENT

PART I: INTRODUCTION . . . . . . . . . . . . . . 5

Background . . . . . . . . . . . . . . . 5

Purpose .. . . . . . . . . . . . . . . . . 9

Scope ........................ 9

PART II: TEST PLAN . . . . . . . . . . . . . . . 11

PART III: INSTRUMENTED AIRCRAFT TESTS . . . . . . . . . 14

Aircraft Instrumentation Systems . . . . . . . . . 14

Test Program . . . . . . . . . . . . . . . . . 21

Reduction of Data . . . . . . . . . . . . . 25

PART IV: AIRCRAFT SIMULATION CODE PARAMETRIC STUDY . . . . . . 30

Description of Aircraft Simulation Computer Code . . . . . 30

Analytical Procedure . . . . . . . . . . . . 34

PART V: ANALYSIS OF DATA . . . . . . . . . . . . . . 37

Straightedge Measurements . . . . . . . . . . 37

Runway Profile Data . . . . . . . . . . . . . 44

Computed Aircraft Response Data . . . . . . . . . 45

PART VI: CONCLUSIONS AND RECOMMENDATIONS . . . . . . . . . 57

Conclusions . . . . . . . . . . . . . . 57

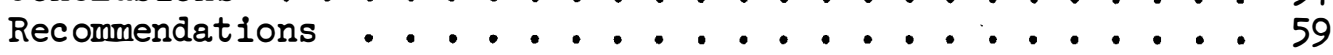

REFERENCES ......................... 61

FIGURES 1-71 
U. S. customary units of measurement used in this report can be converted to metric (SI) units as follows:

\begin{tabular}{lcll}
\multicolumn{1}{c}{ Multiply } & \multicolumn{1}{c}{ By } & & To Obtain \\
\cline { 1 - 1 } inches & 25.4 & & millimetres \\
feet & 0.3048 & & metres \\
pounds (mass) & 0.4535924 & & kilograms \\
inches per second & 25.4 & & millimetres per second \\
feet per second & 0.3048 & & metres per second \\
knots (international) & 0.5144444 & & metres per second \\
ounces & 0.2834952 & kilograms \\
Fahrenheit degreés & $5 / 9$ & & Celsius degrees*
\end{tabular}

* To obtain Celsius (C) temperature readings from Fahrenheit (F) readings, use the following formula:

$$
C=5 / 9(F-32)
$$




\section{PART I: INTRODUCTION}

\section{Background}

1. The failure to employ meaningful surface smoothness criteria during the construction of airfield pavements can manifest itself in either of two ways. The safety and comfort of the crew of an aircraft might be seriously jeopardized during ground operations on an airfield pavement which had been constructed according to surface smoothness requirements which did not prevent an excessive level of roughness. On the other hand, smoothness requirements which are inordinately restrictive would result in unwarranted excessive pavement construction costs.

2. Current U. S. Army Corps of Engineers (CE) criteria governing the construction of airfield pavements contain stringent surface smoothness and gradient requirements $1,2,3$ (see Table 1) which have a vague basis. These requirements impose such restrictions on the pavement contractor that new construction methods, such as slipform pavers, have veen limited in use in the construction of military airfield pavements. This may represent significant additional cost for the construction of military airfield pavements. Construction smoothness criteria are desirable which provide guidelines for the construction of an airfield pavement with a surface sufficiently smooth for aircraft operations but which does not place undue restrictions on the pavement contractor.

3. Previous research in the area of runway smoothness has been primarily confined to statistical analyses of runway profile data, generally power spectral density analyses, correlated with qualitative assessments of the runways into categories such as rough, medium, and smooth. For those cases in which runway profiles were correlated with measured aircraft responses, no definitive relationship between runway unevenness and aircraft response was established. A need exists for 
Corps of Engineers Criteria for Airfield Pavements

\section{Surface smoothness:*}

The finished surfaces of airfield and heliport pavements shall not deviate from the testing edge of an approved 12-ft straightedge more than the tolerances shown for the respective pavement categories below:

\begin{tabular}{|c|c|c|c|c|}
\hline \multirow[b]{2}{*}{$\begin{array}{l}\text { Item } \\
\text { No. } \\
\end{array}$} & \multirow[b]{2}{*}{ Pavement Category } & \multirow[b]{2}{*}{$\begin{array}{l}\text { Direction } \\
\text { of Testing }\end{array}$} & \multicolumn{2}{|c|}{ Tolerances, in. } \\
\hline & & & $\begin{array}{l}\text { Flexible } \\
\text { Pavement } \\
\end{array}$ & $\begin{array}{l}\text { Rigid } \\
\text { Pavement }\end{array}$ \\
\hline 1 & $\begin{array}{l}\text { Runways and taxiways having } \\
\text { cross slopes of } 1 \% \text { or less }\end{array}$ & $\begin{array}{l}\text { Longitudinal } \\
\text { Transverse }\end{array}$ & $\begin{array}{l}1 / 8 \\
3 / 16\end{array}$ & $\begin{array}{l}1 / 8 \\
1 / 4\end{array}$ \\
\hline 2 & $\begin{array}{l}\text { Runways and taxiways having } \\
\text { cross slopes greater than } 1 \%\end{array}$ & $\begin{array}{l}\text { Longitudinal } \\
\text { Transverse }\end{array}$ & $\begin{array}{l}1 / 8 \\
1 / 4\end{array}$ & $\begin{array}{l}1 / 8 \\
1 / 4\end{array}$ \\
\hline 3 & $\begin{array}{l}\text { Calibration hardstands and } \\
\text { compass swinging bases }\end{array}$ & $\begin{array}{l}\text { Longitudinal } \\
\text { Transverse. }\end{array}$ & -- & $\begin{array}{l}1 / 8 \\
1 / 8\end{array}$ \\
\hline 4 & $\begin{array}{l}\text { Hangar access, loading } \\
\text { operational maintenance, } \\
\text { stub parking, transient and } \\
\text { base flight aprons; dispersed } \\
\text { parking hardstands including } \\
\text { taxilanes; helicopter, power- } \\
\text { check, warmup, holding, and } \\
\text { launching pads having grades } \\
\text { of } 1 \% \text { or less in all } \\
\text { directions }\end{array}$ & Longitudinal & $3 / 16$ & $1 / 4$ \\
\hline 5 & $\begin{array}{l}\text { Same pavement categories } \\
\text { listed in item } 4 \text { above but } \\
\text { with grades greater than } 1 \% \\
\text { in all directions }\end{array}$ & $\begin{array}{l}\text { Longitudinal } \\
\text { Transverse }\end{array}$ & $\begin{array}{l}1 / 4 \\
1 / 4\end{array}$ & $\begin{array}{l}1 / 4 \\
1 / 4\end{array}$ \\
\hline 6 & $\begin{array}{l}\text { Nonaircraft traffic paved } \\
\text { areas, such as blast pads } \\
\text { and shoulders }\end{array}$ & $\begin{array}{l}\text { Longitudinal } \\
\text { Transverse }\end{array}$ & $\begin{array}{l}1 / 4 \\
1 / 4\end{array}$ & $\begin{array}{l}1 / 4 \\
1 / 4\end{array}$ \\
\hline
\end{tabular}

The finished surface of airfield and heliport rigid pavements shall have no abrupt change of $1 / 8$ in. or more.

* Taken from CE 807.22 and CE 02611. 
Table 1 (Continued)

Gradients:*

Finished airfield pavement surfaces will have gradients conforming with the following criteria:

a. Runway and Taxiway Transverse Gradients.

Type of Transverse Gradient

Pavement Minimum Maximum

Remarks

$\begin{array}{lll}\text { Rigid } \quad 1.0 \% & 1.5 \%\end{array}$

New runway pavements should be center line crowned. Existing runway and taxiway pavements with insufficient transverse gradients for rapid drainage should provide for increased gradients when the pavements are overlaid or reconstructed.

Flexible $\quad 1.0 \% \quad 1.5 \%$

NOTE: The above transverse gradient requirements for runways and taxiways are not applicable at or adjacent to intersections where pavement surfaces must be warped to match abutting pavements.

b. Runway Longitudinal Gradient.

(1) Where economically feasible, runways will have a constant center line gradient from end to end. The $1.0 \%$ maximum specified by AFM 86-8 will not be exceeded.

(2) Where terrain dictates the need for center line grade changes, changes will be at intervals of not less than $1000 \mathrm{ft}$, but in no case will a grade change occur less than $3000 \mathrm{ft}$ from a runway end.

(3) The first $300 \mathrm{ft}$ of the overrun area (measured from the runway end) will have the same center line gradient as the adjoining end $3000 \mathrm{ft}$ of runway. This provision does not change the point from which the glide angle is measured.

c. Taxiway Longitudinal Gradient. At multimission bases, taxiway longitudinal gradients will not exceed 1.5\%. At other than multimission bases the maximum gradient will not exceed $3.0 \%$ except that a gradient

* Taken from TM 5-824-1. 


\section{Table 1 (Concluded)}

of $5.0 \%$ is permitted for a distance of not more than $400 \mathrm{ft}$. This exception does not apply within 600 ft of a runway entrance. Here, the $3 \%$ maximum will not be exceeded.

d. Aprons and Hardstands. Gradients in the direction of drainage will be not less than $0.5 \%$ and not more than $1.5 \%$.

e. Engine-Power-Check Pads. Transverse gradient will be $1.0 \%$ usualiy with ridge at center, draining toward two edges. Longitudinal gradient will be level. 
information to quantify the influence of runway roughness on aircraft and aircraft crews during ground operations. With such information, realistic smoothness criteria might be developed.

\section{Purpose}

4. The purpose of this study was to determine the influence of runway roughness on aircraft operations and to develop improved airfield pavement surface smoothness criteria for the construction of new airfields based upon aircraft and aircraft crew operational requirements.

\section{Scope}

5. The study consisted of three phases. First, a literature review was conducted to determine the state of the art of research related to runway roughness and aircraft response to runway roughness. The primary objective of this review was to determine previous investigators' results, conclusions, and opinions concerning the procedure of defining a smooth (rough) airfield pavement. Associated with this review was another literature review of the topic of human response to vibration, since it was hypothesized that the most likely critical response of the aircraft/crew system would be that of the human element. That is, the adequacy of the airfield pavement surface would be judged with respect to the ability of aircraft crews to perform satisfactorily during aircraft ground operations.

6. The second phase of the study consisted of field tests to measure alrcraft response to runway roughness. Aircraft were instrumented with accelerometers at three locations within the fuselage along with the supporting signal conditioning and recording systems. Aircraft response was measured during a series of ground operations on several runways. Ground operations considered during the field tests included takeoffs, landings, and taxies over a range of speeds. Three track profiles were measured at each of the runway test sites to define the pavement surface corresponding to the measured aircraft response data. 
The results of this phase of the study were to be used to verify the aircraft simulation computer code of a subsequent phase of the program as well as to give a direct measure of the influence of a known runway surface on the aircraft system.

7. Runway surface measurements were also made at a number of civil airports where slipform pavers had been used during the construction of the pavement systems. These measurements were used to evaluate the level of roughness that might be anticipated when slipform pavers are used.

8. The third phase of the study was an analytical investigation of runway roughness. The success of this phase of the study was dependent upon the ability to accurately model the complex aircraft system in order to compute aircraft responses to runway profile input. Therefore, considerable effort was directed toward the verification of an aircraft simulation computer code developed by the Air Force Flight Dynamics Laboratory (AFFDL). 4,5 Aircraft acceleration response at three locations on the aircraft was computed using the simulation code with the runway profiles measured during the field tests. It was proposed that the computed response data be compared with corresponding measured response data to ensure accurate modeling of the aircraft system. Once the computer program had been verified, a parametric study was to be conducted using the simulation code with hypothetical runway profiles as the input forcing function. Profiles were varied in both amplitude and frequency as well as form.

9. The results of the field tests and the analytical parametric study were to be analyzed with respect to the vibration tolerance level of humans obtained in the literature review to determine the runway smoothness criteria for the construction of new runway parements. 
10. The pavement smoothness research program consisted of two separately funded studies. The first study was funded under the Short Range Airfield Pavements Research Program with the principal objective of developing runway smoothness requirements for the construction of airfield pavements, based upon actual aircraft operational requirements. Particular emphasis was placed upon B-52 operational requirements to quickly obtain requirements for a major program of construction of B-52 bases. The second study, funded under Project AT04: Pavements, Soils and Foundations, was a natural extension of the first study to refine the surface smoothness requirements for the construction of airfield pavements.

11. The two studies have been combined into one program with the basic elements presented in Figure 1. Figure 2 is a further breakdown of the program into specific tasks. The milestones necessary for the accomplishment of the pavement smoothness research program were as follows :

a. Questionnaires such as the one shown in Figure 3 were distributed to $\mathrm{B}-52$ and $\mathrm{KC}-135$ pilots during the condition survey program conducted by WES during 1972. Based on the results of these questionnaires, the runways at Grand Forks AFB, Minot AFB, Ellsworth AFB, and AF Plant 42 Palmdale were judged to be rougher and were selected for instrumented B-52 studies.

b. Roughness measurements were made at several civil airports which had runways constructed by slipform paving methods to determine the degree of surface unevenness associated with these paving methods: Runway evaluation studies were conducted for these civil runways to determine the feasibility of operating an instrumented B-52 from these runways for the purpose of evaluating the actual influence of slipform paving type roughness on B-52 operations. Tests with an instrumented B-52 on civil airport runways were subsequently canceled because of the insurmountable logistics problems associated with supporting B-52 operations at civil airports, but the straightedge measurements of the surface unevenness were analyzed to evaluate the possibility of meeting CE construction criteria with these paving methods. 
c. A literature review of previous pavement smoothness studies was conducted to determine the state of the art of pavement smoothness research. For the most part, previous investigators of the subject have concentrated their efforts into statistical analyses of the runway profile in an effort to correlate profile statistical information and qualitative evaluations of the level of roughness of the particular pavements by aircraft crews. Some aircraft response data have been measured and correlated with the pavement profile data but no definitive conclusions were found which defined the magnitude and frequencies of pavement roughness that are responsible for objectionable aircraft response during ground operations. A further literature search was conducted to obtain information concerning human response to whole body vibration. A great number of studies have been conducted in this area and general guidelines of human tolerance levels of response to whole body vibration have been established. This information has been used to select aircraft vibration levels, resulting from runway roughness, which are not acceptable for safe operations of aircraft flight crews.

d. Field tests were conducted at the National Aviation Facilities Experimental Center (NAFEC), Atlantic City, New Jersey, during the months of November and December 1972. This program was conducted in conjunction with the Federal Aviation Administration (FAA)-sponsored Dynamic Load Effects Study. A Boeing 727 aircraft was instrumented to measure the acceleration response of the aircraft during a schedule of ground operations representative of the modes of operation the aircraft routinely encountered.

e. The U. S. Air Force provided a B-52H for the instrumented aircraft studies conducted during the months of May and June 1973 at the following test sites: Grand Forks AFB, North Dakota; Ellsworth AFB, South Dakota; Minot AFB, North Dakota; and AF Plant 42, Palmdale, California. The tests were conducted at the, test sites mentioned above with the cooperation of the Air Force Weapons Laboratory, which provided the instrumentation and personnel for the collection and reduction of measured aircraft response data.

f. Runway profiles were measured along the center line of the runway and approximately $9 \mathrm{ft}^{*}$ on each side of the center line at each test site runway.

A table of factors for converting U. S. customary units of measurement to metric (SI) units is presented on page 4. 
g. An aircraft simulation computer code developed by the Flight Dynamics Laboratory, Wright-Patterson AFB, was modified and used to compute aircraft acceleration response data from input data of aircraft characteristics and runway profiles.

h. The computed aircraft responses in the form of acceleration was to be compared with the measured aircraft responses and if necessary the computer program was to be modified. Once the simulation computer code was verified, aircraft responses to a variety of hypothetical runway profiles were calculated to determine the effects of various forms and magnitudes of parement unevenness on aircraft operations.

i. Based upon the results of the pilot's evaluations, measured profiles, measured aircraft responses, and computed aircraft responses, maximum pavement roughness levels which allow safe aircraft operations were established. Having achieved this goal, realistic runway pavement construction criteria and permissible differential heave were determined. 


\section{PART III: INSTRUMENTED AIRCRAFT TESTS}

12. Aircraft response data were measured during field tests with two instrumented aircraft. The first series of field tests was conducted during November-December 1972 at NAFEC using an instrumented Boeing 727-100 aircraft leased from United Airlines. This test series was conducted in conjunction with a study of the effects of aircraft dynamic wheel loads and was originally intended primarily as an educational exercise for the future B-52 tests. The second series of field tests was conducted at four USAF bases during the period May-June 1974, using an instrumented B-52H obtained from the 319th Bomber Wing, Grand Forks AFB, North Dakota. The objective of this series of tests was to obtain measured aircraft response data for ground operations on runways previously judged to be rougher than the other runways of the U. S. Air Force. These data were to provide insight into the aircraft response that was considered objectionably rough and, when compared with the computed aircraft response using the measured profile data from the test site runways, to provide a means of verifying the aircraft simulation computer code selected for the analytical phase of this study.

\section{Aircraft Instrumentation Systems}

13. Aircraft response during ground operations was measured in the form of accelerations at three locations within the fuselage of the aircraft. Instrumentation systems installed on board both the Boeing .727 and the $\mathrm{B}-52 \mathrm{H}$ aircraft were similar with the exception that the main gear of the Boeing 727 was instrumented with strain gages to measure the aircraft dynamic loads transmitted to the pavement system. Boeing 727 instrumentation system

14. The instrumentation systems installed on board the United Airlines B-727 for the dynamic wheel load study consisted of full temperature-compensated strain gage bridge networks to measure vertical, side, and drag wheel loading of the main landing gear. 
Vertical wheel loads were measured by strain gages installed on the axles of the main gear, side loads were measured by strain gages installed on the side struts, and longitudinal (drag) forces were measured by strain gages on the drag struts. The calculation of the side and drag wheel loads required measurement of the main oleo strut cylinder extension. This extension was sensed by a potentiometer-type linear-displacement transducer installed on the torsion links. A full set of primary and secondary (duplicate) strain gages was installed on both the port and the starboard main landing gears.

15. Signal-conditioning and recording equipment for the landing gear instrumentation were provided by United Airlines. Each gage was separately excited, and each output signal was conditioned, amplified, and recorded on a 14-track tape recorder. Additional information recorded for each test run included a voice signal and a time code signal.

16. In addition to the instrumentation associated with the measurement of the aircraft gear loads, accelerometers were installed on board the B-727 aircraft to measure the aircraft acceleration response during ground operations. Vertical translational accelerometers were mounted at the pilot's station, the aircraft center of gravity (CG) and the tail of the aircraft. Furthermore, longitudinal and transverse translational accelerometers, as well as pitch and roll angular accelerometers, were installed at the CG of the aircraft. Supporting instrumentation, such as signal-conditioning equipment and tape recorders, was also installed on board the aircraft. Voice and time code signals were recorded along with the acceleration response data.

17. The installation and caltbration of all alrcraft wheel load instrumentation on board the United B-727 were provided by United Airlines with assistance from the Boeing Company.

18. Personnel of the Boeing Flight Test Center Calibration Laboratory at Boeing Field, Seattle, were responsible for the installation and calibration of strain gages on the side and drag struts of the main gear. Calibration of the gages consisted essentially of applying 
known axial loads to the strut in both compression and tension and measuring the resulting output voltages of the strain gages.

19. Personnel at the United Airlines Maintenance Base were responsible for the installation and calibration of the strain gages on the main gear axle and the potentiometer for the measurements of the oleo strut extension. After installation of the axle strain gages and the potentiometers was completed, calibration of the gages was initiated by raising the aircraft by jacks at the wing spar and tail locations, and measuring the output voltages of the gages.

20. Calibration curves for each gage installed on the aircraft main gears were determined using the least-squares method to obtain the best-fit straight line for the measured data points.

21. WES provided all instrumentation associated with the measurement of aircraft acceleration response data as well as all personnel responsible for the installation and operation of the equipment.

22. A total of five Kistler translational nonpendulous servoaccelerometers with a working range of $\pm 5 \mathrm{~g}^{\prime} \mathrm{s}$ and two Systron-Donner angular accelerometers with a working range of $\pm 15 \mathrm{rad} / \mathrm{sec}^{2}$ were installed on board the aircraft at the locations indicated in Figure 4. One translational accelerometer, was installed at the pilot's station and one was installed in the tail of the aircraft to measure vertical accelerations. The remaining three translational accelerometers were installed as a unit at the CG of the aircraft to measure the vertical, longitudinal, and transverse components of acceleration. The two angular accelerometers were also installed at the CG to measure the pitch and roll components. of angular acceleration.

23. Celibration of the accelerometers consisted of takinf an output voltage measurement for the accelerometer in its normal upright position and then inverting the accelerometer and taking another output voltage measurement. This procedure yields the gage output for a known acceleration $(I g)$ in the positive and negative vertical direction.

24. Figure, 5 shows a block diagram of the supporting electronic equipment associated with the aircraft main gear load measurements. Strain and displacement gages were excited and the output signals were 
separately conditioned and amplified within the signal-conditioning equipment and then recorded on a Sangamo Model 3500 analog magnetic tape recorder. The $24-\mathrm{v}$ d-c power requirement for the signal-conditioning equipment, as well as the 115-v, 400-Hz power requirement for the Sangamo tape recorder, was supplied by the aircraft power unit. All data were recorded at a tape speed of 7-1/2 ips with a carrier frequency of $135 \mathrm{~Hz}$.

25. A time code generator was furnished by NAFEC and included in the on-board electronic equipment. The time signal from this unit along with voice annotations was recorded on the magnetic tape along with the measured signals from the main gear gages. An oscilloscope was installed on board the aircraft in order to monitor selected signals from the main gear gages.

26. The supporting instrumentation system installed on board the Boeing 727 aircraft associated with the aircraft acceleration response is presented in Figure 6. Basically, this system consisted of a 14-channel Madec signal-conditioning unit, designed and built by the Mobility and Environmental Systems Laboratory of WES, which processed the raw electrical output signal from the accelerometers of the system for recording on a Pemco Model 110-A analog magnetic tape recorder. An Irig-B time code, furnished by a time code generator, was recorded along with the acceleration data.

27. Power for both the signal-conditioning unit and the tape recorder was obtained from the aircraft $110-v$ a-c source. The $110-v$ a-c current was modified by a Lambda LCD 4-22 power supply to obtain the required $30-v$ d-c power for the signal-conditioning system and as likewise modified by another 8-amp 30-v d-c power supply to obtain the $30-v d-c$ power for the Pemco recorder.

\section{$\mathrm{B}-52 \mathrm{H}$ instrumentation system}

28. The instrumentation system installed on board the $\mathrm{B}-52 \mathrm{H}$ aircraft consisted of a total of six accelerometers installed at three locations within the fuselage of the aircraft along with a wheel rotation counter installed on the forward landing gear (Ftgure 7). Translational accelerometers were installed at the pllot's station, the alreraft $C G$, and the tall of the aircraft to measure the vertical 
acceleration response of the aircraft. An angular accelerometer was installed at the pilot's station to measure the rotational acceleration in the pitch mode. Two angular accelerometers were installed at the aircraft CG to measure the rotational response in the pitch and roll modes. In addition, a wheel rotation counter was installed on the forward landing gear to determine the aircraft velocity and longitudinal location on the runway. A magnetic tape recorder and other support instrumentation, such as signal-conditioning units and power supplies, were installed on board the aircraft. A voice channel was provided to mark on the data tape the instant that the aircraft was in alignment with runway markers which were erected every $500 \mathrm{ft}$ along each of the four test site runways.

29. Figure 8 is a schematic diagram of the instrumentation system installed on board the aircraft. All translational accelerometers were model LSBE16-1 linear accelerometers manufactured by Schaevity Engineering of Pannsauken, New Jersey. Primary characteristics of the accelerometers are given in Table 2. Basically, the linear accelerometers were a solid state, $d-c$ closed-loop force balance accelerometer. They operated on a torque balance principle. Briefly, linear acceleration applied to the accelerometer, and thus to the unbalanced mass, develops a torque and an infinitesimal displacement of the pendulous unbalanced mass. The motion of the mass develops an electrical signal which is amplified and supplied to an electrical torque generator acting on the mass which develops an equilibrating torque proportional to the electrical signal and the applied linear acceleration. A voltage proportional to the applied acceleration is produced by passing the generated current through a stable resistor.

30. All angular accelerometers installed on board the B-52 were model ASMC 40-20 angular accelerometers manufactured by Schaevity Engineering. Basically, the principle of operation of the angular accelerometers is similar to that of the linear accelerometer except that a balanced mass system is utilized in the angular accelerometer. Table 3 contains the primary characteristics of the ASMC 40-20 angular accelerometer. 
Table 2

Primary Characteristics of Translational Accelerometer Installed on Instrumented $\mathrm{B}-52$

\begin{tabular}{ccc}
\hline & $\begin{array}{c}\text { Nominal Natural } \\
\text { Frequency, Hz }\end{array}$ & $\begin{array}{c}\text { Output } \\
\text { Impedance, K ohms }\end{array}$ \\
\cline { 2 - 3 } \pm 0.25 & 40 & 15 \\
\pm 0.5 & 50 & 10 \\
\pm 1.0 & 100 & 5 \\
\pm 2.0 & 110 & 5 \\
\pm 5.0 & 125 & 5 \\
\pm 10.0 & 140 & 5 \\
\pm 20.0 & 160 & 5 \\
\pm 50.0 & 200 & 5
\end{tabular}

Linearity (best fitted straight line by least squares): $\pm 0.05 \%$ full. scale Hysteresis: $0.02 \%$ full scale

Resolution: $0.0005 \%$ full scale

Cross-axis sensitivity: \pm 0.002 g per $g$ up to $\pm 10-g$ range inclusive; $\pm 0.005 \mathrm{~g}$ per $g$ over $10-g$ range

Thermal coefficient of sensitivity: $0.01 \%$ per ${ }^{\circ} \mathrm{F}$

Shock survival: up to $1 / 2-g$ range inclusive: $50 \mathrm{~g}-1 \mathrm{~lm}$; over $1 / 2-g$ range: $100 \mathrm{~g}-11 \mathrm{~ms}$

Acceleration survival:

Sinusoidal: up to $1 / 2-g$ range inclusive: $10 \mathrm{~g}$ (20 to $2000 \mathrm{~Hz}$ ); over 1/2-g range: $20 \mathrm{~g}$ (20 to $2000 \mathrm{~Hz}$ )

Constant: up to $1-g$ range to $50 \mathrm{~g}$; over $1-\mathrm{g}$ range to $100 \mathrm{~g}$

Options: telemetry output ( $28 \mathrm{v}$ DC in, 0.2 to $4.8 \mathrm{v}$ DC out)

$1 \mathrm{~g}$ (or any) bias

outpat to input isolation

Weight: $3 \mathrm{oz}$ 
Table 3

Primary Characteristics of Angular Accelerometer Installed on Instrumented B-52

\begin{tabular}{|c|c|c|c|}
\hline $\begin{array}{c}\begin{array}{c}\text { Range } \\
\mathrm{rad} / \mathrm{sec}^{2} \\
\end{array} \\
\end{array}$ & $\begin{array}{l}\text { Cross-Axis } \\
\text { Sensitivity } \\
\mathrm{rad} / \mathrm{sec}^{2} / \mathrm{g} \\
\end{array}$ & $\begin{array}{c}\text { Nominal } \\
\text { Natural } \\
\text { Frequency, } \mathrm{Hz} \\
\end{array}$ & $\begin{array}{c}\text { Output } \\
\text { Impedance } \\
\mathrm{K} \text {, ohms } \\
\end{array}$ \\
\hline \pm 50 & 0.2 & 30 & 20 \\
\hline \pm 100 & 0.2 & 50 & 20 \\
\hline \pm 500 & 1.0 & 100 & 10 \\
\hline \pm 1000 & 2.0 & 120 & 5 \\
\hline \pm 1500 & 3.0 & 130 & 5 \\
\hline
\end{tabular}

Linearity (best fitted straight line by least squares): . $\pm 0.1 \%$ full scale Hysteresis: $0.02 \%$ full scale

Resolution: $0.0005 \%$ full scale

Thermal coefficient of sensitivity: $0.01 \%$ per ${ }^{\circ} \mathrm{F}$

Shock survival: up to 100-rad/ $\mathrm{sec}^{2}$ range inclusive: $50 \mathrm{~g}-11 \mathrm{~ms}$; over 100-rad/sec 2 range: $100 \mathrm{~g}-11 \mathrm{~ms}$

Acceleration survival:

Sinusoidal: up to 100-rad/ $\mathrm{sec}^{2}$ range: $10 \mathrm{~g}(20$ to $2000 \mathrm{~Hz}$ ); over 100-rad/sec range: $20 \mathrm{~g}$ (20 to $2000 \mathrm{~Hz}$ )

Constant: up to $100-\mathrm{rad} / \mathrm{sec}^{2}$ range to $50 \mathrm{~g}$; over $100-\mathrm{rad} / \mathrm{sec}^{2}$ range to $100 \mathrm{~g}$

Weight: 2 oz 
31. The wheel rotation counter consisted of a proximity transducer securely attached to the stationary portion of the aircraft wheel and produced an electrical signal proportional to the distance between the sensing element of the transducer and a metallic object. A series of impulse signals were generated as the wheel rotated due to the presence of holes in the rim of the wheel. Therefore, it was possible to measure the rotation of the wheel as a function of time.

32. A 14-channel Genesco magnetic tape recorder was used to record all data signals. Six channels of aircraft acceleration response were recorded along with the signal from the wheel rotation counter and a voice channel monitoring the aircraft intercom system. All signals were recorded with a $57.5-\mathrm{kHz}$ center frequency and a recording rate of 30 ips.

33. The power for all components of the instrumentation system was supplied by Gel-Cell rechargeable batteries.

\section{Test Program}

\section{Boeing 727 field tests}

34. The instrumented Boeing 727 tests were conducted at the NAFEC Airport during the period 12 November-11 December 1972. The primary purpose of the NAFEC tests was the FAA-sponsored Aircraft Dynamic Wheel Load Effects Study; however, additional instrumentation was installed on board the aircraft for the purpose of measuring aircraft response to pavement roughness. This was a particularly beneficial situation in that aircraft response could be measured for a large number of ground operations within the full range of alrcraft ground operating modes, on two runways. Aircraft response measurements were obtained for the following modes of aircraft ground operation:

$$
\begin{aligned}
& \text { a. Creep-speed taxi ( } 3 \text { to } 8 \text { knots). } \\
& \text { b. Low-speed taxi ( } 15 \text { to } 30 \text { knots). } \\
& \text { c. Medium-speed taxi ( } 45 \text { to } 80 \text { knots). } \\
& \text { d. High-speed taxi ( } 85 \text { to } 130 \text { knots). } \\
& \text { e. High-speed braking ( } 130 \text { to } 45 \text { knots). }
\end{aligned}
$$


f. Takeoff rotation ( 85 to 130 knots).

g. Touchdown.

h. High-speed braking with reverse thrust.

i. Turning ( 4 to 30 knots).

35. The instrumented B-727 arrived at NAFEC Airport on 11 November 1972. Checkout operations for the on-board gear load instrumentation were initiated immediately upon arrival of the aircraft, and the system of accelerometers and associated supporting instrumentation was installed within the fuselage of the aircraft.

36. Tests on the flexible pavement of runway 13-31 were initiated on 12 November with a thorough checkout of all instrumentation systems. Dynamic tests on runway 13-31 were initiated on 20 November and completed on 24 November. During this period, aircraft load and acceleration measurements were recorded for approximately 146 aircraft operations involving all nine of the above-listed dynamic modes of operation.

37. Acceleration response data along with the three components of main gear loading and oleo strut displacement for each of the main gears were measured and recorded on magnetic tape. Aircraft configuration, location on the runway, and speed data were also measured and recorded manually.

38. Dynamic tests on the NAFEC rigid pavement structure of runway 04-22 began on 30 November 1972, with a series of creep-speed taxi runs. Aircraft load and acceleration response data were collected for 148 aircraft operations during the period of dynamic testing, which continued until 11 December. Again, response data were measured during all nine modes of aircraft ground operation used.

B-52H fiela tests

39. The B-52H field tests were conducted at the following sites during the period 16 May-28 June 1973:

a. Grand Forks AFB, North Dakota.

b. Ellsworth AFB, South Dakota.

c. Minot AFB, North Dakota.

d. AF Plant 42, Palmdale, California. 
The selected aircraft and aircrew performed a series of taxi tests and one heavyweight takeoff at each of the test bases. Training missions were flown during both deployment and redeployment to utilize these missions to the maximum. The high-speed taxi restriction of AFM 66-1, Vol II, SAC Supplement 2, was waived for this test.

40. The B-52H arrived at Grand Forks AFB on 1 May 1973, and AFWL personnel from Kirtland AFB began instrumenting the aircraft. Instrumentation was installed and checked out by the starting test date of 15 May. AFWL coordinated requirements with the 319th Bomber Wing (LGM) prior to arrival of the aircraft. The instrumentation process required minimal SAC support and was scheduled so as not to interfere with the aircraft's normal flying and maintenance schedule.

41. An integral B-52 crew was required for this test, and they were given a detailed briefing covering test procedures with runway roughness rating criteria and were required to rate the level of roughness of each runway at the time of testing. After all tests were complete, each crew member was asked to rank each test base relative to each other. Because of the rating requirement, it was important that the same crew members conduct the full test program.

42. At each test base, two series of taxi tests and a heavyweight takeoff and landing were required to obtain the necessary data. Both series of taxi tests were identical except that the pilot performed the first series and the copilot the second. Prior to each series an operational checkout of the aircraft antiskid control circuit and brake system was accomplished to ensure the integrity of these systems during the unusual operation schedule of these tests.

43. Marking devices were erected along the full length of each runway of each test site at 500-ft intervals to permit the identification of the aircraft location on the runway during each test run. This was accomplished by placing flags between the existing 1000-ft runway distance markers.

44. The aircraft was refueled to $320,000 \mathrm{Ib}$ prior to each series of tests. Brake energy limits were computed at the end of each taxi test run as a safety precaution. 
45. Each pilot, in turn, performed the following test cycle at each test location. A pace vehicle was used so that the desired speed could be consistently maintained throughout each taxi run. The aircraft was accelerated to the designated speed as rapidly as possible, and braking of the aircraft was initiated at the 2000-ft-remaining marker.

a. High-speed ( 45 knots) taxi run on the runway.

b. Exit runway and return heading in opposite direction.

c. Low-speed (20 knots) taxi run on runway.

d. Exit runway and return.

e. Low-speed (20 knots) taxi run on runway.

f. Exit runway and return.

g. High-speed ( 45 knots) taxi on runway.

h. Exit runway and return for takeoff.

1. Takeoff, return, and land when gross weight was 270,000 lb. The aircraft was then refueled back to $320,000 \mathrm{Ib}$ and the other pilot performed the identical test cycle. At the completion of the two test cycles, the aircraft was refueled to $488,000 \mathrm{lb}$ in preparation for the final test and redeployment the following day.

46. Maintenance and fire department vehicles (equipped with hot brake cooling equipment) were positioned at the end of the runway to meet the aircraft upon completion of each taxi test run. Maintenance personnel inspected the aircraft at this time to make certain that the brakes were not too hot for safe operations of the aircraft.

47. In addition to the normal SAC aircrew preflight briefing, a similarly detailed briefing was conducted by the project officer prior to each day's test activity. The following personnel were required to - attend:

a. B-52 aircrew.

b. Participating AFWL personnel.

c. Pace vehicle driver and radio operator.

d. Fire chief and fire department personnel.

e. Maintenance tower and base operations personnel.

f. Safety officer. 
48. The briefing included the following items:

a. Radio frequencies and other communications requirements for all participating radio-equipped vehicles and personnel.

b. Use of all special signals and instructions.

c. Coordination requirements between the pace vehicle driver, pace vehicle radio operator, and B-52 aircraft.

d. Coordination and communications requirements between maintenance ground crew/fire department personnel and aircrew during the hot brakes check.

e. Procedure for hot brakes check after each taxi run to include consideration of residual heat buildup and necessary cooling.

f. Fire department coverage and procedures for each taxi test and hot brake check.

g. Procedures and parking of the aircraft should an emergency occur; e.g., overheated brakes or wheel failures.

h. Weather (all taxi tests were conducted on dry runway).

49. The B-52H field test program was coordinated with various

$A F$ agencies as follows: AFWL provided the required engineering expertise for each test, and complete instrumentation of the aircraft. SAC/LGWC provided a bomb cluster rack for mounting bomb bay accelerometers. SAC/LGMM monitored the test and prepared to take appropriate action should any material or support problems develop. 15AF provided scheduling assistance for the desired deployment and redeployment missions, and ensured that all necessary material and support arrangements were accomplished at AF Plant 42 Palmdale. All other support was provided by the test site AFB. The 319th Bomber Wing supported this test program with B-52H, serial number 61-040, and an aircrew dedicated to the entire test program at all test sites.

\section{Reduction of Data}

50. Even though the results of the Boeing 727 field tests could be considered a limited success the results of the B-52 field tests must be regarded as a disappointment. The Boeing 727 tests did provide the WES personnel with experience with aircraft response measurements as 
well as a large amount of measured B-727 response data for a measured runway profile. Both should be valuable during future runway smoothness studies, but were of minor benefit for the present. study due to the limitations of the simulated aircraft computer code and the decision not to use WES personnel for the subsequent instrumented B-52 field tests. The measured $B-52$ response data have not been reduced to a usable form as of the writing of this report, but will be investigated further if possible. Details of the reductions of the field test data are presented in the remainder of this section.

$\underline{B-727}$

51. The raw acceleration data from the B-727 aircraft were returned to WES for reduction. As stated earlier, the primary purpose for this series of tests, from a runway. smoothness point of view, was to develop a procedure for the subsequent field tests with the B-52 aircraft. From this point of view, this series of tests was a complete success, since the WES Instrumentation Services personnel demonstrated that they could instrument an aircraft quickly and inexpensively and obtain the required aircraft response data.

52. The data thus collected were then played back on an oscillograph to produce hard copies for visual inspection and analysis. The measured response data agreed well with measured B-727 response data collected by other investigators. 6

53. During and immediately following the field tests with the B-727, a quantity called absorbed power was considered a useful measure of the ride quality of a vehicle from the viewpoint of the occupants of the vehicle. Therefore, the absorbed power assoclated with the aircraft response at the pilot station was computed using the measured acceleration response data at the pilot station and an analog computer network operated by the WES Mobility and Environmental Systems Laboratory (M\&ESL). Also, a digital computer code developed by M\&ESL for the computation of absorbed power was modified and verified by the analog results.

54. Briefly, the absorbed power associated with the acceleration response at a point in a vehicle is the measure of the amount of energy 
that would be absorbed by a human undergoing the motion of that point. Much research has been conducted by both the WES M\&ESL and the U. S. Army Tank and Automotive Command (TACOM) in the area of ride quality of off-road vehicles. The concept of absorbed power has been accepted by both of these organizations as a valuable measure of the severity of the human response to whole body vibrations. Thus, it seemed that it would be a useful tool in the pavement smoothness project.

55. However, the failure of the subsequent B-52 field tests to produce any useful measured aircraft response data precluded any further work in the area of absorbed power for the present smoothness study oriented toward B-52 operations. That is, the absorbed power computer code would not be verified for the B-52 response and therefore no concrete evaluation could be made based upon absorbed power results. Even though no absorbed power analyses were performed using the B-52 response data, the absorbed power concept is still considered to be a promising measure of the severity of the aircraft response and will be investigated further during future smoothness studies.

56. The AFFDL was contracted to compute $B-727$ response data for the runways at the NAFEC airport for comparison with measured aircraft response data. Qualitatively the measured and computed response data agreed fairly well in that the rougher areas of the profile produced the greater responses in both the measured and computed acceleration-time histories. In addition, at the request of the FAA, the combination of the measured and computed B-727 aircraft responses was used to identify the rough areas of a civilian airport runway on the East Coast that had been rated as very rough by the aircrews operating on the runway. Agreement between the two was very good.

57. Despite the qualitatively excellent agreement between measured and computed aircraft response data, quantitative results were not nearly so good. That is, the computed amplitude of the aircraft acceleration response generally differed from the measured value by as much as a factor of two. The AFF'DL investigated the problem and concluded that the modeling of the B-727 landing gear was not accurate. Therefore, no 
conclusive verification of the computer code using the measured B-727 data was possible at this time.

$\underline{B-52}$

58. The data reduction of the measured $B-52$ acceleration response was not a success. During the data collection phase, one of the eight data channels of the equipment malfunctioned, producing erroneous data. 59. However, the main problem in reducing the experimental data thus far has been the lack of an accurate calibration signal with the data. With no calibration it is not possible to reduce the raw electrical signals to usable engineering terms. AFWL personnel from Kirtland AFB tried to reduce the data for several months with no success. Consequently, the data, in the form of magnetic tapes, were transferred to WES to further, attempt reduction. However, attempts at data reduction at WES also proved to be fruitless.

60. Toward the end of the data reduction phase of the project, the AFFDL published a report ${ }^{4}$ containing a comparison of computed aircraft response, using the aircraft simulation computer code, with measured aircraft response for several military aircraft, including a B-52. Although the verification for the case of the B-52 was not as rigorous as had been planned for this project, the report did indicate that the simulation code did sufficiently model the B-52 aircraft during ground operations.

61. Therefore, with the publication of the AFFDL report supporting the accuracy of the aircraft simulation code, further effort toward data reduction of the B-52 data was suspended and the thrust of the project was directed toward an analytical parametric study. Even though reduction of the measured aircraft response was suspended, it was not permanently abandoned. The plan was to attempt further reduction during the latter part of the project if time and cost constraints would allow and further in the future if these constraints demanded. No further data reduction was possible during this project.

62. The results of the instrumented afrcraft field tests might be summarized in the following manner: 
a. The B-727 aircraft was instrumented and aircraft responses were measured and recorded. Reduction of the measured data was successful and the results agreed, generally, with measured data published by previous investigators. 3 Comparison of the measured response data with data computed with the aircraft simulation code was qualitatively good, but not quantitatively. The AFFDL was to modify the computer code to more accurately model the B-727.

b. A B-52H was instrumented and aircraft response data were measured, but reduction of the data was not successful. Therefore, the measured B-52 data were not used to verify the aircraft simulation computer code or to establish limiting response criteria.

c. Verification of the aircraft simulation code was provided by results published in an AFFDL report. 1 The effort of the project was directed toward a parametric study using the aircraft computer code. 
63. A parametric investigation of the influence of runway roughness on aircraft response was conducted using the aircraft simulation computer code developed by the AFFDL. The objective of this phase of the program was to determine the form, amplitude, and frequency of pavement unevenness responsible for intolerable aircraft response during ground operations.

\section{Description of Aircraft Simulation Computer Code}

64. The following portion of this report contains a description of the sumulation computer code as used in this study and a discussion of the analytical study undertaken to determine the limiting level of runway roughness. A detailed description of the AFFDL computer program which formed the basis for the computer code of this study can be found in References 4 and 5.

65. The mathematical model representing a great range of aircraft might be illustrated as in Figure 9. The aircraft is modeled as an elastic structure, with corresponding elastic degrees of freedom, as well as three rigid body degrees of freedom in pitch, plunge, and horizontal translation. Additional degrees of freedom are incorporated into the model to account for the motion of the landing gear during ground operations.

66. The motion of the aircraft elastic structure is defined in terms of the free vibration mode shapes for the particular aircraft under investigation. Data pertirent to this method of defining the motion of the flexible aircraft are the measured vibrational mode shapes and frequencies along with the corresponding computed generalized masses for the structure.

67. A detailed analysis of both the nose and the main landing gear assemblies is required to accurately model the aircraft. Both the forces generated within the shock absorbers and the forces transmitted by the tire of the landing gear must be accounted for in the aircraft model. 
68. Procedures for the modeling of two types of landing gear shock absorbers are presented in Reference 4 and included in the computer program used during the analytical phase of this study. The two types of struts are the single-acting and the double-chambered shock absorber. The primary aircraft of this study, i.e., the B-52, is equipped with the single-acting shock absorber and this absorber will be discussed in detail.

69. Figure 10 is a schematic diagram of a single-acting shock absorber, such as the one installed on the B-52. The main components of this system are the compressed air, the viscous hydraulic fluid, and the metering pin/orifice device.

70. Three types of forces are generated within the shock absorber during ground operations: the pneumatic forces, hydraulic forces, and an internal strut friction force. Previous studies at the AFFDL have concluded that internal friction is responsible for a mere 0.6 percent of the forces generated within the strut. Therefore, the internal friction forces were neglected during the development of the aircraft simulation computer code and during the course of this study.

71. The largest of the three types of forces within the shock absorber of the B-52 aircraft is the pneumatic force and it can be expressed as (see Figure 10):

$$
F_{p}=\frac{p_{1} V_{1}}{S} \text { for } 0<S \leq S_{\max }
$$

where

$$
\begin{aligned}
& \mathrm{p}_{1}=\text { the fully extended strut pressure }\left(S=S_{\max }\right) \\
& \mathrm{V}_{1}=\text { the fully extended strut air volume }\left(S=S_{\max }\right) \\
& S=\text { strut stroke }
\end{aligned}
$$

72. The hydraulic force can be expressed as:

$$
F_{h}=\frac{\rho_{h} A_{h}^{3} \dot{s}|\dot{s}|}{2\left(C_{d} A_{0}\right)^{2}}
$$

where

$$
\rho_{h}=\text { density of the hydraulic fluid }
$$


$\begin{aligned} A_{\mathrm{h}} & =\text { hydraulic piston area } \\ \dot{\mathrm{S}} & =\text { strut piston velocity }\end{aligned}$

$\mathrm{C}_{\mathrm{d}}=$ orifice coefficient

$A_{0}=$ effective orifice area (orifice area minus metering pin area)

73. The forces generated by the deflection of the tire and consequently transmitted to the piston of the shock absorber can be represented by an equation of the form:

$$
F_{t}=k z_{t}
$$

where

$k=$ stiffness coefficient for the tire

$z_{t}=$ deflection of the tire

The tire stiffiess coefficient is the slope of the tire load-deflection curve.

74. The profile of the supporting surface provides the "forcing function" for the aircraft model. The profile was defined in numerous ways during the analysis of the aircraft response to surface inequalities of different forms. Basically, the profile was introduced in the form of elevation of the surface at specified equal increments, usually $2 \mathrm{ft}$.

75. Additional forces, such as lift, thrust, and drag, acting on the aircraft during ground operations were also accounted for in the development of the aircraft simulation model.

76. The differential equations of motion for an aircraft such as the B-52 of this study can be expressed in the following manner (see Figure 9 for illustration of notation):

$$
\begin{aligned}
& \mathrm{MZ}=\mathrm{F}_{\mathrm{gm}}+\mathrm{F}_{\mathrm{gn}}+\mathrm{I}-\mathrm{W} \\
& \mathrm{m}_{1} z_{1}=F_{\text {tm }}-F_{g m}-w_{1} \\
& \mathrm{~m}_{2} \mathrm{z}_{2}=\mathrm{F}_{\text {tn }}-\mathrm{F}_{\mathrm{gn}}-\mathrm{w}_{2} \\
& I_{y y} \phi=B_{g n}-A_{g m} \\
& \mathrm{MXX}=\mathrm{F}_{\mathrm{T}}-\mathrm{F}_{\mathrm{td}}-\mathrm{F}_{\mathrm{ad}} \\
& M_{1} \ddot{q}_{1}=F_{g m} \xi_{1}+E_{g n} \xi_{2}-2 \zeta_{1} \omega_{1} M_{1} q_{1}-\omega_{1}^{2} M_{1} q_{1}
\end{aligned}
$$


where

$$
\begin{aligned}
& M=\text { aircraft mass (minus unsprung mass of both landing gears) } \\
& F_{g m}=\text { force transmitted by main landing gear to the aircraft } \\
& \text { flexible fuselage ( } \mathrm{g}_{\mathrm{gm}}=\mathrm{F}_{\mathrm{pm}}+\mathrm{F}_{\mathrm{hm}} \text { ) } \\
& \mathrm{F}_{\mathrm{gn}}=\text { force transmitted by the nose gear }\left(\mathrm{F}_{\mathrm{gn}}=\mathrm{F}_{\mathrm{pn}}+\mathrm{F}_{\mathrm{hn}}\right) \\
& \mathrm{L}=\text { aerodynamic lift } \\
& \mathrm{W}=\text { aircraft weight } \\
& m_{1}, m_{2}=\begin{array}{l}
\text { unsprung mass of the main and nose landing gear, } \\
\text { respectively }
\end{array} \\
& \mathrm{F}_{t_{\mathrm{m}}}, \mathrm{F}_{\mathrm{tn}}=\text { main and nose tire forces, respectively } \\
& \mathrm{w}_{1}, \mathrm{w}_{2}=\begin{array}{l}
\text { unsprung weight of the main and nose landing gear, } \\
\text { respectively }
\end{array} \\
& I_{y y}=\text { mass moment of inertia in pitch } \\
& \mathrm{F}_{\mathrm{T}}=\text { thrust } \\
& F_{t d}=\text { tire drag } \\
& \mathrm{F}_{\text {ad }}=\text { aerodynamic drag } \\
& M_{1}=\text { generalized mass of the } i^{\text {th }} \text { vibrational mode shape } \\
& q_{1}=\begin{array}{l}
\text { generalized coordinates associated with } 1^{\text {th }} \text { vibration } \\
\text { mode shape }
\end{array} \\
& \xi_{1}, \xi_{2}=\text { modal deflections at the main and nose attachment points } \\
& \zeta_{i}=\begin{array}{l}
\text { structural damping associated with } i^{\text {th }} \text { vibration mode } \\
\text { shape }
\end{array} \\
& \omega_{1}=\text { frequency of the } 1^{\text {th }} \text { vibration mode }
\end{aligned}
$$

A solution procedure based upon a three-term Taylor series was used to solve this set of nonlinear differential equations.

77. Figures 11 through 14 are typical of the results obtained by the developers of the aircraft simulation code. 4 Figure 11 contains a comparison of the measured and computed responses- of a 37,636-1b-F-4C aircraft during a 29-knot constant-speed taxi over a repaired runway section. The authors ${ }^{4}$ report that the computed CG response was within 9 percent of the measured response for their corresponding peak values.

78. Figure 12 contains a comparison of measured and computed acceleration responses for a B-52 aircraft during a 40-knot taxi on an actual runway. The peak levels of the computed acceleration are within 6 percent of the corresponding measured levels. Furthermore, it is 
obvious from Figure 12 that the overall form of the computed response is very similar to that of the measured response.

79. Figure 13 is a comparison of the computed acceleration response at the CG of a C-14I aircraft with the corresponding measured response. The profile forcing function for this particular test was that of a 1 - cos bump at 20 fps. Again, the overall forms of the two acceleration-time histories are very similar, with the peak values of computed acceleration being within 11 percent of the measured values.

80. The final illustration of the validity of the simulation computer code is contained in Figure 14. Here the mean value of the computed acceleration response is compared with the corresponding mean value of measured acceleration response at the pilot station of a KC-135 during a takeoff from an actual airfield. Again the comparison is very good in form as well as magnitude. Note that both curves indicate an area of increased response at about the 4000-ft mark on the runway.

81. A more detailed discussion of the aircraft mathematical model and a listing of the resulting computer code along with a user's manual are included in References 4 and 5 .

\section{Analytical Procedure}

82. Figure 15 illustrates the procedure developed for the parametric study conducted to determine the height and form of profile deviations which are responsible for unacceptable aircraft response. This procedure will be discussed in detail in the remainder of this section.

83. First a hypothetical profile with an impulse form was generated and input into the aircraft simulation code discussed previously in this section. All pertinent aircraft characteristics of the B-52 were likewise input into the program along with a specific constant speed. Therefore, it was possible to compute the acceleration response for a B-52 traversing a perfectly smooth profile with the exception of an impulse at one location, at a specific constant speed.

84. This aircraft response, in the form of an acceleration-time history, was then input into a Fast Fourier Transform computer code 
which transformed the acceleration response from the time domain to the frequency domain. A plot of the fourier transform of the acceleration versus frequency yields a relationship similar to the one illustrated in frame 5 of Figure 15. This curve generally has one spike at the predominant response frequency, $\omega_{\text {critical }}$, of the system.

85. Next, this critical frequency of oscillation was converted to a critical profile wavelength by the formula

$$
\lambda_{\text {critical }_{i}}=\frac{(\text { SPEED })_{i}}{\omega_{\text {critical }_{i}}}
$$

Now, any profile deviation with this wavelength will excite the aircraft system at its critical frequency for ground operations at the particular (SPEED) 1 - Therefore, a hypothetical profile was generated with the critical pavement wavelength and various magnitudes of deviation as illustrated in frame 6 of Figure 15. This hypothetical profile was then introduced into the aircraft simulation code along with the B-52 structural and aerodynamic characteristics and a speed of (SPEED) 1 .

86. The acceleration-time history generated during this phase of the analysis is illustrated in frame 8 of Figure 15. Normally, the acceleration response was of a periodic nature with magnitude increasing until a limiting magnitude of acceleration was reached after several cycles of motion. These limiting values of acceleration were then plotted with respect to the corresponding magnitude of pavement deviation as illustrated in frame 9 of Figure 15. The magnitude of pavement deviation, $h_{i}$, necessary to produce aircraft acceleration response at the upper tolerable limit of $0.4 \mathrm{~g}$ for ground operation at aircraft speed equal to (SPEED), was then determined. At this point in the procedure one has determined the magnitude of pavement roughness, occurring at a wavelength of $\lambda$ critical corresponding to the critical aircraft response frequency of $\omega_{\text {critical for aircraft speed of }}$ (SPEED) $)_{1}$, necessary to produce intolerable aircraft acceleration response.

87. Now it was necessary to repeat the procedure illustrated by frames 1 through 9 of Figure 15 for a range of aircraft ground speeds. 
Having completed this, the critical pavement heights were plotted versus the corresponding aircraft speeds to obtain a curve similar to that in frame 10 of Figure 15. It was then possible to determine the minimum magnitude of pavement deviation to develop intolerable aircraft acceleration response under the worst possible condition of a pavement with periodic roughness at a frequency which matches the critical frequency of the aircraft system.

88. This particular approach to periodic roughness was used.for the following forms of surface deviation: sinusoidal waveform, multistep waveform, and two types of multiramp waveforms. Details of the results of the parametric study of periodic roughness are presented in Part V.

89. The single-encounter (isolated bump) type of pavement roughness was analyzed in a much more simple manner. That is, it was only necessary to input a runway profile with a single bump and compute the resulting aircraft acceleration response. It was possible to determine the critical magnitude of single-encounter roughness by merely varying the magnitude of the bump until an intolerable aircraft acceleration response was produced. Again, it was necessary to investigate the single-encounter roughness for a range of aircraft speeds. The results of the single-encounter roughness analysis are also given in Part V. 


\section{PART V: ANALYSIS OF DATA}

90. Data were collected or generated in many forms to satisfy the requirements of this study. They were in the form of: straightedge measurements of pavements constructed by slipform methods; runway profile elevations at several airfields; measured aircraft response data; and computed aircraft response data. The analysis and results associated with each of these forms of data are discussed separately in this Part.

\section{Straightedge Measurements}

91. Results of straightedge measurements of runway pavements constructed by slipform pavers have been reported previously. ${ }^{7}$ A brief summary of these results is given here to establish the level of roughness that might be expected when slipform pavers are employed during pavement construction. The following field observations were made from August 1971 to January 1973.

92. Smoothness measurements were made at eight projects. The distance from the bottom of a straightedge laid on the pavement surface to the pavement surface was measured with a scale. The straightedge was placed parallel and perpendicular to the direction of the paving lane. For longitudinal measurements, the straightedge was placed along the edge and in the interior of paving lanes. For transverse measurements, the straightedge was placed with its end along the lane edges, across longitudinal construction joints, and in the interior of paving lanes.

93. On five of the eight projects, measurements were made with a I2-ft-Iong straightedge and on one project a l6-ft-long straightedge was used. On two projects, only edge slump measurements were made with a 4-ft-long straightedge.

94. The term "edge slump" refers to the deviation of the unsupported paving lane edge from its original shape. In Figure 16, the term "edge slump" refers to the change in the shape of the pavement edge from the original square shape to that shown, or to the magnitude of the downward movement of the corner $\left(\Delta_{e}\right)$. 
95. Transverse measurements are (a) measurements of deviation of the surface from the straightedge at the edge of a paving lane, and (b) measurements within a lane exclusive of the deviation along the edge. Longitudinal measurements were made in the same manner as the transverse measurements within the interior of the paving lane. In addition, for both transverse and longitudinal measurements, the percentage of measurements which exceed a certain deviation was computed with a base representing both the number of straightedge positions and the number of measurements (locations where the pavement surface deviates from the straightedge).

96. The manner in which measurements were made and summarized may be clarified by Figure 16. In this sketch, the end of the straightedge is located at the edge of the paving lane. In some cases, when fill-in lanes were in place, the straightedge was placed with the center point of the straightedge at the longitudinal construction joint. The deviation $\Delta_{e}$ is the deviation of the edge or, as defined, the edge slump. For the one straightedge position, the readings $\Delta_{1}$ and $\Delta_{2}$ represent two measurements or locations where the surface deviates from the straightedge within the interior of the paving lane. Longitudinal measurements are taken in the same way as $\Delta_{1}$ and $\Delta_{2}$.

97. No attempt was made to select particular areas on the pavement for taking measurements; rather, locations were selected at random. In some instances, a series of measurements were made at a particular location while, at others, only one was made. Deviations from the bottom edge of the straightedge were measured with a scale to the nearest $1 / 16$ in.

98. Surface texture, which included textare applied with a burlap örag, texture applied with a wire comb, and grooves applied with a rotating drum, made accurate measurements difficult. Because of the surface texture, it was difficult to seat the straightedge and the tip of the scale, and as a result, there was considerable scatter in the measurements. The precision of the measurements was also affected by the texture, i.e., more confidence could be placed in a measured deviation 
of $1 / 4 \mathrm{in.} \mathrm{than} \mathrm{in} \mathrm{a} \mathrm{deviation} \mathrm{of} 1 / 8 \mathrm{in.} \mathrm{Smoothness} \mathrm{measurements} \mathrm{from}$ all the projects observed are summarized in Tables 4 and 5 .

99. Grade and smoothness requirements for construction profects 1 , $3,4,5,7,8$, and 9 had been established by FAA specifications. The smoothness requirements were set at a maximum deviation of $1 / 4$ in. from a 16-ft straightedge in any direction. For a vertical alignment a maximum deviation of $1 / 4 \mathrm{in}$. from an established grade was allowed, and for a horizontal alignment a maximum of 0.10-ft deviation from an established line was allowed. In addition, no edge could have a deviation of more than 1/4 in. from a straightedge.

100. The smoothness requirements for project 2 , a highway pavement, were set at a maximum deviation of $1 / 8 \mathrm{in}$. from a 10-ft straightedge in a longitudinal direction with no specific requirement for the transverse direction. An edge slump of 3/8 in. was allowed.

- 101. The transverse measurements at the longitudinal joints showed that the free edges do slump or sag. The area affected by the edge slump appears to be a strip up to $4 \mathrm{ft}$ wide along the edges of the paving lane. The distance affected by edge slump appears to be proportional to the slab thickness and magnitude of edge slump; however, the measurements failed to show this conclusively. Typical measured shapes of several as-placed edges are shown in Figure 17, in which it can be seen that the deviation decreases as the distance from the edge increases. When adjustments are made or the edges manually manipulated to remove the effects of the edge slump, the shape may be altered.

102. A larger percentage of the transverse measurements along the edge of the longitudinal joint exceed 1/4 in. more than in the slab interior (Table 4). This is furtiner illustrated by the differences in the average deviation between the slab edge and interior, and by the difference between the deviation along the edge of a slipformed lane and the deviation along the edge of a fill-in lane. The measurements show, in general, that the average deviation is greater along the edge than in the interior, and that the deviations along the edge of the slipformed lanes are larger than those along the edge of fill-in lanes; however, there were several notable exceptions. The measurements at project 3 
Table 4

Surmary of Transverse Smoothness Measurements of Slipformed Pavements

\begin{tabular}{|c|c|c|c|c|c|c|c|c|}
\hline Profect & $\begin{array}{c}\text { No. of } \\
\text { Straightedge } \\
\text { Positions } \\
\end{array}$ & $\begin{array}{l}\text { No. of } \\
\text { Readings }\end{array}$ & $\begin{array}{l}\text { Maximum } \\
\text { Deviation, } \\
\text { In. } \\
\end{array}$ & $\begin{array}{l}\text { Average } \\
\text { Deviation, } \\
\text { In. } \\
\end{array}$ & $\begin{array}{l}\text { Readings }> \\
1 / 4 \text { in. } \%\end{array}$ & $\begin{array}{l}\text { Positions Having } \\
\text { Readings }> \\
1 / 4 \text { in., } \% \\
\end{array}$ & $\begin{array}{l}\text { Edge Deviations } \\
>1 / 4 \text { In. } \%\end{array}$ & Remarks \\
\hline 1 & 20 & 83 & $5 / 16$ & 0.17 & 1 & $5-$ & - & Interfor of lane \\
\hline 1 & 24 & - & $5 / 16$ & 0.20 & - & -- & 25 & Edge of lane \\
\hline 2 & -- & 110 & $3 / 4$ & 0.18 & - & -- & 13 & $\begin{array}{l}\text { Edge of lane, } \\
\text { highway pavement }\end{array}$ \\
\hline 3 & 33 & 134 & $1 / 2$ & 0.18 & 19.5 & 36 & - & Interior of lane \\
\hline 3 & 20 & - & $9 / 16$ & 0.10 & - & - & 10 & Edge of lane \\
\hline 4 & 22 & 29 & $7 / 16$ & 0.17 & 7 & 9 & - & Interior of lane \\
\hline 4 & 22 & - & $3 / 4$ & 0.47 & -- & - & 82 & Edge of lane \\
\hline 4 & 30 & 14 & $3 / 8$ & 0.16 & 7 & 3 & - & Interfor of lane \\
\hline 4 & 24 & - & $5 / 8$ & 0.27 & - & - & 50 & Edge of lane \\
\hline 4 & 24 & 13 & $1 / 4$ & 0.14 & 0 & 0 & - & $\begin{array}{l}\text { Fill-in lane } \\
\text { Interior }\end{array}$ \\
\hline 4 & 24 & - & $5 / 8$ & 0.24 & - & - & 41 & Fill-1n lane edge \\
\hline 5 & 21 & - & $3 / 4$ & 0.40 & - & - & 71 & Edge of lane \\
\hline 5 & 21 & - & $1 / 2$ & 0.32 & - & - & 57 & Edge of fill-1n lane \\
\hline 5 & 15 & - & $5 / 16$ & 0.18 & - & -- & 13 & Edge of lane \\
\hline 5 & 15 & - & $5 / 16$ & 0.10 & - & - & 6.5 & Edge of fill-in lane \\
\hline 8 & 42 & 20 & $1 / 8$ & 0.12 & 0 & 0 & - & Intertor of lane \\
\hline 8 & 34 & $\div$ & $5 / 16$ & 0.16 & - & - & 3 & Edge of lane \\
\hline 8 & 34 & 27 & $3 / 16$ & 0.14 & 0 & 0 & - & $\begin{array}{l}\text { Interior of fill-1n } \\
\text { lane }\end{array}$ \\
\hline 9 & 24 & 一 & $1 / 2$ & - & - & 8 & - & Interfor of lane \\
\hline 9 & 24 & 一 & $5 / 8$ & 0.30 & - & - & 46 & Edge of lane \\
\hline 9 & 24 & - & $5 / 16$ & - & - & 4 & - & $\begin{array}{l}\text { Interior of fill-in } \\
\text { lane }\end{array}$ \\
\hline 9 & 12 & - & $9 / 16$ & 0.19 & - & -- & 33 & Edge of fill-in lane \\
\hline
\end{tabular}


Table 5

Sumnary of Longltudinal Smoothness Measurements of Slipformed Pavements

\begin{tabular}{|c|c|c|c|c|c|c|c|c|}
\hline Project & $\begin{array}{c}\text { No. of } \\
\text { Straightedge } \\
\text { Positions } \\
\end{array}$ & $\begin{array}{l}\text { No. of } \\
\text { Readings }\end{array}$ & $\begin{array}{l}\text { Maximum } \\
\text { Deviation, } \\
\text { in. } \\
\end{array}$ & $\begin{array}{l}\text { Average } \\
\text { Deviation, } \\
\text { In. } \\
\end{array}$ & $\begin{array}{l}\text { Readings > } \\
1 / 8 \text { in., } \%\end{array}$ & $\begin{array}{l}\text { Positions Having } \\
\text { Readings }> \\
1 / 8 \text { in. } \% \\
\end{array}$ & $\begin{array}{l}\text { Readings }> \\
1 / 4 \text { in., } \% \\
\end{array}$ & $\begin{array}{l}\text { Positions Having } \\
\text { Readings }> \\
1 / 4 \text { in. } \% \\
\end{array}$ \\
\hline 1 & 12 & 25 & $1 / 4$ & 0.12 & 24 & 33 & 0 & 0 \\
\hline 3 & 60 & 83 & $3 / 8$ & 0.17 & 61 & 48 & 2 & 3 \\
\hline 4 & 16 & 17 & $3 / 8$ & 0.07 & 64 & 69 & 18 & 19 \\
\hline 7 & 74 & 188 & $5 / 16$ & 0.12 & 24 & 60 & 1 & 3 \\
\hline 8 & 46 & 65 & $3 / 8$ & 0.14 & 26 & 37 & 1 & 2 \\
\hline 9 & 24 & - & $5 / 16$ & - & - & 54 & - & 12 \\
\hline
\end{tabular}


showed less deviation along the slab edge than in the interior, as indicated by the percentage of measurements larger than $1 / 4 \mathrm{in}$. and by the average measurements. Another exception is project 8 where the fill-in lane showed a larger percentage of the edge measurements exceeding $1 / 4 \mathrm{in}$. and a larger average deviation than did the slipform lanes. This was caused by the manual manipulation of the edges to reduce the effects of edge slump.

103. On project 3, the surface had been worked extensively, producing large amounts of grout which were used along the edge to build up the edge and eliminate the effects of edge slump. This resulted in a square corner along the edge, but at times overbuilding of the edge created a surface shaped as shown in Figure 18.

104. On project 8 , concrete with small aggregate had been placed by hand along the edge of slipformed lanes. The freshly mixed concrete was worked into the surface and a square corner formed by hand. There was no indication that overcompensating for the edge slump resulted in a surface shaped like that shown in Figure 17, but the measurements did show that deviations along the edges of the slipformed lanes were less than those along the edges of the fill-in lanes, which was different from what the measurements on the other projects showed.

105. The magnitude of the edge slump will be proportional to the slab thickness. Figures 19 and 20 show average edge deviations and percent of measured deviation exceeding $1 / 4$ in. plotted as a function of slab thickness. The two points on each curve which do not follow the general pattern are measurements on projects 3 and 8 , where hand manipulation reduced the effect of edge slump.

106. From the measurements made, no deflnite correlation was apparent between the transverse measurements made within the slab interior and slab thickness. The range of thickness was limited ( 11.5 to 16 in.) but it appears that the average deviation in the interior of the slab may be independent of slab thickness (see Figure 2l). The two points plotted for the fill-in lanes tend to substantiate this contention, but more points would be necessary to draw any definite conclusions. However, there is no physical reason 
why the slab thickness should affect the smoothness away from the edge. The variations or differences that occur from job to job are probably a function of other factors such as machine adjustment, machine response capability, mix uniformity, personnel experience, etc., rather than pavement thickness.

107. Measurements with the straightedge parallel to the direction of paving show smaller average deviations and smaller percentages of readings which exceed $1 / 4 \mathrm{in}$. than do the measurements with the straightedge perpendicular to the direction of paving. This is caused primarily by the edges since the average deviations and percentages for the transverse measurements in the lane interior are similar to those for the longitudinal measurements.

108. As for the transverse measurements within the paving lane interior, there appears to be no definite relationship between the longitudinal smoothness and slab thickness. Average deviation plotted versus slab thickness (Figure 22) suggests that longitudinal smoothness is independent of slab thickness. However, the range of slab thicknesses and number of measurements are too small to draw any definite conclusions. As for the transverse measurements in the interior of the slab, the variation or difference in longitudinal smoothness is probably a function of a number of factors and is probably not directly related to pavement thickness.

109. The smoothness of the surfaces varied from job to job. The quality of the surface obtained appeared to be commensurate with the overall quality of the construction. The experience of personnel and the attention given details seem to be the two most important factors in determining the quality of the surface. There were noticeable improvements on several jobs as work progressed and the personnel gained experience.

110. The transverse measurements indicate that it is relatively easy to meet 1/4-in. tolerance within the paving lane interior, but that it is more difficult to meet this tolerance along the lane edges. In order to meet smoothness requirements along the edge of slipformed 
lanes, the machine and concrete mixture must be properly adjusted and the machine must move forward at a uniform rate without frequent stops.

111. The longitudinal measurements also indicate that it would be difficult to meet a 1/8-in. tolerance in the longitudinal direction, but that a 1/4-in. tolerance could be met rather easily. It should be noted that the requirement for the jobs observed was a 1/4-in. tolerance, as measured with a 16-ft straightedge, and there was no incentive for the contractor to improve the longitudinal smoothness. With closer control it may have been possible to improve the longitudinal smoothness, but with a l/8-in. tolerance there will probably always be areas which will require corrective measures such as grinding.

\section{Runway Profile Data}

112. Profiles were measured for seven runways during the course of this study. These runways were located at NAFEC; at the Jackson, Miss., Municipal Airport; and at Ellsworth, Grand Forks, Minot, and Palmdale Air Force Bases. The primary purpose of the runway profiles was as input forcing functions for the aircraft simulation computer code. That is, aircraft response was to be computed using the simulation code for aircraft operations on the test site runways and compared with measured aircraft response for these same runways. In addition, a statistical analysis was to be performed using the measured profiles in order to compare the surface condition of test site runways with the results of previous studies in the area of runway roughness.

113. In reality, neither of the intended uses of the profile data

'have been realized because of the problems discussed earlier. As a result the aircraft simulation computer code was used without additional verification and the emphasis of the program was directed toward an analytical parametric study using the aircraft simulation computer code with hypothetical runway profile input. Modification of the computer code is in progress to provide a realistic modeling of the Boeing 727 aircraft which would allow a comparison of measured and computed aircraft response data for that particular aircraft. Also, further efforts with 
the measured $B-52$ response data could lead to usable measured response data for this aircraft and thus a comparison of measured and computed data for the B-52 aircraft would be possible.

114. The plotted runway profiles are presented in Figures 23 through 26 for NAFEC runways 04-22 and 13-31, runway 07-25 at Palmdale Plant 42, and runway 17-35 at Grand Forks AFB. The runway elevation data for muway 15L-33R at the Jackson Municipal Airport are available on computer cards, and the Air Force Weapons Laboratory has the elevation data for the runways at Minot and Ellsworth on magnetic tapes.

\section{Computed Aircraft Response Data}

115. The Air Force criterion regarding whole body vibration, 0.4-g acceleration, has been adopted for the purpose of defining the upper limit of tolerable aircraft acceleration response. Figure 27 contains a set of curves developed by experimenters illustrating the levels of acceleration within the frequency domain which have been found to bound specific regions for which human subjects perceive vibration, find it unpleasant, or refuse to tolerate it further (Reference 8). Curves I, II, and III are for subjects vibrated without any protection and exposure times of 5 to $20 \mathrm{~min}$, while the short-time tolerance curve is for subjects with the standard Air Force lap belt and shoulder harness with an exposure time of approximately $1 \mathrm{~min}$. The Air Force criterion of $0.4 \mathrm{~g}$ is also shown in this figure to illustrate its relationship with the work of a large number of experimental investigations in the area of whole body vibration. The 0.4-g criterion evolved from a number of previous studies concerned with aircraft vibration. Basically, it was generally found by subjective ratings that aircraft crews became concerned or irritated by vibration levels which exceed the 0.4-g level.

116. Therefore, the $0.4-8$ level of aircraft vertical acceleration was used to define the limit of tolerable acceleration. In order to introduce a certain degree of conservatism into the analysis, an 
acceleration level of $0.2 \mathrm{~g}$ was selected as the acceptable level of vertical acceleration for a newly constructed airfield. It was felt that this would allow a certain amount of pavement surface deterioration during the life of the pavement before the level of pavement roughness becomes great enough to generate aircraft accelerations greater than the 0.4-g level.

117. Having adopted the Air Force vibration criterion for the upper level of tolerable aircraft acceleration response and having somewhat arbitrarily selected an upper level of aircraft response for a newly constructed airfield pavement the question that remained was: What level of pavement roughness will produce these levels of aircraft response? The procedure presented in Part IV was followed to obtain these limiting levels of pavement roughness for four forms of periodic roughness and one form of single-encounter roughness. The forms of pavement roughness are illustrated in Figure 28.

Single-encounter analysis

118. The single-encounter form of roughness is probably the most likely form of severe roughness encountered on an alrfield pavement. A series of simulated constant-speed taxi tests were conducted using the aircraft simulation code for the $\mathrm{B}-52 \mathrm{H}$ aircraft. A step function form of single-encounter roughness was used as the input profile with the height of the step being varied during each test. Figures 29 through 33 contain the aircraft acceleration response-time histories for aircraft speeds of $30,60,90$, and 120 knots. The procedure for each test was the same; that is, the runway profile was made up of four steps of . Increasing magnitude spaced sufficiently far apart to allow the response of the aircraft resulting from the previous burmp to diminish to a low level prior to encountering the next bump. The heights of the burms were varied until an aircraft acceleration response greater than $0.4 \mathrm{~g}$ was produced. Each of Figures 29 through 33 contains three plots. The top plot is the profile of the hypothetical runway as a function of time while the middle and bottom plots represent the aircraft acceleration response-time histories at the pilot station and CG. The $\pm 0.4-\mathrm{g}$ line 
is also shown on the acceleration-time histories to clearly indicate the point at which the response exceeds the tolerable limit of $0.4 \mathrm{~g}$.

119. Figure 34 contains a summary of the maximum aircraft response at the pilot station as a function of amplitude of pavement roughness. This figure contains a curve for each speed considered. The amplitude of roughness, 1.e., step helght, at which each of these curves intersects the 0.4-g acceleration line represents the step height required to produce an intolerable response at the pilot station of the aircraft for the constant taxi speed associated with each curve. The step height at which each of the curves intersects the $0.2-g$ acceleration line represents the step height necessary to produce an aircraft response at the upper level of acceptable response for newly constructed airfleld pavement.

120. These required step heights are plotted as a function of aircraft speed in Figure 35. The top curve represents the amplitude of pavement roughness in the form of a single-encounter step function required to produce intolerable aircraft response throughout the range of aircraft ground speeds, while the bottom curve is a similar relationship using the 0.2-g acceptable level of acceleration. Also shown in Figure 35 are the current CE pavement smoothness criteria as applied to plan grade and abrupt changes. It can be seen that the amplitude of single-encounter pavement roughness necessary to generate the intolerable 0.4-g aircraft response falls well above the controlling $\mathrm{CE}$ criteria regarding abrupt changes for the entire ground speed range of the B-52H. Likewise, the height of single-encounter step necessary to generate $0.2-g$. acceleration falls above the current $C E$ smoothness criteria for abrupt changes. The results of this analysis indicate that, in the case of single-encounter form of roughness, the smoothness criteria for abrupt changes can be relaxed to allow 0.2-in. deviation from a 10-ft straightedge for newly constructed airfield pavements. An even greater deviation, perhaps 0.6 in., could be allowed before the airfield would require repair. Periodic-roughness analysis

121. The initial task of the analysis of periodic roughness was to 
determine the wavelength of pavement roughness which would represent the most severe case of periodic excitation to the aircraft structure. During the early stage of the analysis it was hypothesized that the most severe case would be that of a periodic function, of any form, with a wavelength that matches the dominant frequency of the aircraft structural dynamic response. In order to determine this critical wavelength of roughness it was first necessary to determine the dominant response frequency of the aircraft. Therefore, a hypothetical profile in the form of an impulse function was generated and input into the aircraft simulation code along with the mechanical and aerodynamic properties of the B-52 aircraft, and a simulated constant-speed taxi was performed. The results of this exercise for the typical case of a 75-knot taxi are presented in Figure 36. The top plot is the impulse profile that was input into the computer code while the bottom two plots are the resulting aircraft acceleration response at the pilot station and CG of the aircraft.

122. The aircraft response was then input into a computer program which computed the Fast Fourier Transform of the acceleration, as a function of time, in the frequency domain. The plotted results of this transformation for the particular case of the 75-knot taxi of the B-52 are presented in Figure 37. Note the sharp spike in the curve at a frequency of approximately 1 cps. This indicates that, of the many frequencies that make up the frequency composition of the aircraft response, the dominant frequency is approximately.l cps. Consequently a forcing function with an excitation frequency of 1 cps should generate the maximum aircraft response. Therefore, periodic runway roughness with a frequency which matches this critical frequency of the aircraft should likewise generate the maximum aircraft response. Or, in other words, the minimum magnitude of periodic roughness required to excite the aircraft beyond some acceptable level of response (say $0.4 \mathrm{~g}$ ) would be that roughness with a frequency which matches the critical frequency of the aircraft.

123. This critical aircraft response frequency is a function of the speed of the aircraft; therefore, it was necessary to follow the 
procedure discussed above for the range of possible ground speeds of the B-52. The curve of Figure 38 is a plot of the results of this endeavor for a speed range of 10-120 knots. These critical aircraft response frequencies were then used to compute the corresponding critical wavelengths of periodic runway roughness. Again, the critical wavelength of periodic roughness is a function of aircraft speed and is presented graphically in Figure 39.

124. Before proceeding to the next element of the parametric study a test run was made to determine if the magnitude of aircraft response did indeed increase to a limiting value for a constant-amplitude periodic runway profile and if it did how many cycles were necessary to obtain this limiting magnitude. The plotted results of this test run are contained in Figure 40, for a simulation of a 10-knot taxi on a profile with a sinusoidal waveform with a constant amplitude of 0.075 in. and a wavelength of $174 \mathrm{in}$. These results supported the assumption that the aircraft response did reach a limiting magnitude after 25 cycles for the case of a 10-knot taxi. Similar test runs were conducted for the full aircraft speed range.

125. Computer simulations were made for aircraft taxies over profiles with periodic roughriess of a frequency matching the critical frequency of the aircraft for a range of aircraft speeds, amplitudes of roughness, and forms of periodic roughness. The forms of periodic roughness considered during this study were: the sinusoidal waveform, the multi-step function, and two forms of multiple-ramp functions. Sinusoidal waveform

126. Figures 41 through 47 contain the simulation mans for the profile with a sinusoidal waveform throughout the speed range of 10-120 knots. In all cases the critical pavement wavelength corresponding to the aircraft speed was used. Again the top plot is the hypothetical profile while the middle and bottom plots are the acceleration-time histories at the pilot station and CG of the aircraft. Note the $\pm 0.4-\mathrm{g}$ lines plotted on both acceleration-time histories. The object of each of the runs was to determine the magnitude of pavement 
roughness necessary to excite the aircraft beyond the $0.2-$ and $0.4-g$ level of acceleration.

127. Figure 48 is a plot of the limiting value of acceleration at the pilot station versus the corresponding magnitude of roughness for various speeds within the ground speed range of the B-52. The data necessary for this series of curves were obtained from the information presented in Figures 41 through 47 and discussed above. The aircraft response at the pilot station was selected because it was the greater of the two aircraft responses computed.

128. Figure 49 contains a further summary of the results for the sinusoidal waveform. It is a plot of the levels of sinusoidal profile magnitude necessary to produce an aircraft acceleration response of both the 0.2- and 0.4-8 amplitude for the range of aircraft ground speeds. For the special case of a runway with a sinusoidal profile, the magnitude of the roughness must be on or above the plotted curve (curve labeled I) at any particular speed to produce intolerable aircraft response, i.e., response greater than $0.4 \mathrm{~g}$. Similarly, the magnitude must be on or above curve III to produce an aircraft response greater than $0.2 \mathrm{~g}$. Although no pavement is likely to be constructed with a pure sinusoidal profile, these plots are worthwhile in that the sinusoidal waveform represents one of the most severe forms of pavement roughness possible, and the curves of Figure $49 \mathrm{might}$ be considered the lower limits of the magnitude of pavement roughness that might produce intolerable or unacceptable aircraft responses. Therefore, one might agree that a pavement constructed with a surface deviation that is less than the minimum value of the relationship represented by this curve - would not be responsible for an aircraft response in excess of the tolerable limit. However, the minimum value of this relationship is approximately $0.05 \mathrm{in}$. for intolerable aircraft response and $0.018 \mathrm{in}$. for unacceptable aircraft response, and a construction smoothness criterion of this value would be much too restrictive, particularly since runways constructed according to the current $\mathrm{CE}$ criteria are certainly considered adequate as evident from the responses obtained 
to the questionnaires discussed earlier. Therefore, it was necessary to consider the forms of pavement roughness more likely to occur on an airfield pavement.

129. Thus, hypothetical runway profiles consisting of multiple-step functions, multiple-step ramp functions, and single-encounter step functions were investigated. The critical pavement wavelengths were considered for the periodic forms of roughness in much the same manner as was done for the sinusoidal waveform.

130. Before considering other forms of periodic roughness, another interesting point might be raised by the information presented in Figure 49. That is the relationship of the amplitude of sinusoidal roughness required for intolerable aircraft response with respect to the $\mathrm{CE}$ smoothness criteria of an allowable level of $1 / 8-i n$. deviation from a 12-ft straightedge as applied to a profile of a pure sinusoidal form. This relationship is presented in Figure 49 by the two curves labeled I and II, where curve II is the allowable amplitude of roughness and curve $I$ is the amplitude of roughness that will cause intolerable aircraft dynamic response of $0.4 \mathrm{~g}$. This would indicate that a pavement could be constructed which easily meets current CE smoothness criteria, but which causes excessive aircraft response. Again, this may not be as significant as it may appear since the possibility of constructing an airfield with a sinusoidal profile is very remote, but this does point out an apparent failure of the current CE criteria to control periodic, nonabrupt surface deviations. Mult1ple-step waveform

131. Figures 50 through 53 contain the acceleration-time histories at the pilot station and CG of the aircraft for constant-speed taxies of $10,60,90$, and 120 knots, respectively, over hypothetical runways composed of multiple-step functions. The step functions contained within each of the four segments of the hypothetical profile were spaced at the critical pavement wavelengths corresponding to the critical aircraft response frequency. The amplitude of the step function is varied from one segment to the next, but the amplitude of the step function remains constant within each segment. Again the object of this phase of the 
study was to provide a profile input with a sufficient number of cycles for the aircraft response to attain a constant amplitude within each segment and to increase the magnitude of the profile from one segment to the next until the constant level of aircraft response exceeded $0.4 \mathrm{~g}$.

132. Figure 54 contains a sumary of the data of Figures 50 through 53. This figure contains the plotted limiting values of aircraft acceleration response with respect to the corresponding roughness magnitude for the range of B-52 ground speeds. The intersection of each of these curves with the $0.4-g$ aircraft response line and the $0.2-g$ was then plotted in Figure 55. As was the case for the sinusoidal profiles, curve I of Figure 55 represents the minimum magnitude of roughness of the multiple-step. waveform necessary to produce intolerable aircraft acceleration response $(0.4 \mathrm{~g})$ at the pilot station for the range of aircraft ground speeds, and curve II represents the minimum magnitude of roughness for a newly constructed airfield pavement (corresponds to aircraft acceleration of $0.2 \mathrm{~g}$ ). Also presented in this figure are the current $\mathrm{CE}$ criteria. The curve for the required magnitude of . multi-step roughness for intolerable aircraft response falls above the CE criteria for abrupt change for all aircraft ground speeds, while a portion of the new construction curve falls slightly below the current criteria. This indicates that the current $C E$ criteria are adequate to control multi-step runway roughness for newly constructed airfield pavements and could be relaxed somewhat for evaluation of existing pavements. In fact, the minimum level of roughness necessary for intolerable aircraft response for the case of multi-step roughness is approximately $0.175^{-i n}$., as indicated by the minimum value of curve I... Multiple-ramp waveforms

133. The two types of multiple-ramp waveforms illustrated in Figures $28 \mathrm{c}$ and $d$ were investigated during this study. The first type of waveform (multi-ramp 1, Figure 28c) resulted in a monotonically increasing elevation of the profile while the second type (multi-ramp 2, Figure 28d) had both positive- and negative-slope ramps and thus very closely resembled the sinusoidal profile discussed earlier. 
134. Mult1-ramp 1. Figures 56 through 61 contain the aircraft acceleration response-time histories for the case of the multi-ramp 1 runway profile. Again the wavelength of the periodic roughness was selected to coincide with the critical frequency of the aircraft for each speed considered. The top plot in each of these figures is the runway elevation as a function of time and the middle and bottom plots are the aircraft acceleration response at the pilot station and $C G$, respectively.

135. Figure 62 contains a summary of the information presented in Figures 56 through 61. This is a plot of the limiting values of aircraft acceleration response at the pilot station for the various amplitudes of multi-ramp 1 waveform. Five curves are presented in this figure for the constant aircraft speeds of $10,30,60,90$, and 120 knots. The amplitude of roughness at the intersection of each of these curves with the. 0.4-g aircraft acceleration represents the minimum amplitude of roughness of the multi-ramp 1 waveform which will cause intolerable aircraft response at the speed associated with that particular curve. The allowable level of roughness for the construction of new airfield pavements is given by the value of the roughness at the intersection of each of these curves with the 0.2-g acceleration line.

136. Figure 63 contains plots of these minimum amplitudes of roughness as a function of aircraft speed for both the case of allowable aircraft response of $0.4 \mathrm{~g}$ and $0.2 \mathrm{~g}$. Also plotted in this figure are the current $\mathrm{CE}$ smoothness criteria concerning pavement plan grade and abrupt changes. It can be seen that the amplitude of multi-ramp 1 roughness required to generate intolerable aircraft response (curve I) is. weII above the current CE criteria for abrupt changes in the pavement profile. Therefore, from the standpoint of evaluation of existing pavements, the current $\mathrm{CE}$ criteria are adequate to control this form of periodic roughness, and in fact, the acceptable amplitude of roughness of this form might be increased to $0.2 \mathrm{in.,}$ the minimum value of curve $I$.

137. The amplitude of roughness, of the form of multi-ramp 1 , required to generate the aircraft response of $0.2 \mathrm{~g}$ is given by curve II 
of Figure 63. The values on this curve very nearly match the values of the CE smoothness criteria for aircraft speeds less than 65 knots. The values of this curve fall well above the current criteria for speeds greater than 65 knots. This would indicate that the current CE criteria for the construction of new airfield pavements are an adequate control of the multi-ramp 1 form of roughness.

138. Multi-ramp 2. Figures 64 through 67 contain the aircraft acceleration response-time histories for a series of constant-speed taxi simulation tests with a pavement profile of the multi-ramp 2 waveform. Again, the data presented in Figures 64 through 67 are the runway profile as a function of time (top plot) and the aircraft response at the pilot station (middle plot) and CG of the aircraft (bottom plot). Data for aircraft taxies at speeds of $30,60,90$, and 120 knots have been computed and presented. Four different roughness amplitudes were input into the aircraft simulation code for each aircraft speed.

139. Figure 68 contains a summary of the data of Figures 64 through 67. There is a curve plotted for each of the aircraft speeds. Each curve is of the magnitude of aircraft acceleration response as a function of the amplitude of multi-ramp 2 roughness. The amplitude of roughness at the intersection of each curve with the 0.4-g line represents the amplitude of roughness required to generate intolerable aircraft response for the corresponding aircraft taxi speed, and the intersection of each curve with the 0.2-g line is the allowable level of roughness for the construction of new airfield pavements if the $0.2-g$ acceleration is chosen as the governing criterion of allowable aircraft response.

140. Figure 69 contains a plot (curve II) of the roughness amplitudes required for intolerable aircraft response $(0.4 \mathrm{~g})$ as a function of the aircraft ground speed. The amplitudes of roughness required to generate an unacceptable level of aircraft response $(0.2 \mathrm{~g})$ for newly constructed pavements have also been plotted in Figure 69 as curve II. Again the CE smoothness criteria have been plotted. Note that for this form of roughness the amplitude of roughness required for intolerable 
aircraft response falls slightly below the level of currently permissible roughness of both forms of the $\mathrm{CE}$ smoothness criteria for aircraft ground speeds of less than 60 knots. However, it would appear that the current criteria are an adequate indicator of excessive roughness of existing pavements.

141. The amplitude of roughness necessary to generate the unacceptable aircraft response of $0.2 \mathrm{~g}$ falls well below the CE abrupt change criteria for aircraft speeds less than 70 knots. This indicates that an airfield pavement could be constructed which adheres to the current CE criteria, but which would generate an unacceptable level of aircraft response at the pilot station. Again, the likelihood of constructing a real airfield pavement with a periodic roughness of this form is very remote, but these data do point out the danger involved if a periodic type of roughness does develop.

Summary

142. Figure 70 contains an overall summary of the results of the parametric study for both single-encounter and multi-encounter forms of roughness using the intolerable level of aircraft response $(0.4 \mathrm{~g})$ as the governing criterion for excessive aircraft response. It can be seen that the required roughness amplitudes for the single-encounter step, multi-ramp 1, and multi-step forms of roughness fall well above the governing CE roughness criteria concerning an abrupt change in the pavement surface. However, the required amplitude of roughness for multi-ramp 2 falls below the governing CE criteria for abrupt change for aircraft speeds less than 60 knots and the required amplitude for the sinusoidal waveform falls well below the governing CE criteria labeled III for the entire ground speed range of the B-52H aircraft. Therefore, the current CE smoothness criteria are indeed adequate and possibly too restricted when evaluating the level of single-encounter roughness of existing pavements. On the other hand, they are too restrictive for the multi-encounter roughness of the multi-step and multi-ramp 1 form; just adequate for the mult1-ramp 2 form of roughness; and not restrictive enough for the sinusoidal form of multi-encounter roughness. 
143. Figure 71 contains the overall summary of the results of the parametric study using the 0.2-g level of aircraft response as the governing criteria of excessive aircraft response for operations on newly constructed pavements. For this case current CE smoothness criteria for new pavements prove to be an adequate control of pavement smoothness for the single-encounter step function and the multiple-encounter roughness of the form of the multi-step and multi-ramp 1 . However, the current criteria are not an adequate control of the sinusoidal and multi-ramp 2 forms of periodic roughness. 
PART VI: CONCLUSIONS AND RECOMMENDATIONS

144. All conclusions herein are based upon two assumptions:

a. The airfield pavements under consideration are for the support of B-52 ground operations or the B-52 response to pavement surface deviations is typical or more severe than the aircraft response for which the pavement is designed.

b. The aircraft computer code used during this study is an accurate model of an actual B-52 aircraft.

145. Conclusions are drawn relative to pavement smoothness criteria for the construction of new airfield pavements and for the evaluation of the condition of existing airfield pavements. These will be referred to as new construction criteria and evaluation criteria. The basis for the evaluation criteria is the surface smoothness necessary (or roughness allowed) to prevent an intolerable vertical acceleration of $0.4-\mathrm{g}$ at the pilot station of the aircraft. The new construction criteria were developed on the basis of defining the surface smoothness necessary to prevent a vertical acceleration of $0.2-8$ at the pilot station. This latter aircraft response limitation (sometimes referred to in this report as an "unacceptable" response) was arbitrarily selected at a value less than 0.4-g to allow for pavement surface deterioration between the time of construction and the time of functional failure.

146. Conclusions are also presented which relate to the ability to meet surface smoothness requirements using slipform pavers.

\section{Conclusions}

147. It is concluded that:

a. Pavement smoothness criteria should control surface roughness of three general forms. These are designated as isolated abrupt changes, periodic abrupt changes, and periodic nonabrupt changes.

b. Current CE criteria provide a means of controlling both forms of abrupt changes in the pavement surface. They do not control periodic nonabrupt changes except at very high aircraft speeds (speeds greater than 110 knots). 
c. The acceptable level of an isolated (nonperiodic; single encounter) abrupt change in the longitudinal direction for newly constructed pavements is 0.2 in. (see Figure 71).

d. It is possible for very small levels of periodic abrupt changes to generate unacceptable aircraft vertical acceleration. Of the three forms of periodic abrupt changes investigated (multi-step, multi-ramp 1 , and multi-ramp 2), the multi-ramp 2 was the most severe form of roughness. The multi-ramp 2 results indicate that pavement deviations as low as 0.05 in. could generate aircraft vertical accelerations that are unacceptable for operations on a newly constructed pavement.

e. Very small amplitudes of periodic nonabrupt changes, well below the level allowed by current $C E$ criteria, can generate unacceptable levels of aircraft response. This is illustrated in Figure 71 by the curves labeled "III" and "sinusoidal." The likelihood of such pavement profile is remote, but these results do point out the serious danger if conditions exist that might generate a periodic unevenness of the pavement surface.

f. The tolerable level of an isolated abrupt change of the pavement surface in the longitudinal direction is approximately 0.6 in. (see Figure 70).

g. The tolerable level of periodic abrupt changes of the pavement surface in the longitudinal direction is approximately $0.1 \mathrm{in.}$. As was the case for the form of roughness associated with new construction criteria, the most severe of the three forms of periodic abrupt changes investigated was the multi-ramp 2 profile (see Figure 70).

h. The maximum tolerable amplitude of pavement roughness of a periodic nonabrupt (sinusoidal) change in the pavement surface is well below the level that would be allowed by the current $\overline{\mathrm{CE}}$ smoothness criteria. Again, this points out the possible danger involved if conditions should exist that might create this type of roughness.

i. It would be relatively easy to meet a smoothness requirement of 1/4-in. deviation from a 16-ft straightedge for transverse measurements within the interior of the paving lane using slipform pavers.

1. It would be more difficult, but definitely possible, to meet a 1/4-in. deviation requirement for transverse measurements at the edge of the slipformed lane. 
k. It would be difficult to meet a 1/8-in. tolerance in the longitudinal direction, but a $1 / 4-i n$. tolerance would present no major problem.

\section{Recommendations}

148. It is recommended that:

a. The current CE pavement smoothness criteria governing the construction of new airfield pavements be modified in the following manner:

(1) Change the acceptable level of isolated abrupt changes in the longitudinal direction to 0.2 in. deviation from a 12-ft straightedge, for those runways constructed primarily for medium to heavy bombers or tankers.

(2) Maintain the restriction on periodic abrupt changes in the longitudinal direction (such as surface deviations at transverse joints spaced at equal spacings) at the current allowable level of $1 / 8-1$. deviation from an approved 12-ft straightedge.

(3) Maintain the current criteria for surface deviations in the transverse direction.

b. The current CE pavement smoothness criteria applied to the evaluation of existing airfields can be modified in the following manner:

(1) Change the acceptable level of isolated abrupt changes in the longitudinal direction to 0.4-in. deviation from an approved straightedge.

(2) Maintain the current criteria in the longitudinal direction when applied to periodic abrupt changes.

(3) Maintain the current criteria for surface deviations in the transverse direction.

c. Additional studies be conducted using a variety of military aircraft to establish the construction and evaluation criteria for runway pavements with traffic dominated by aircraft other than the B-52.

d. Additional instrumented aircraft tests with controlled runway roughness be conducted to verify the aircraft simulation computer code.

e. Additional studies to determine a significant magnitude of aircraft acceleration response to use as an acceptable response for operations on newly constructed pavements, 
and a similar magnitude of aircraft response to use in the evaluation of existing pavements.

f. Additional analytical studies be conducted using the aircraft simulation computer code to determine the acceptable magnitude and interval of center line grade changes, to investigate further the case of periodic nonabrupt surface deviations, and to investigate the influence of a random distribution of surface deviations which models the deviations of actual runway profiles.

8. Additional studies be conducted to determine a measure, such as absorbed power, to describe and quantify the severity of munway roughness for use in the evaluation of existing pavements and as a standard for the construction of new pavements. 
1. Department of the Army, Office of the Chief of Engineers, "Guide Specification for Military Construction, Bituminous Intermediate and Surface Courses for Airfields, Heliports, and Tank Roads (Central-Plant Hot-Mix)," CE 807.22, Dec 1972, Washington, D. C.

2. "Corps of Engineers Guide Specification, Military Construction, Concrete Pavement for Roads and Airfields," CE-0261l, Dec 1975 (or MCGS 02611, Dec 1975), Washington, D. C.

3. Headquarters, Department of the Army, "General Provisions for Airfield Design," Technical Manual TM 5-824-1, Dec 1975.

4. Gerard1, A. G. and Lohwasser, A. K., "Computer Program for the Prediction of Aircraft Response to Runway Roughness," AFWL-TR-73109, Vol I, 1973, Air Force Weapons Laboratory, Kirtland Air Force Base, N. Mex.

5. "Computer Program for the Prediction of Aircraft Response to Runway Roughness," AFWL-TR-73-109, Vol II, 1974, Air Force Weapons Laboratory, Kirtland Air Force Base, N. Mex.

6. Morris, G. J., "Response of Several Turbojet Airplanes to Runway Roughness," NASA TN D-5740, 1970, Langley Research Center, Langley Station, Hampton, Va.

7. Parker, Frazier, Jr., "Airfield Pavement Construction; Slipform Paving Method," Miscellaneous Paper No. S-75-18, Jun 1975, U. S. Army Engineer Waterways Experiment Station, CE, Vicksburg, Miss.

8. Harris, C. M. and Crede, C. E., ed., Shock and Vibration Handbook, Vol 3, McGraw-Hill Book Company, Inc., New York, 1961. 
BASIC PROGRAM METHODOLOGY

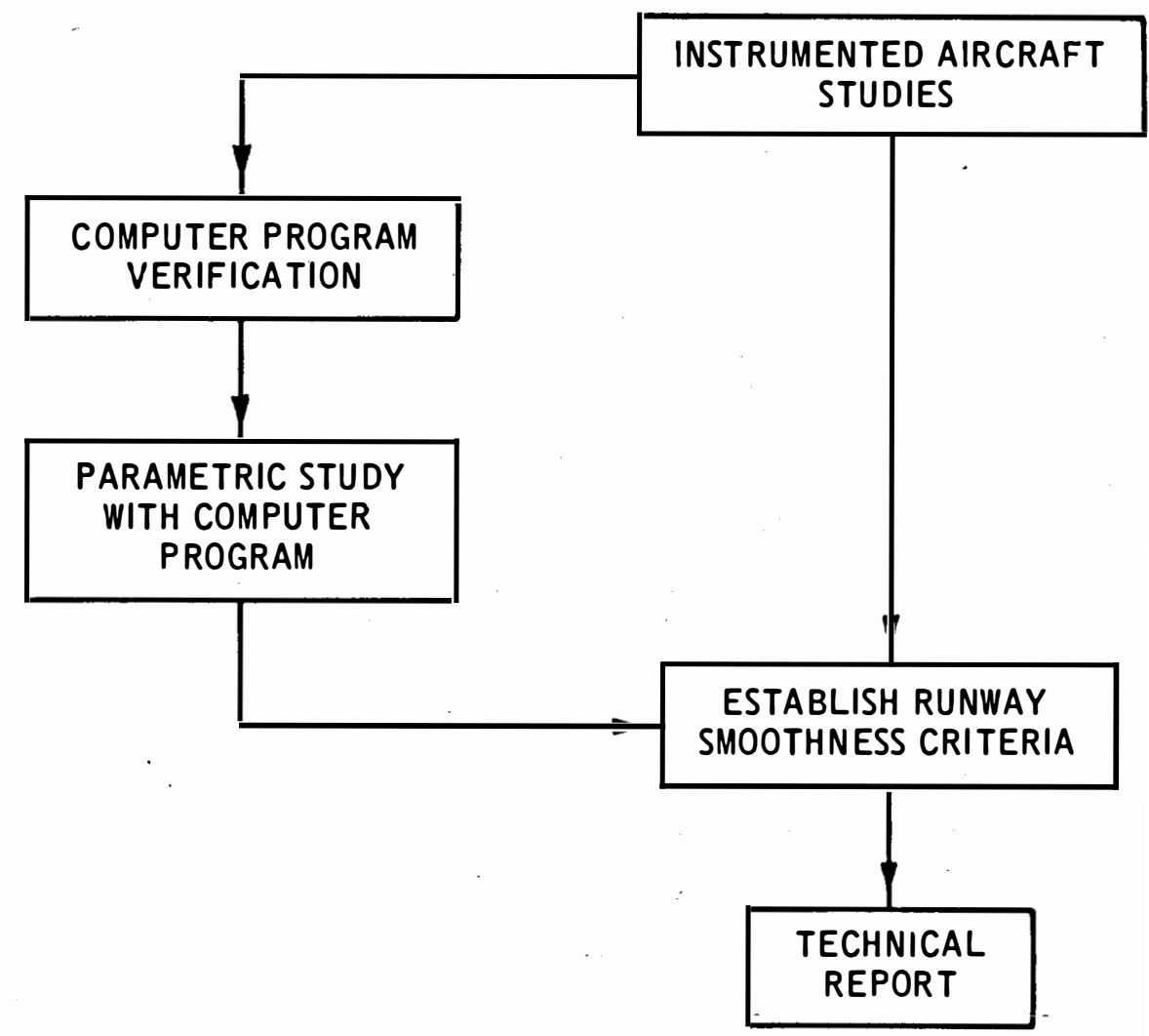

Figure 1. Basic program methodology 


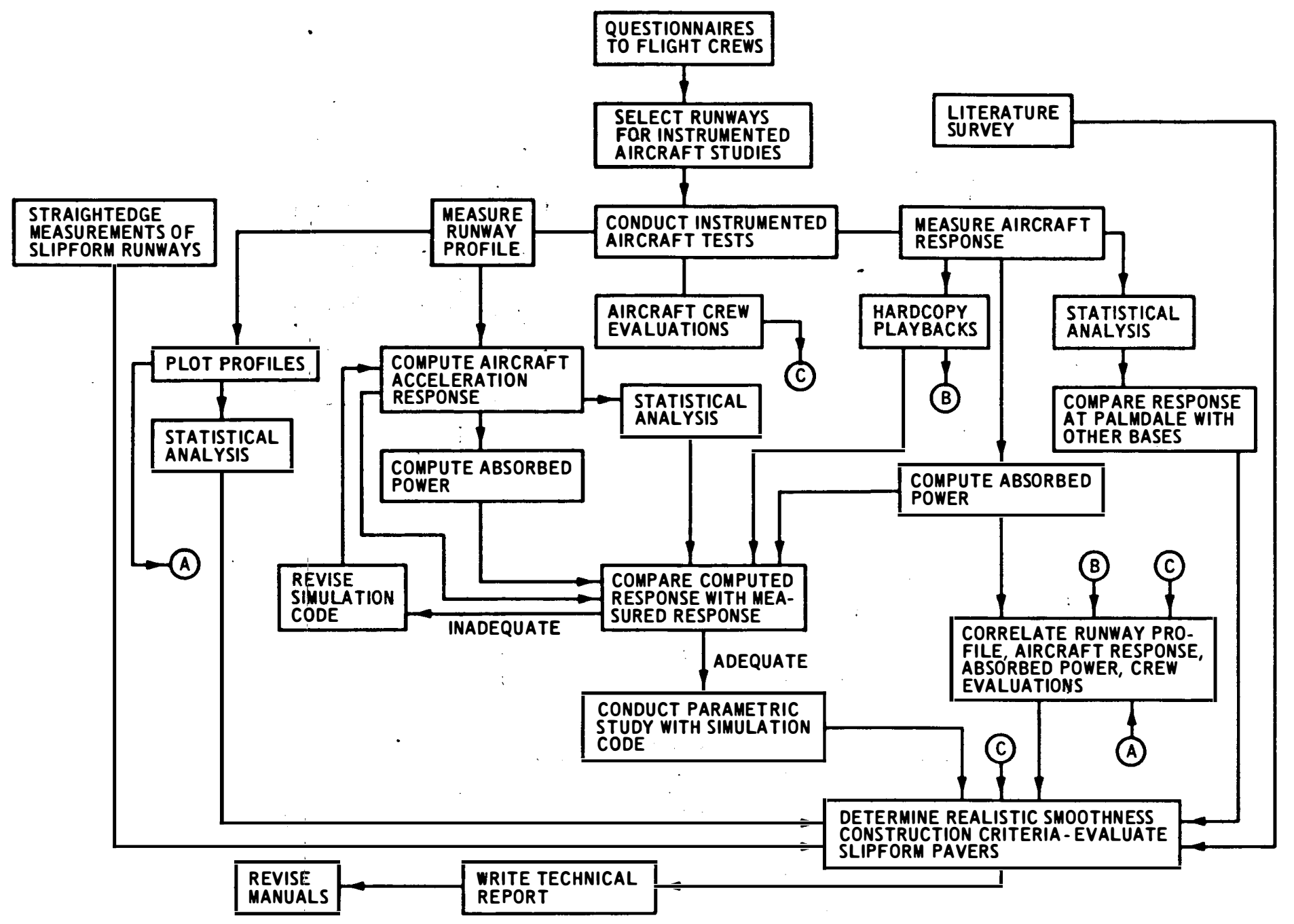

Figure 2. Detailed outline of procedure to verify/revise current Corps of Engineers airfield pavement smoothness requirements 


\section{INFORMATION TO BE OBTAINED FROM OPERATIONS OFFICERS}

FOLLOWING QUESTIONS TO BE ANSWERED BY B-52 AND KC-135 PILOTS.

1. WHAT TYPE AIRCRAFT DO YOU FLY?

2. HOW LONG HAVE YOU BEEN STATIONED AT THIS BASE?

3. WHERE WERE YOU STATIONED PRIOR TO THIS ASSIGNMENT?

4. HAVE YOU EVER FELT UNCOMFORTABLE FROM THE STANDPOINT OF RIDEABILITYWHILE TAKING OFF OR LANDING A B-52 OR KC-135 ON THE RUNWAY AT THIS AIR BASE?

5. HAVE THERE EVER BEEN TIMES IN A B-52 ON THIS AIRFIELD DURING TAKEOFF OR LANDING THAT IT WAS DIFFICULT TO READ THE INSTRUMENTS BECAUSE OF VIBRATIONS OR SHAKING OF DIALS CAUSED BY ROUGHNESS OF PAVEMENT?

6. HAVE YOU EVER EXPERIENCED THE FEELING WHILE MOVING DOWNTHE RUNWAY AT THIS AIRFIELD THAT, DUE TO OSCILLATIONS OF THE AIRCRAFT CAUSED BY UNEVENNESS OF THE PAVEMENT, YOU WERE AIRBORNE WHEN YOU REALLY WERE NOT?

7. FROM YOUR EXPERIENCE IN LANDINGS AND TAKEOFFS AT THIS AIR BASE, HAVE YOU FOUND THE RUNWAY LESS SMOOTH IN WINTER/SPRING THAN IN SUMMER/FALL?

8. HOW WOULD YOU RATE THE SMOOTHNESS CHARACTERISTICS OF THERUNWAYATTHIS AIR BASE? " SMOOTH $\square$; FAIR $\square$; ROUGH

9. HOWMANYSACAIRFIELDS HAVE YOUHADTHE OPPORTUNITYTO OPERATEFROMIN THE CONTINENTAL UNITED STATES?

10. FROM YOUR EXPERIENCE, DO YOU KNOW OF ANY SAC AIRFIELDS THAT YOU WOULD CONSIDER AS VERY ROUGH FROM THE STANDPOINT OF RIDING QUALITY?

Figure 3. Example of questionnaire distributed to B-52 and $\mathrm{KC}-135$ pilots 


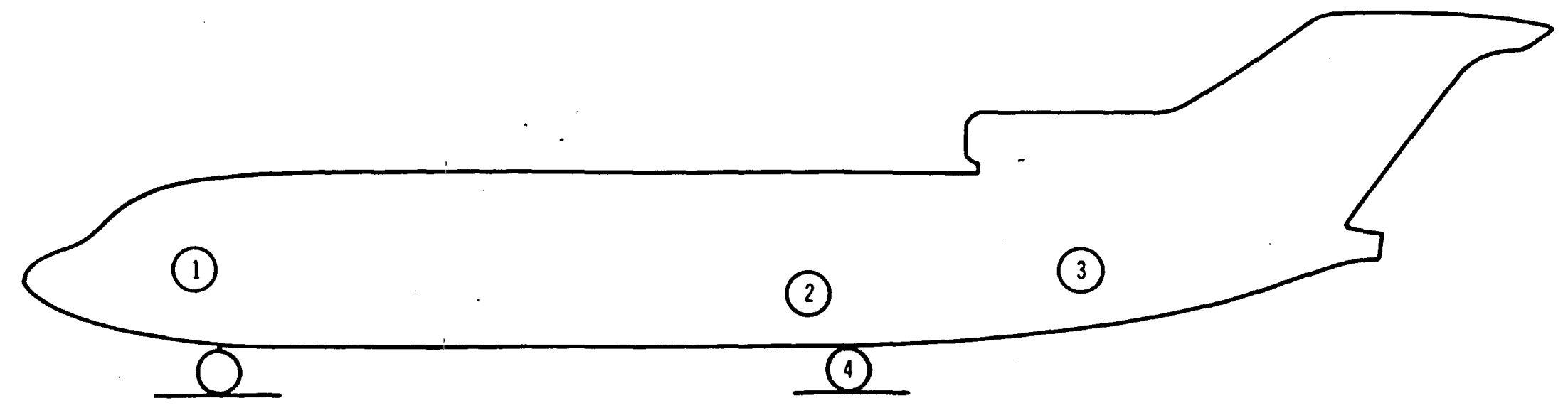

\begin{tabular}{|c|c|c|c|}
\hline$\frac{\text { PILOT'S } \frac{1}{S T A T I O N}}{\text { - VERTICAL ACCELEROMETER }}$ & $\begin{array}{l}\frac{2}{\text { CENTER OF GRAVITY }} \\
\text { - VERTICAL ACCELEROMETER } \\
\text { - LONGITUDINAL ACCELEROMETER } \\
\text { - LATERAL ACCELEROMETER } \\
\text { - ANGULAR ACCELEROMETER } \\
\text { FOR: } \quad * \text { PITCH } \\
\quad * \text { ROLL }\end{array}$ & - VERTICAL ACCELEROMETER & $\begin{array}{l}\frac{4}{\text { MAIN GEAR }} \\
\text { - STRAIN GAGES: } \\
\text { * SIDE STRUT } \\
\text { * DRAG STRUT } \\
\text { * AXLE } \\
\text { - POTENTIOMETER (TO MEASURE } \\
\text { STROKE OF SHOCK ABSORBER) }\end{array}$ \\
\hline
\end{tabular}

Figure 4. Location of gages on the Boeing 727 aircraft 


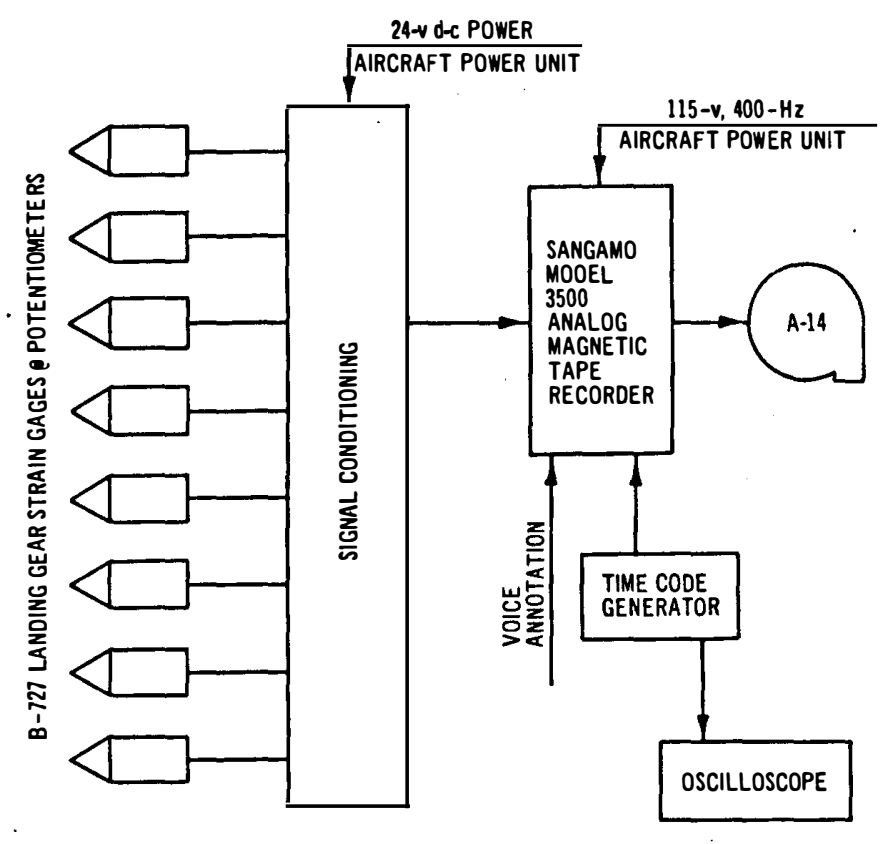

Figure 5. Instrumentation system associated with gages mounted on main gears of United ${ }^{-} \mathrm{B}-727$ aircraft 


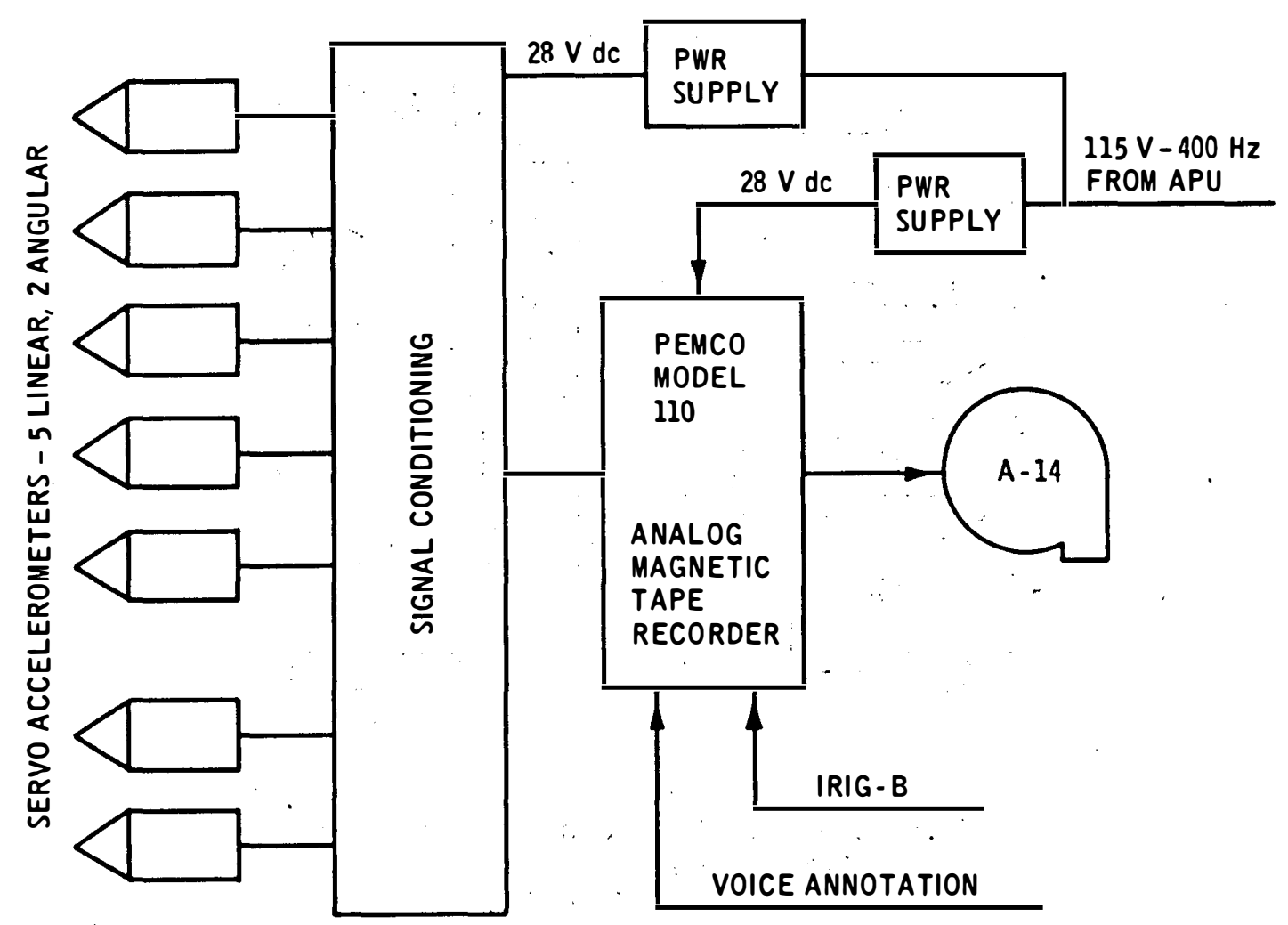

Figure. 6. Diagram of instrumentation system installed on board the Boeing 727 aircraft to measure aircraft acceleration response 

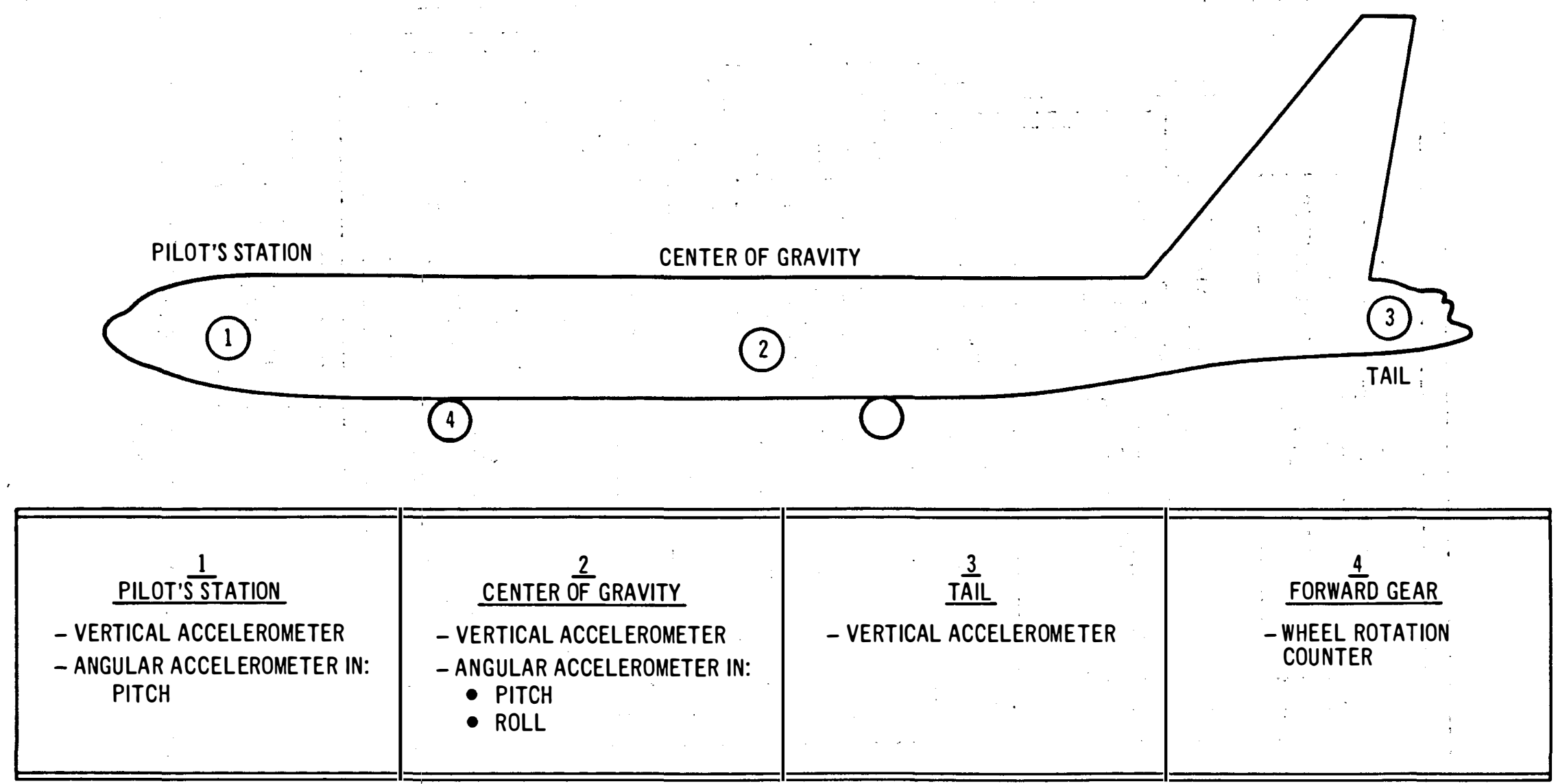

Figure 7. Location of gages on the B-52 aircraft 


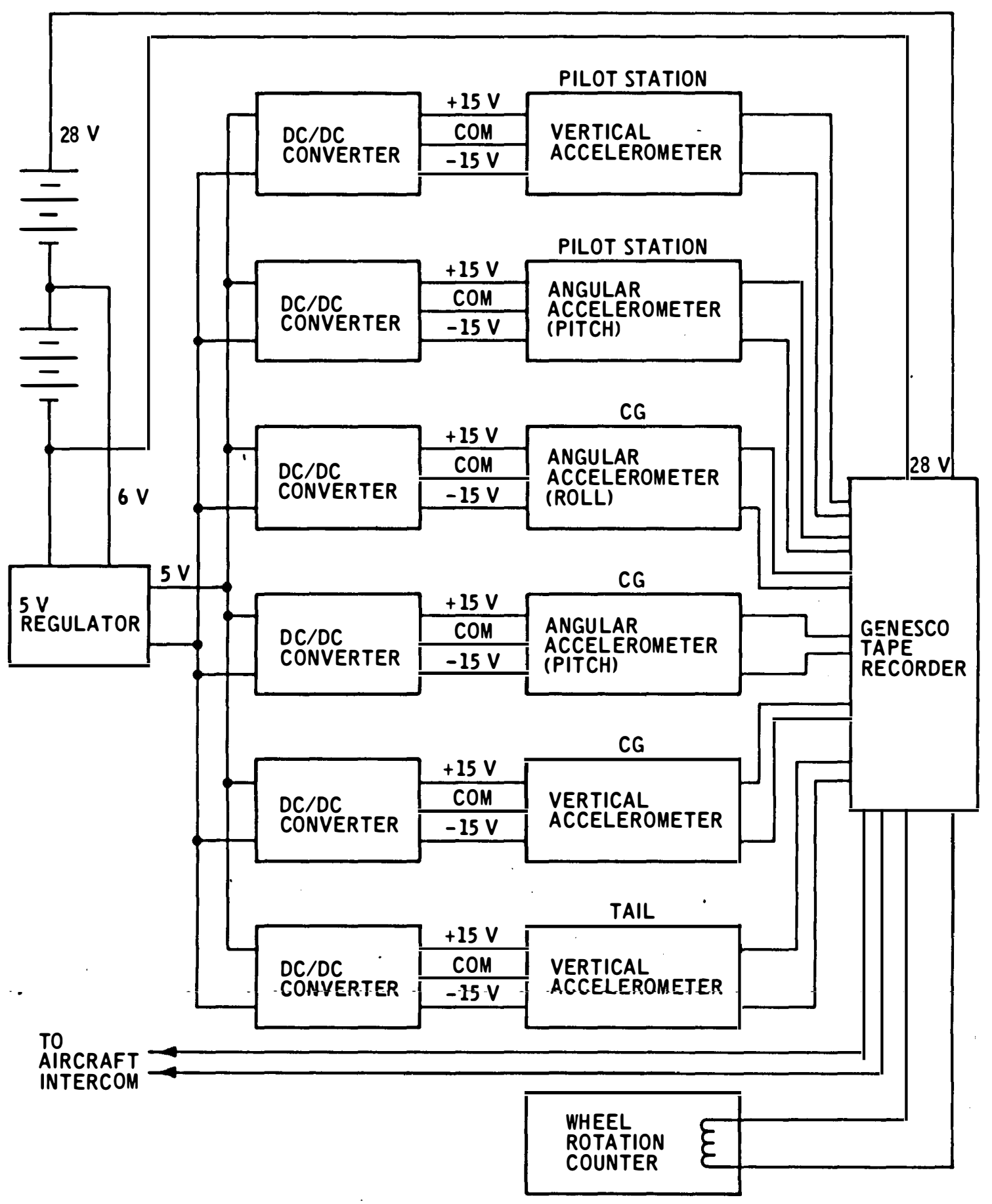

Figure 8. Schematic of instrumentation system installed on board $\mathrm{B}-52 \mathrm{H}$ aircraft 


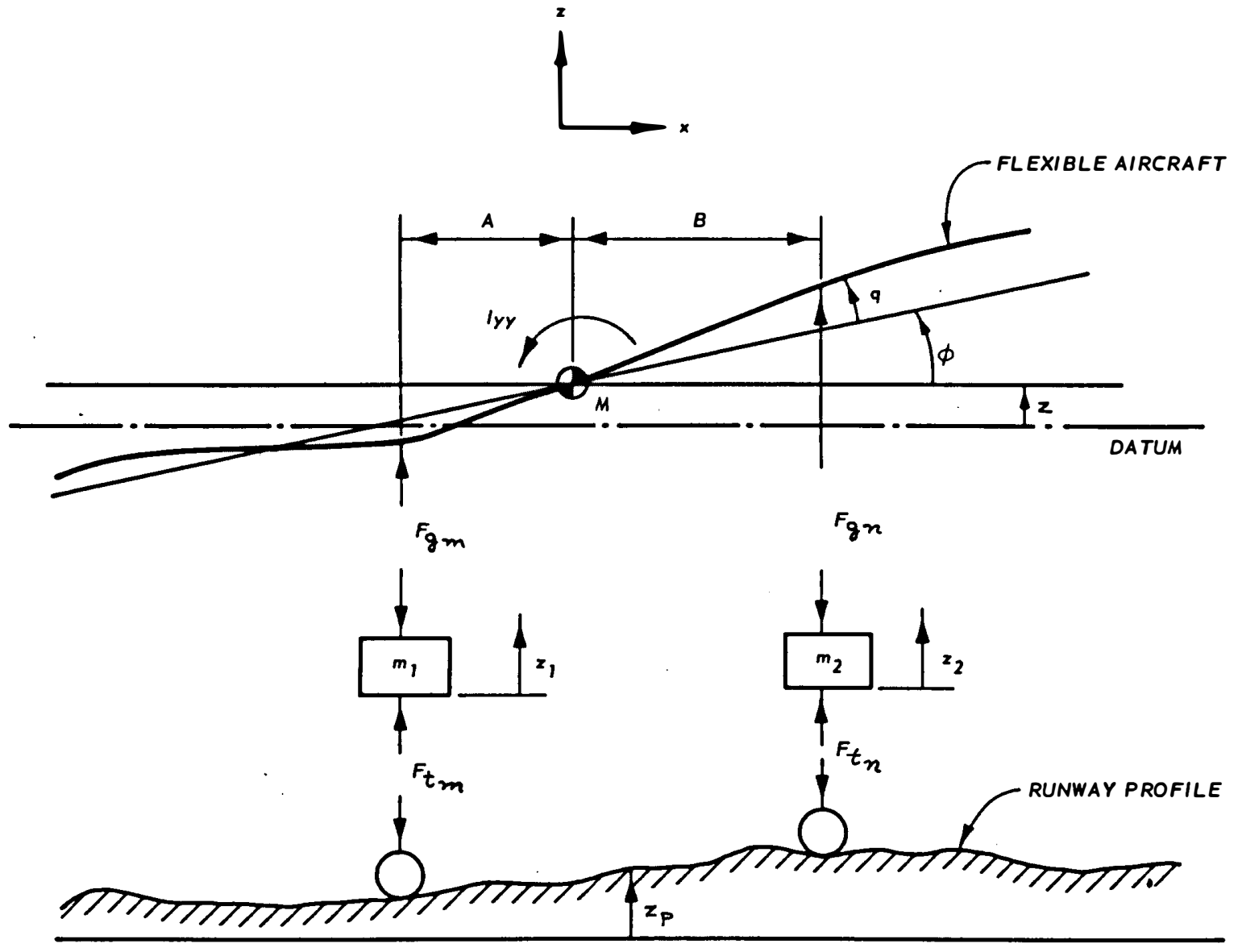

PROFILEDATUM

Figure 9. General aircraft mathematical modeI 


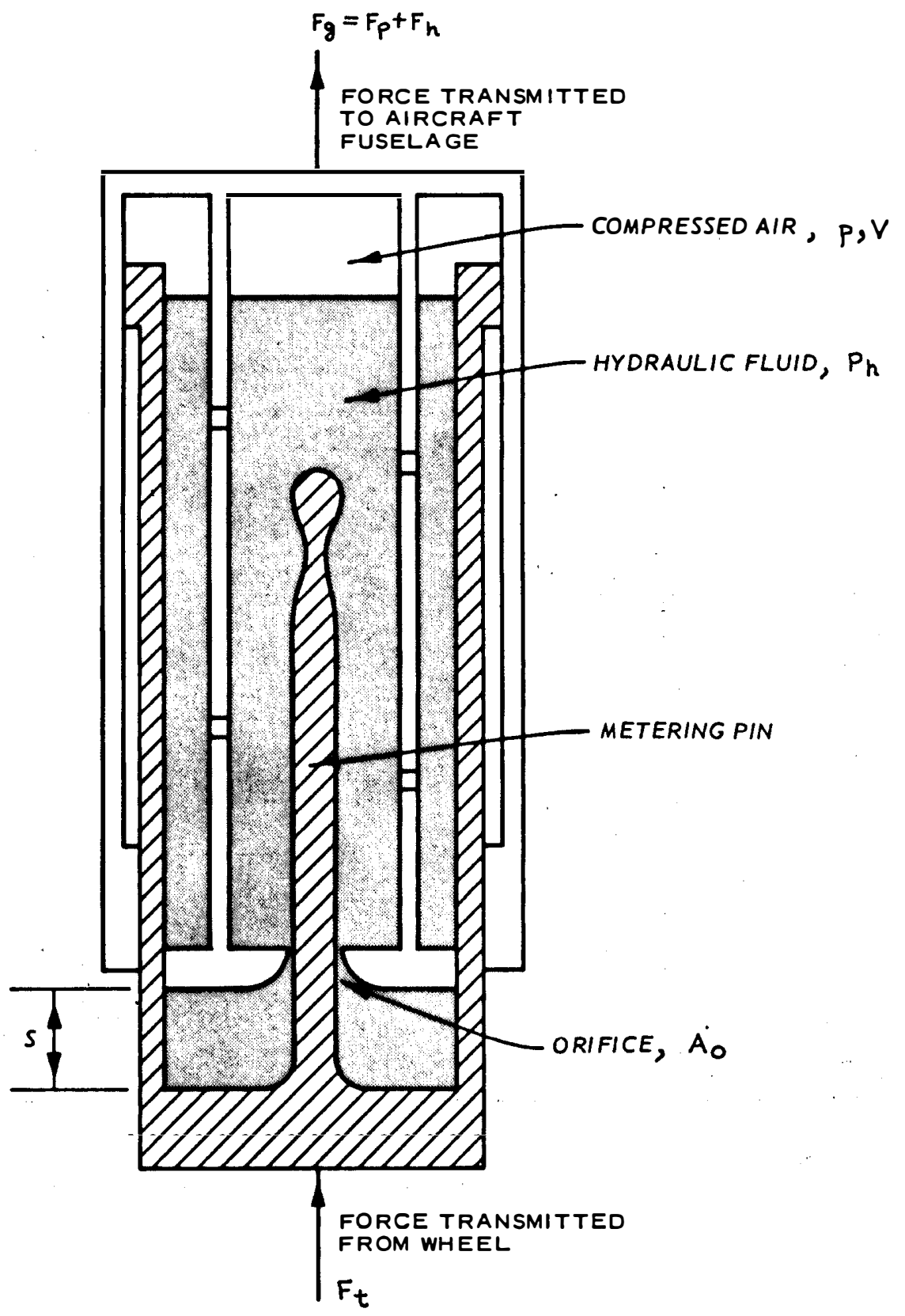

Figure 10. Schematic of shock absorber of B-52 landing gear 


\section{SIMULATED}

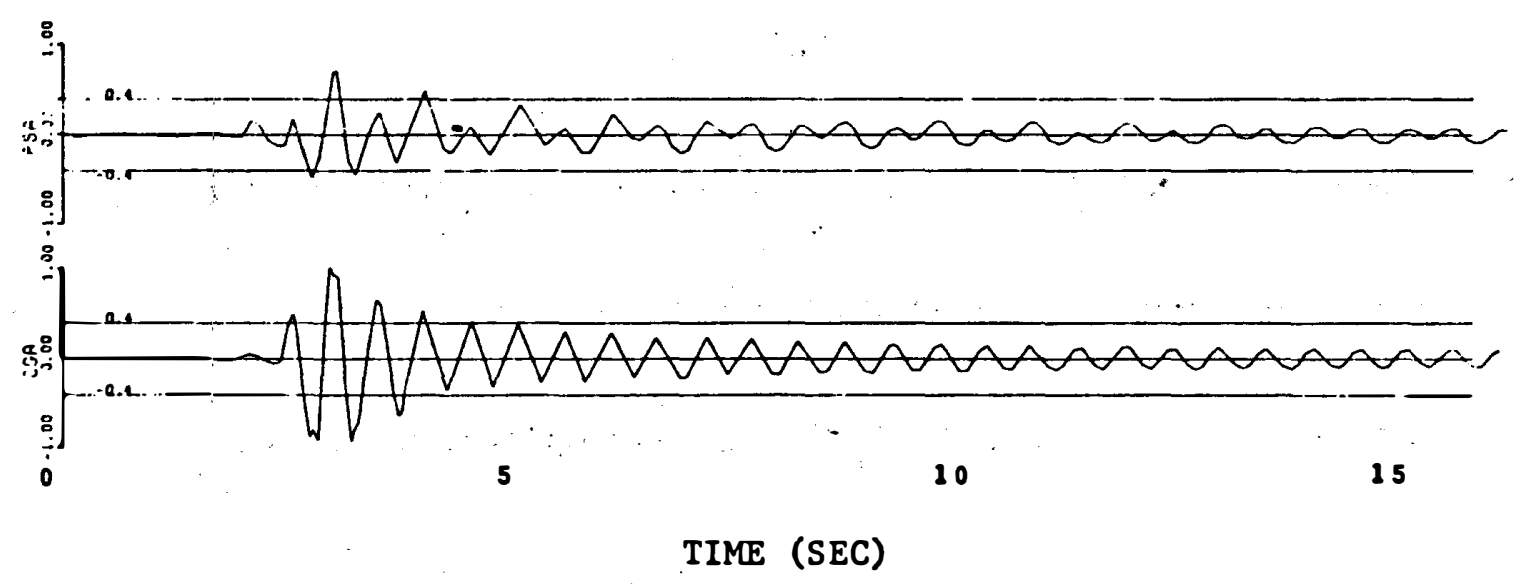

\section{EXPER I MENTAL}

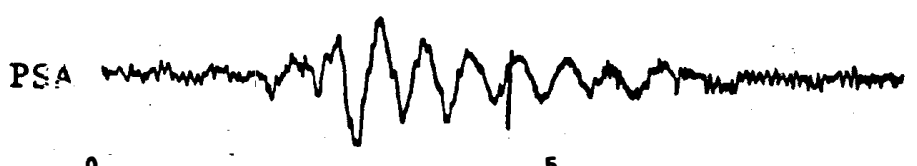

5

10

TIME (SEC)

CGA

Figure 11. Response of F-4C aircraft for a 29-knot taxi over a ramp 1.5 in. high and $15.5 \mathrm{ft}$ long (taken from Reference 2) 


\section{SIMULATED}

PILQT STATION ACCELERATION

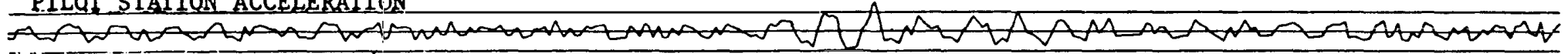

\section{G ACCELERÁTIOON}

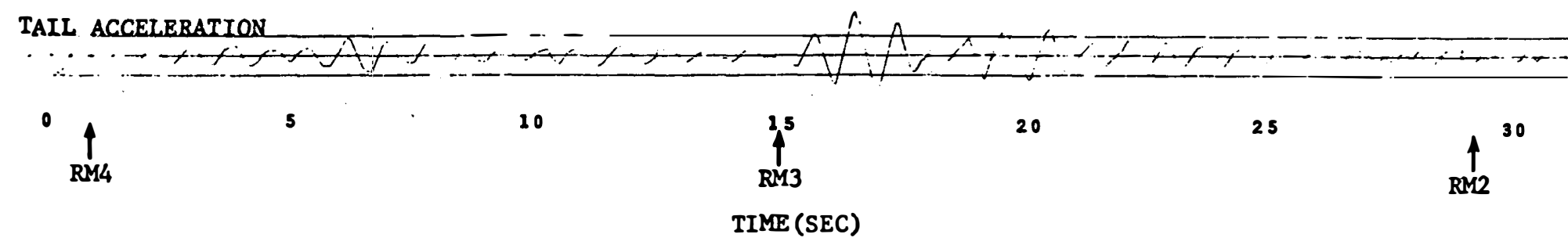

\section{EXPER I MENTAL}

PILOT STATION ACCELERATION

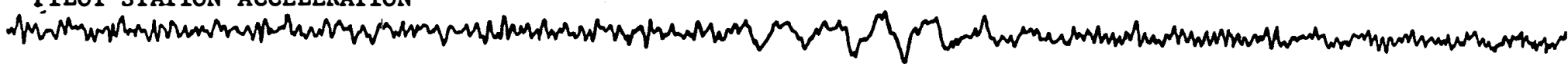

C G ACCELERATION

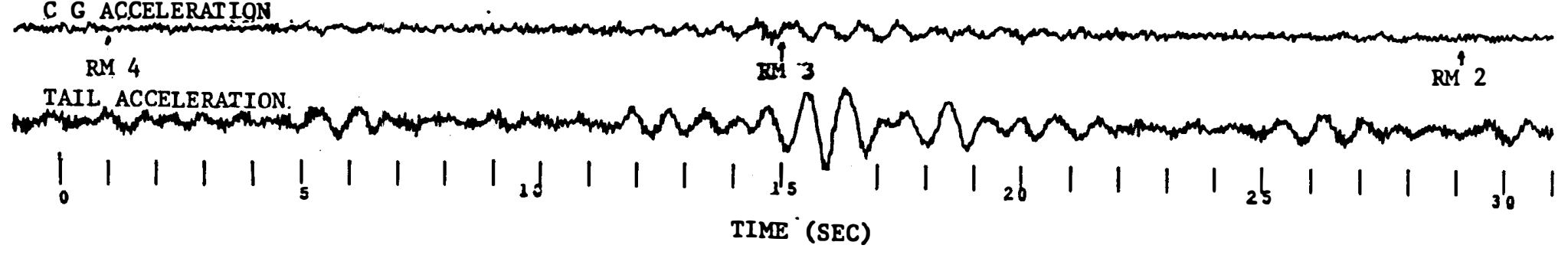

Figure 12. B-52 response for a 40-knot taxi on an actual runway (taken from Reference 2) 


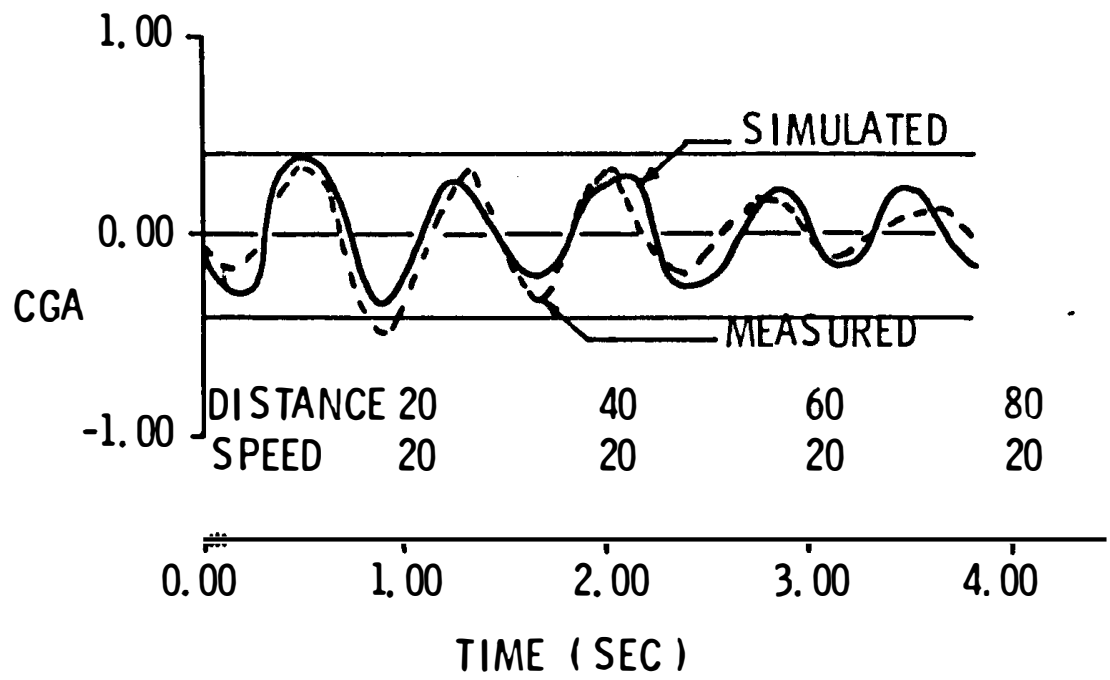

Figure 13. C-14l traversing a $1-\cos$ bump at 20 fps (taken from Reference 2)

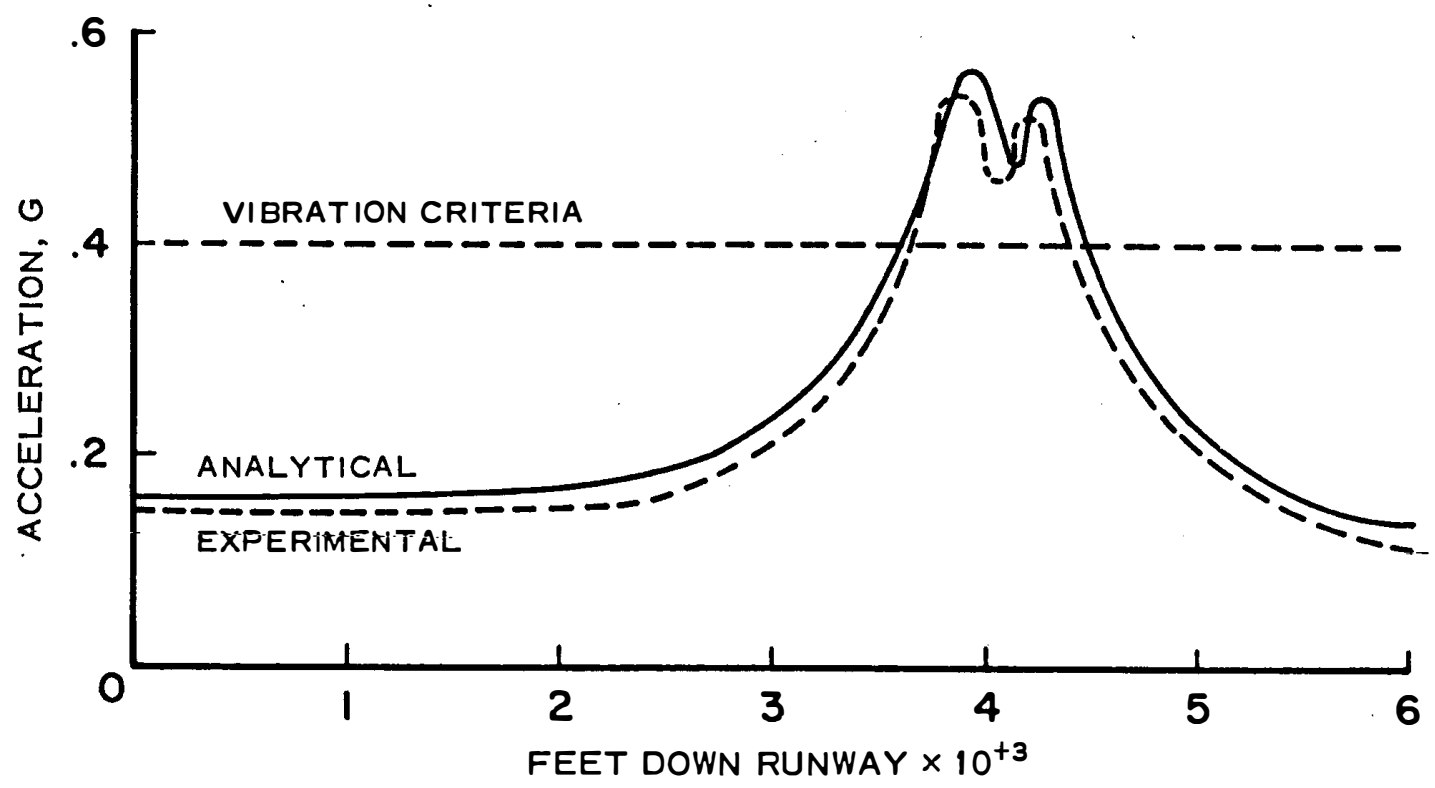

Figure 14. Mean value of acceleration for a takeoff of a $\mathrm{KC}-135$ on an actual runway (taken from Reference 2) 


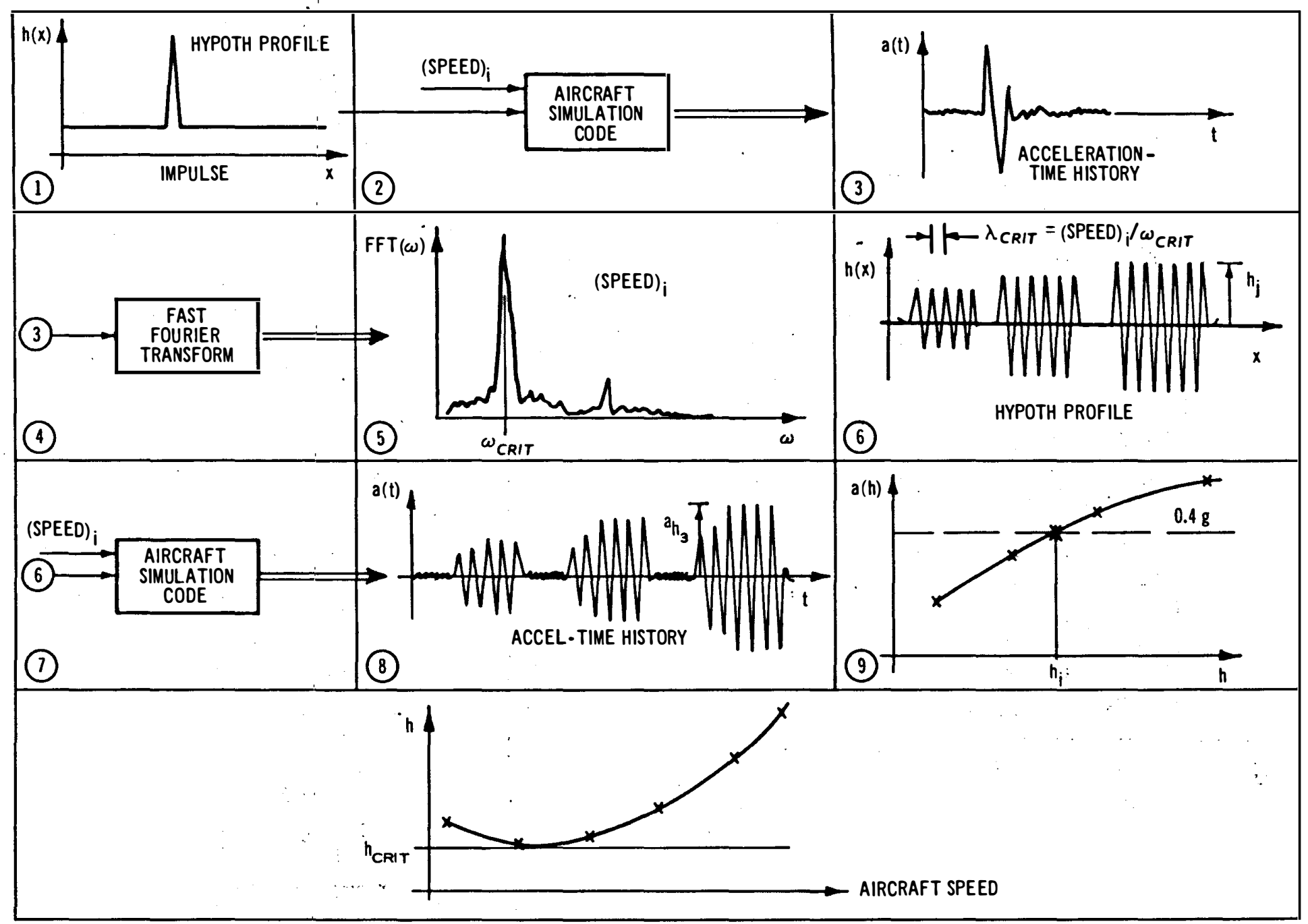

Figure 15. Outline of procedure employed during multi-encounter analysis 


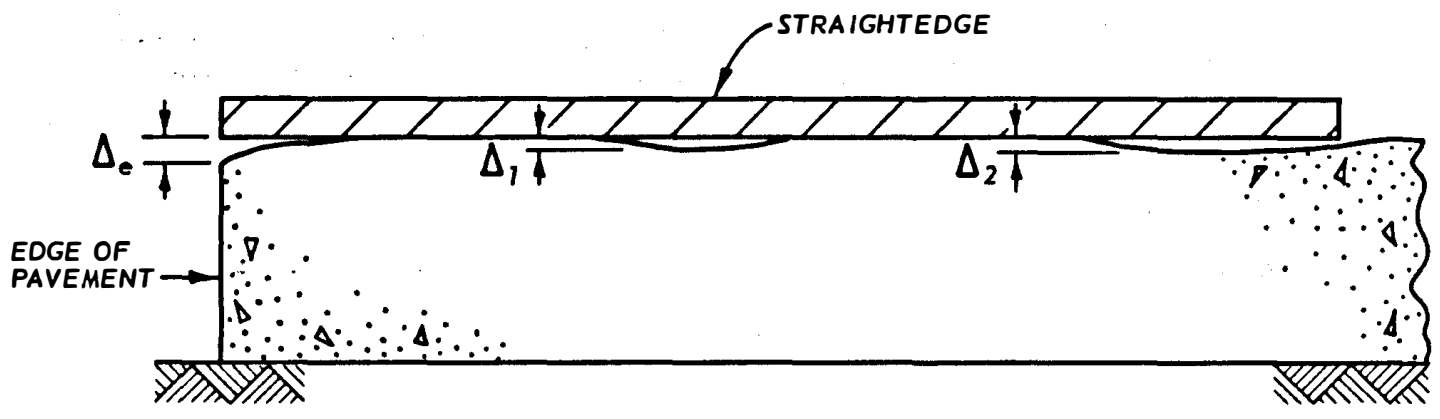

Figure 16. Placement of straightedge and measurement of deviation DISTANCE FROM EDGE, FT
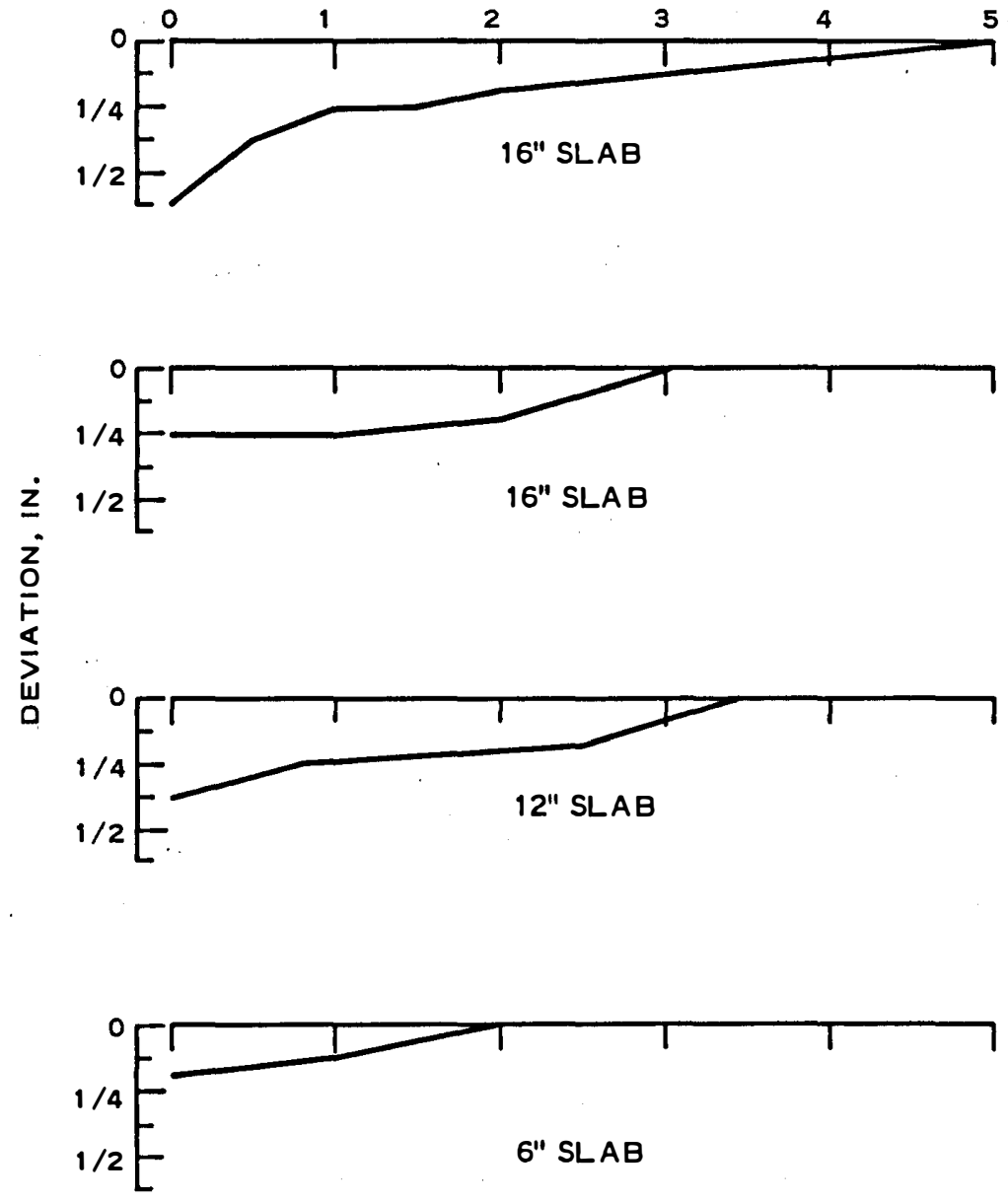

Figure 17. Typical measured shapes of free edges 


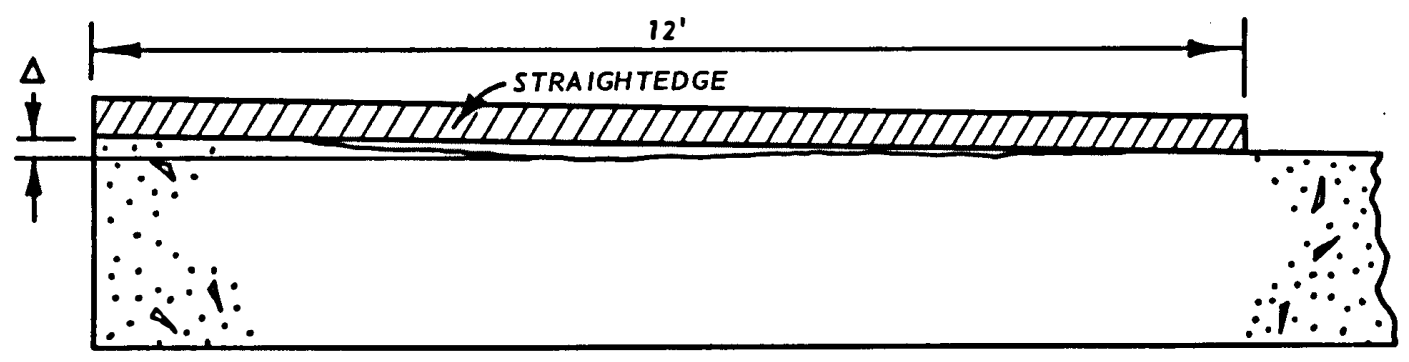

TYPICAL SHAPE OF EDGE

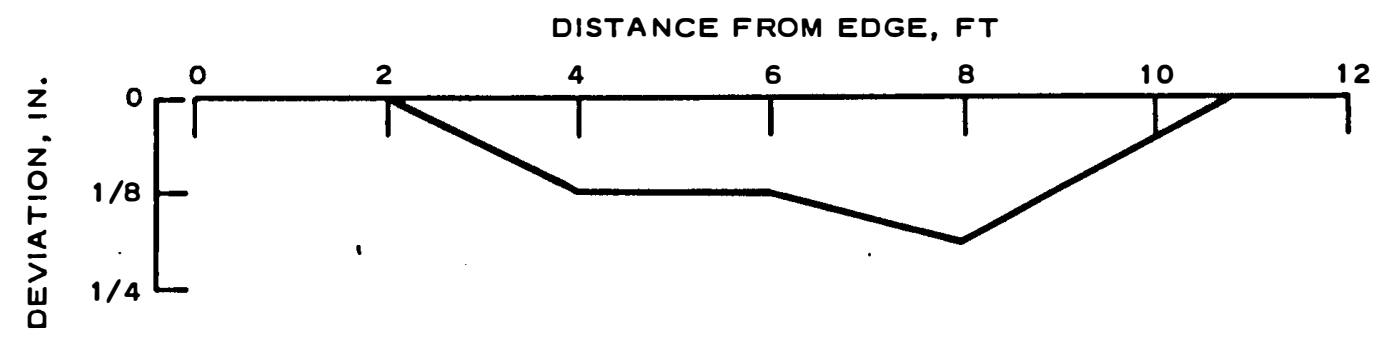

MEASURED SHAPE ALONG EDGE

Figure 18. Edge showing influence of overcompensating for edge slump

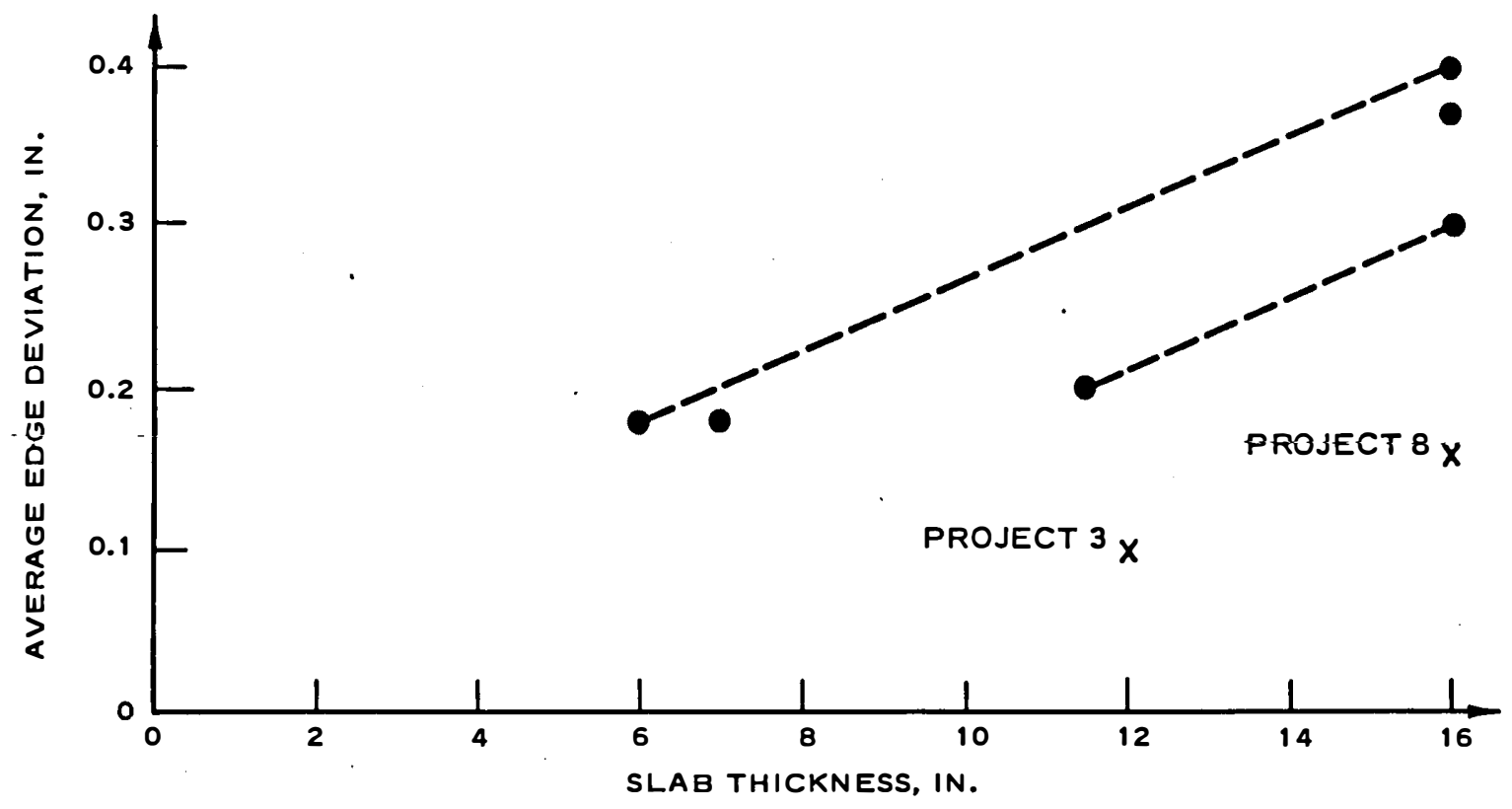

Figure 19. Relation between edge slump and slab thickness 


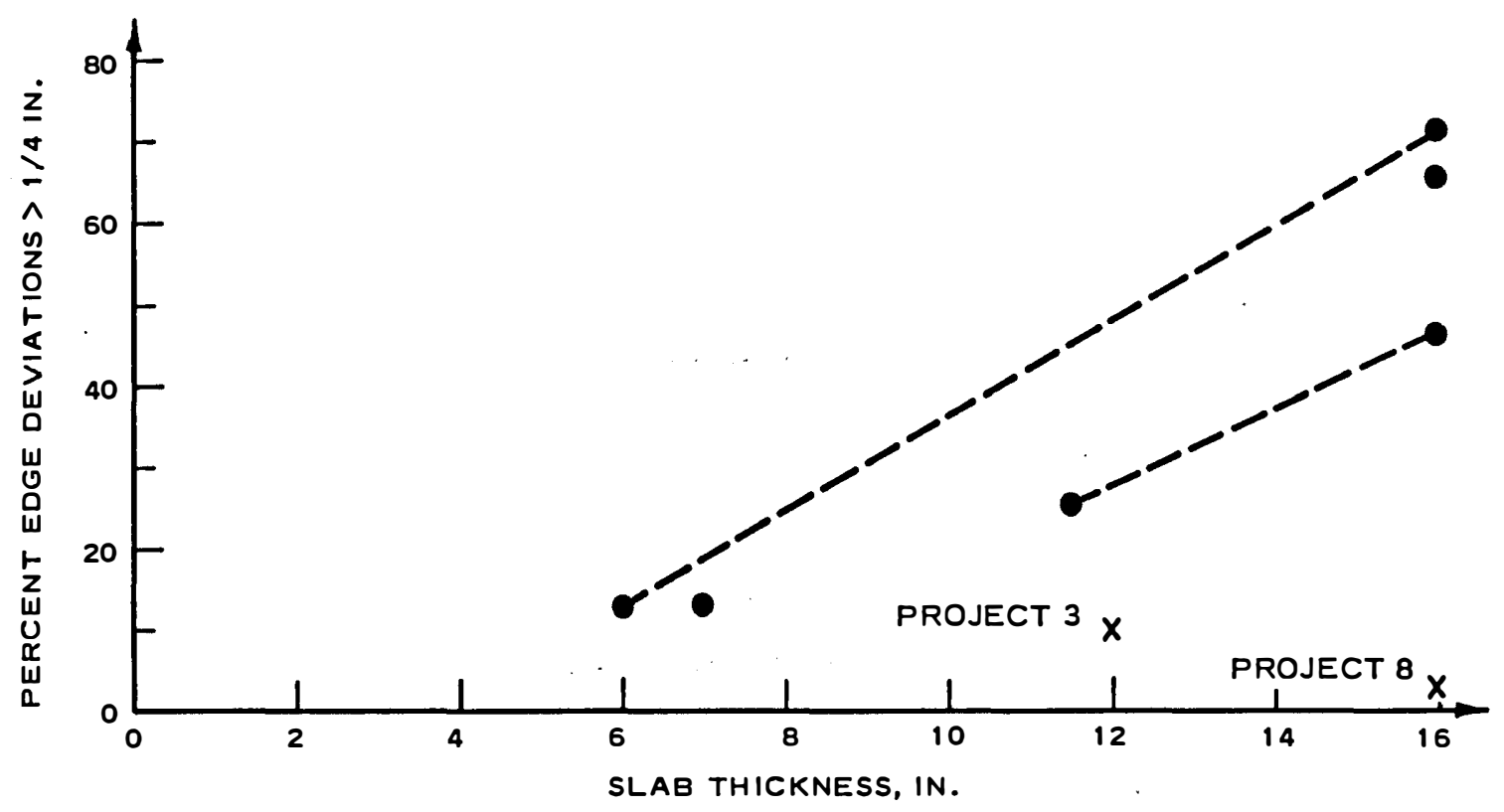

Figure 20. Relation between percentage of edge deviations exceeding 1/4 in. and slab thickness

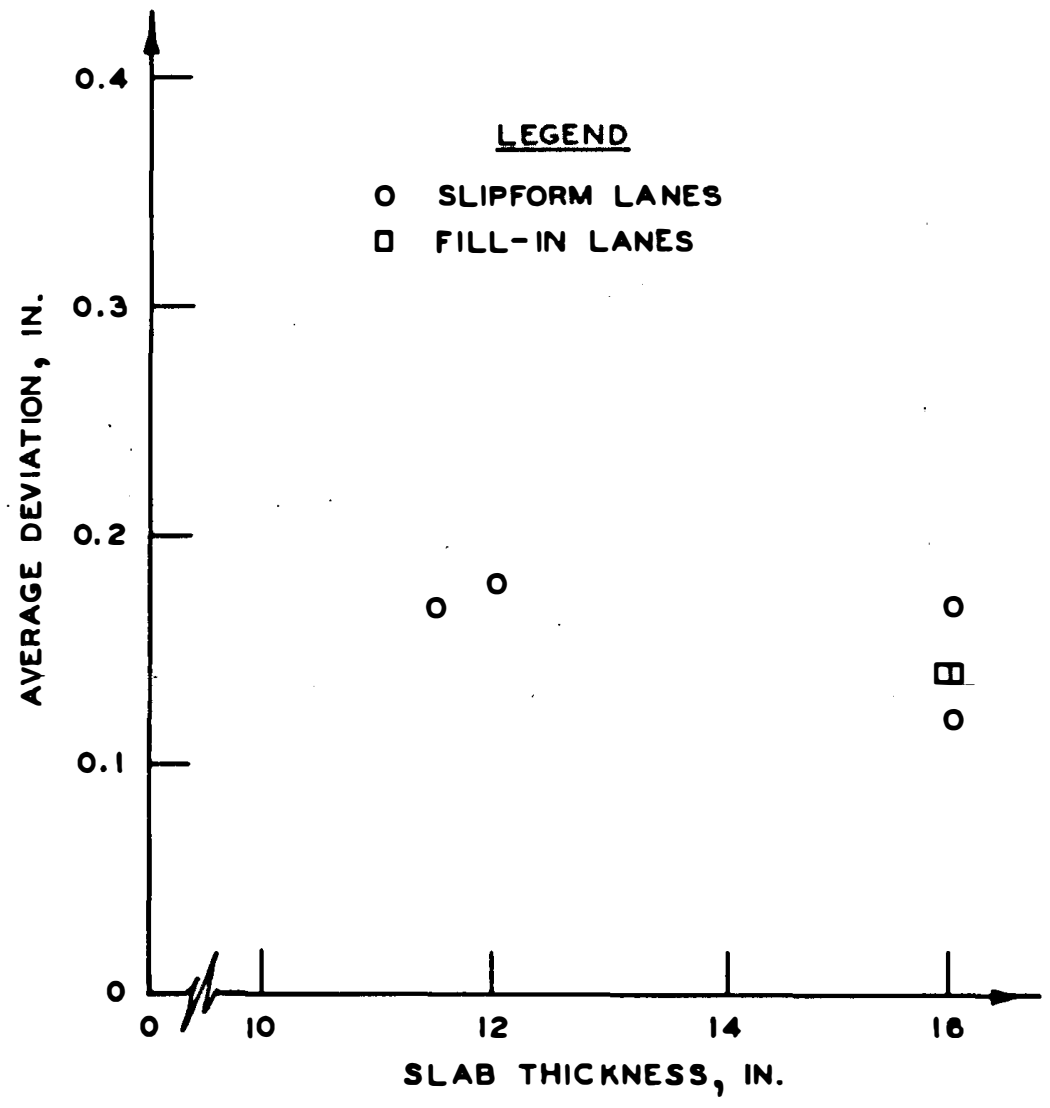

Figure 21. Average deviation in transverse measurements versus slab thickness 


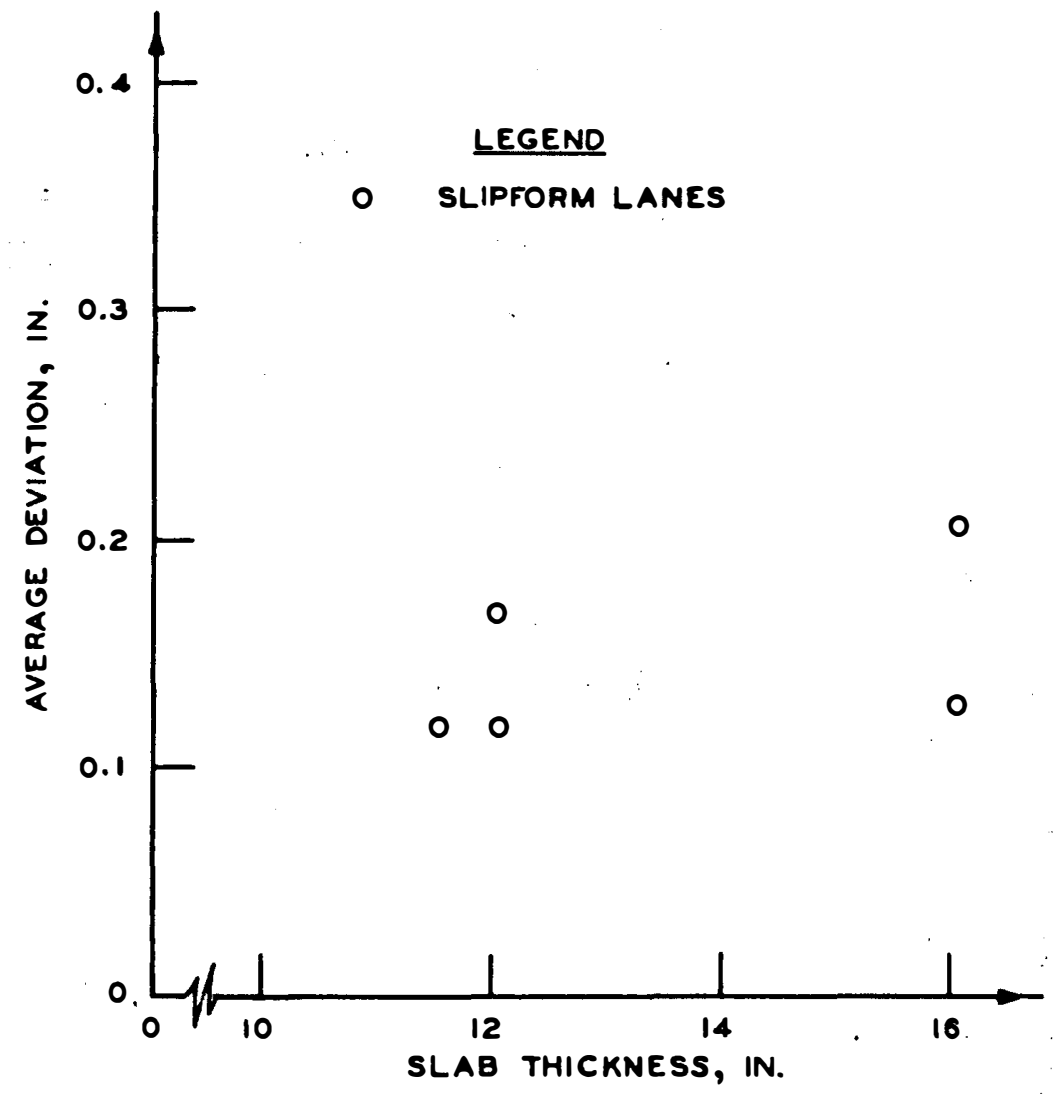

Figure 22. Average deviation in longitudinal measurements versus slab thickness 


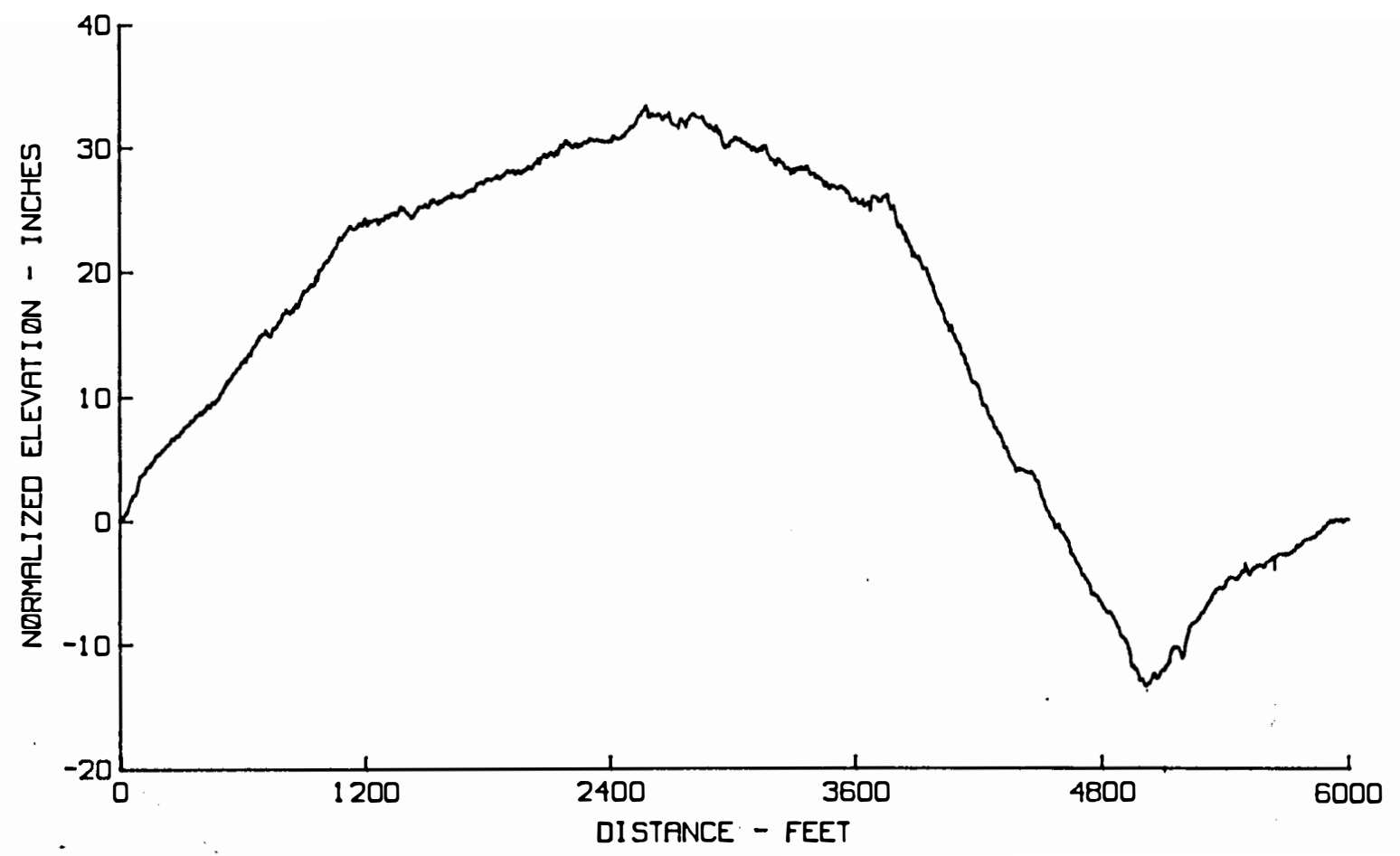

Figure 23. Computer plot of center-line profile of runway 04-22 at NAFEC

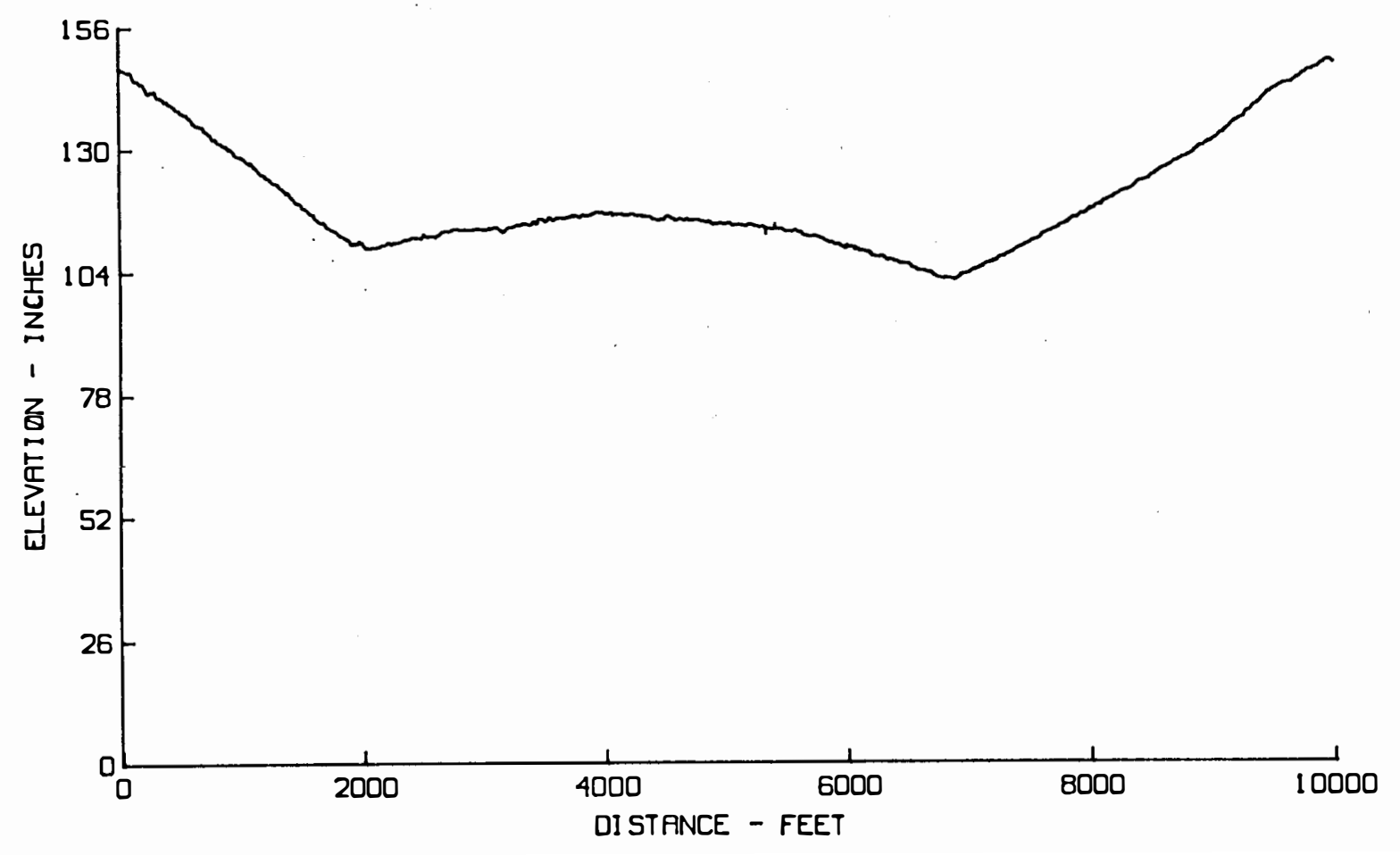

Figure 24. Computer plot of profile of runway 13-31 at NAFEC (along a line $9.5 \mathrm{ft}$ left of runway center line) 


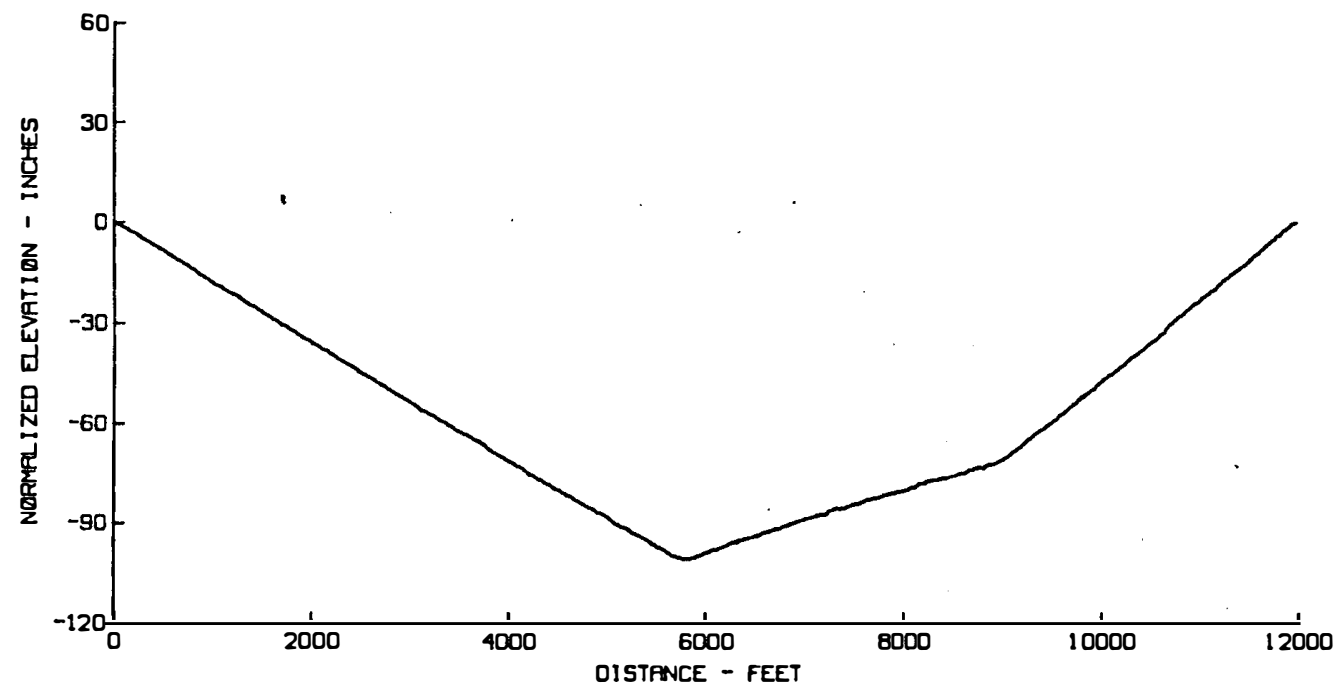

Figure 25. Computer plot of center-line profile of runway 07-25 at Air Force Plant 42 Palmdale 


\section{GRANDFORKS RUNWAY CENTERLINE}

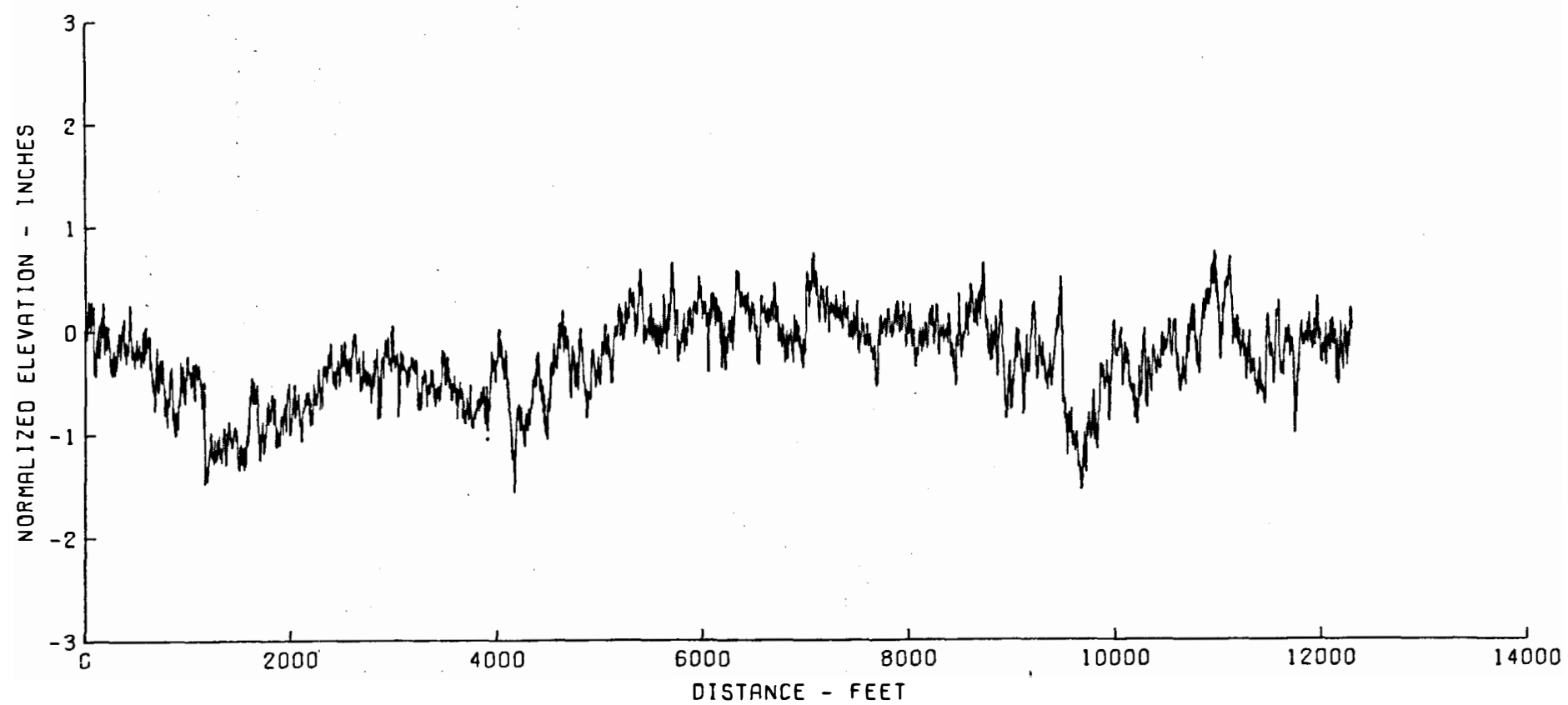

Figure 26. Computer plot of center-line profile of runway 17-35 at Grand Forks AFB 


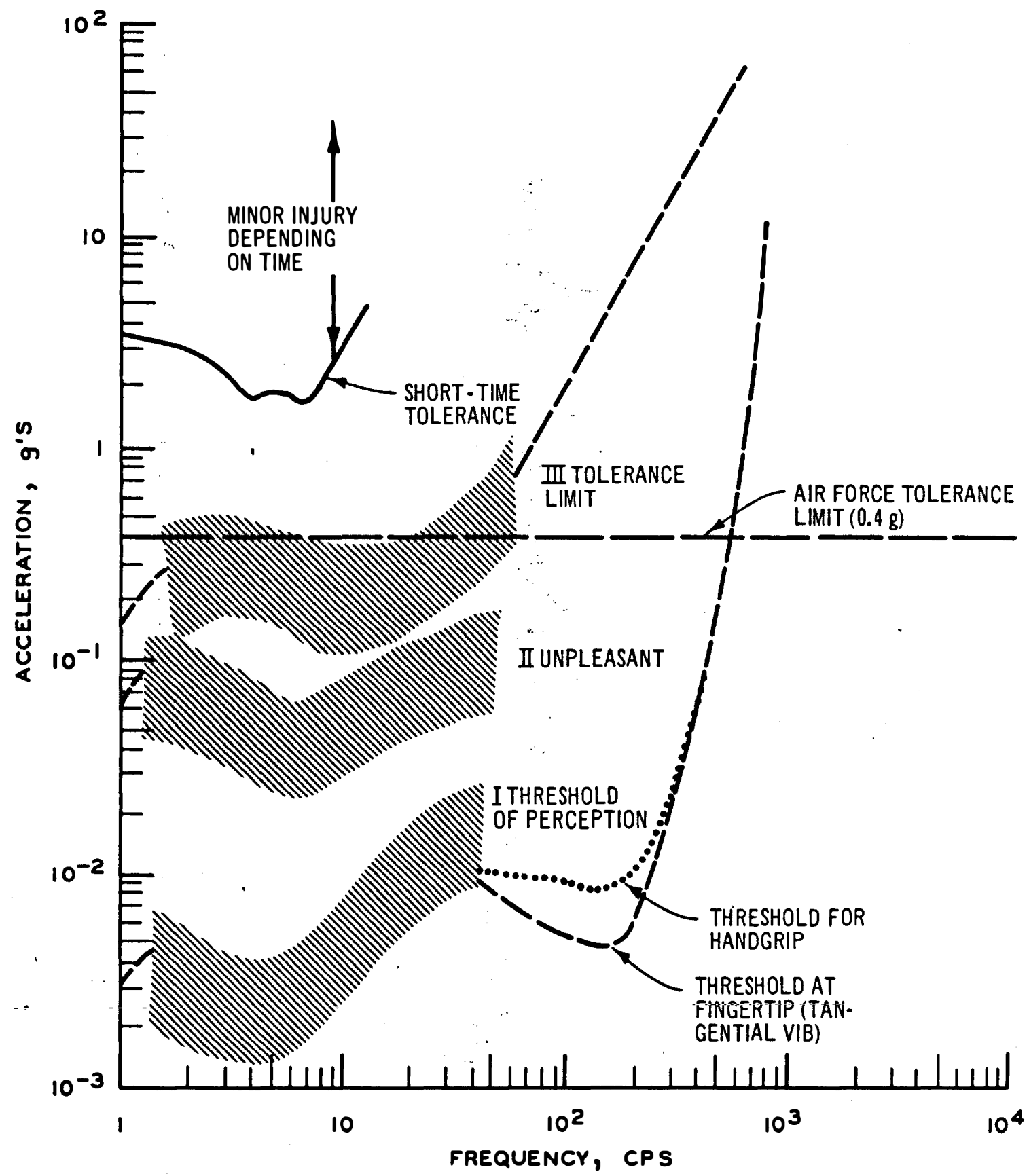

Figure 27. Human tolerance critéria for exposure to vertical vibration (from Reference 5) 


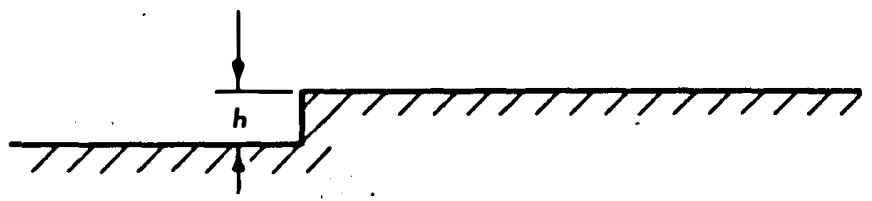

a. SINGLE - ENCOUNTER STEP

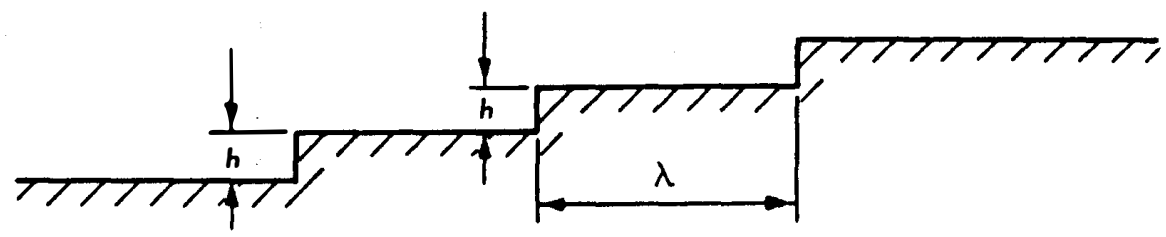

b. MULTI-STEP

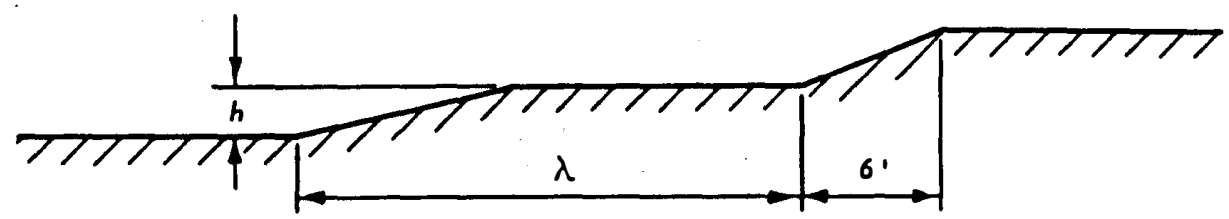

c. MULTI-RAMP 1

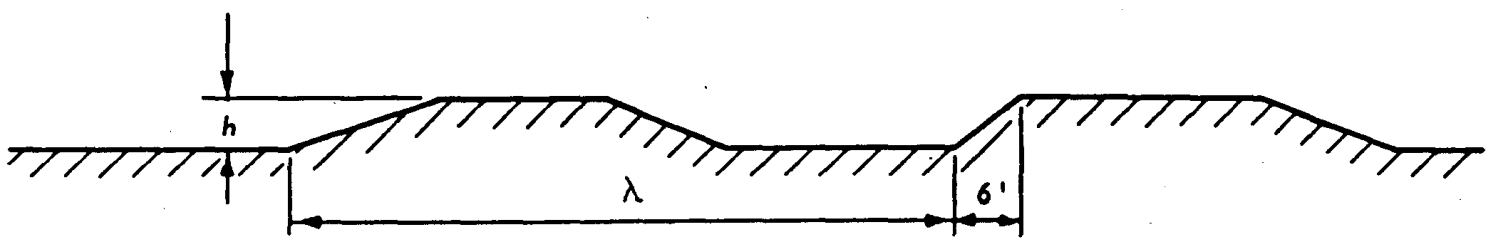

d. MULTI-RAMP 2

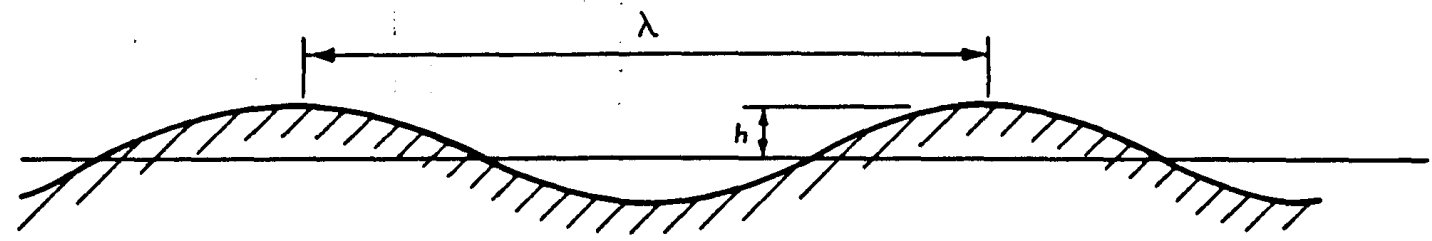

e. SINUSOIDAL

Figure 28. Forms of hypothetical profiles investigated during analytical study 

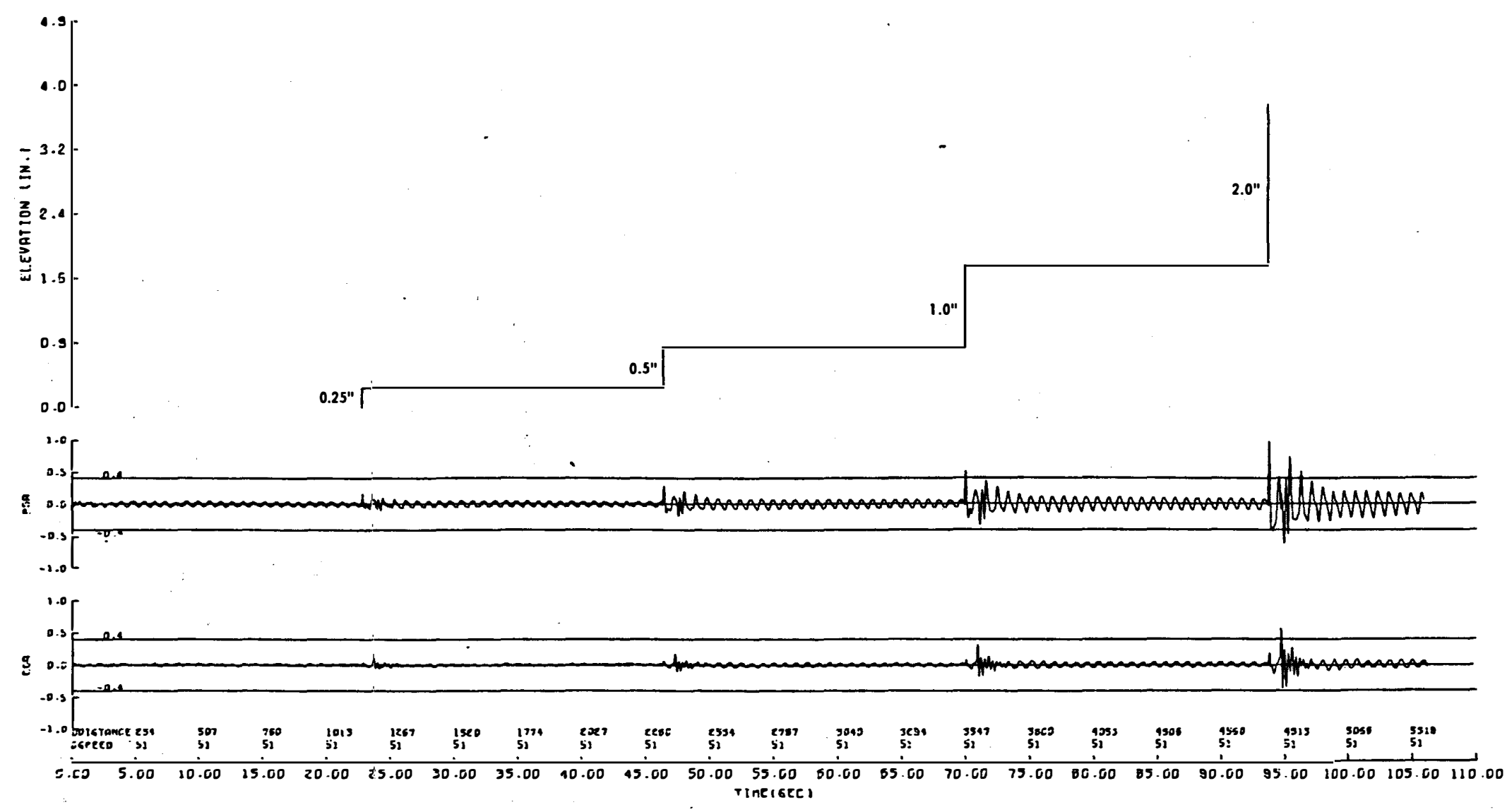

Figure 29. Aircraft acceleration response-time history; $B-52 \mathrm{H}$ taxilng at 30 knots 

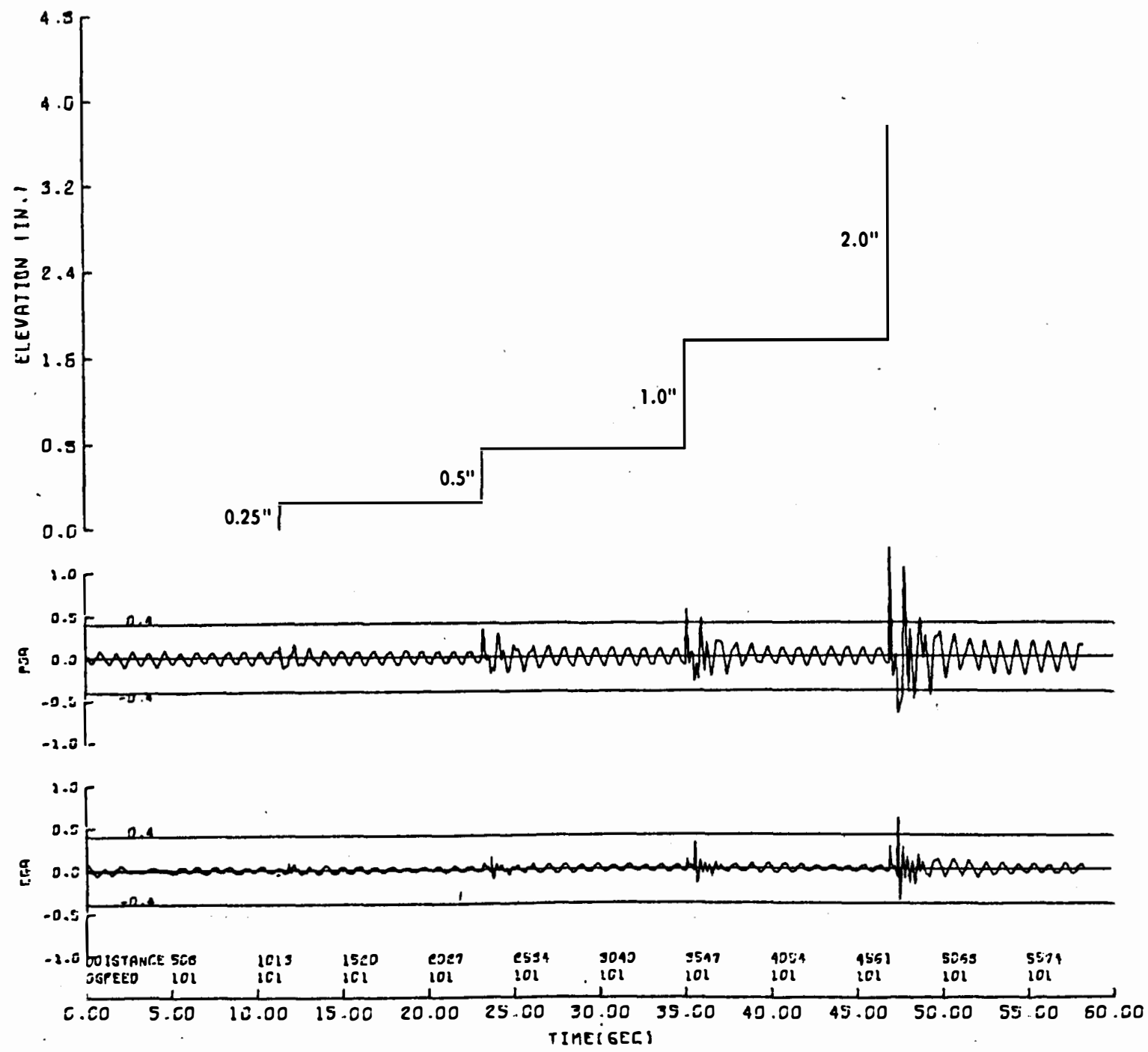

Figure 30. Aircraft acceleration response-time history; B-52H taxiing at 60 knots 

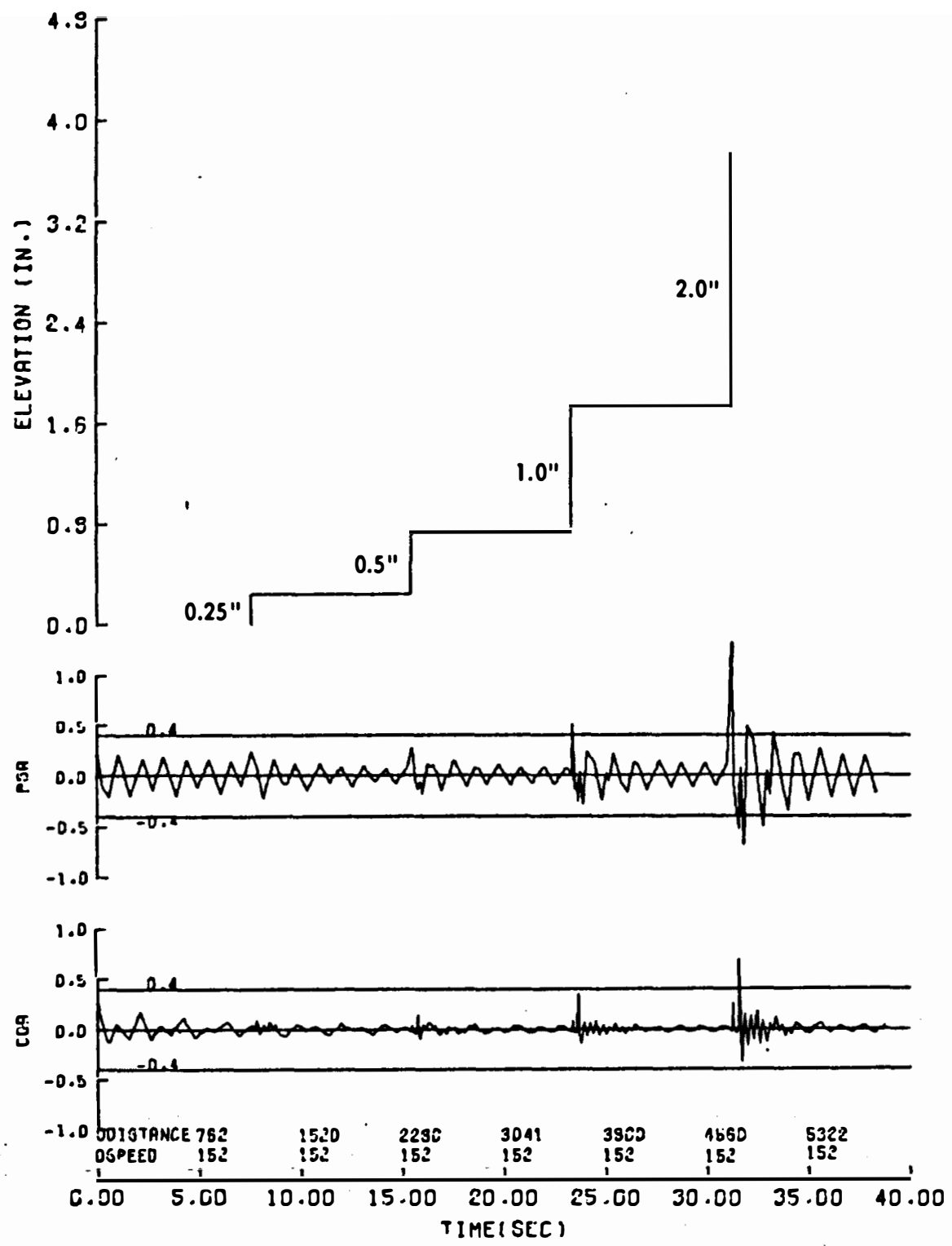

Figure 31. Aircraft acceleration response-time history; $\mathrm{B}-52 \mathrm{H}$ taxiing at 90 knots; step functions of $0.25,0.5,1.0$, and 2.0 in. 


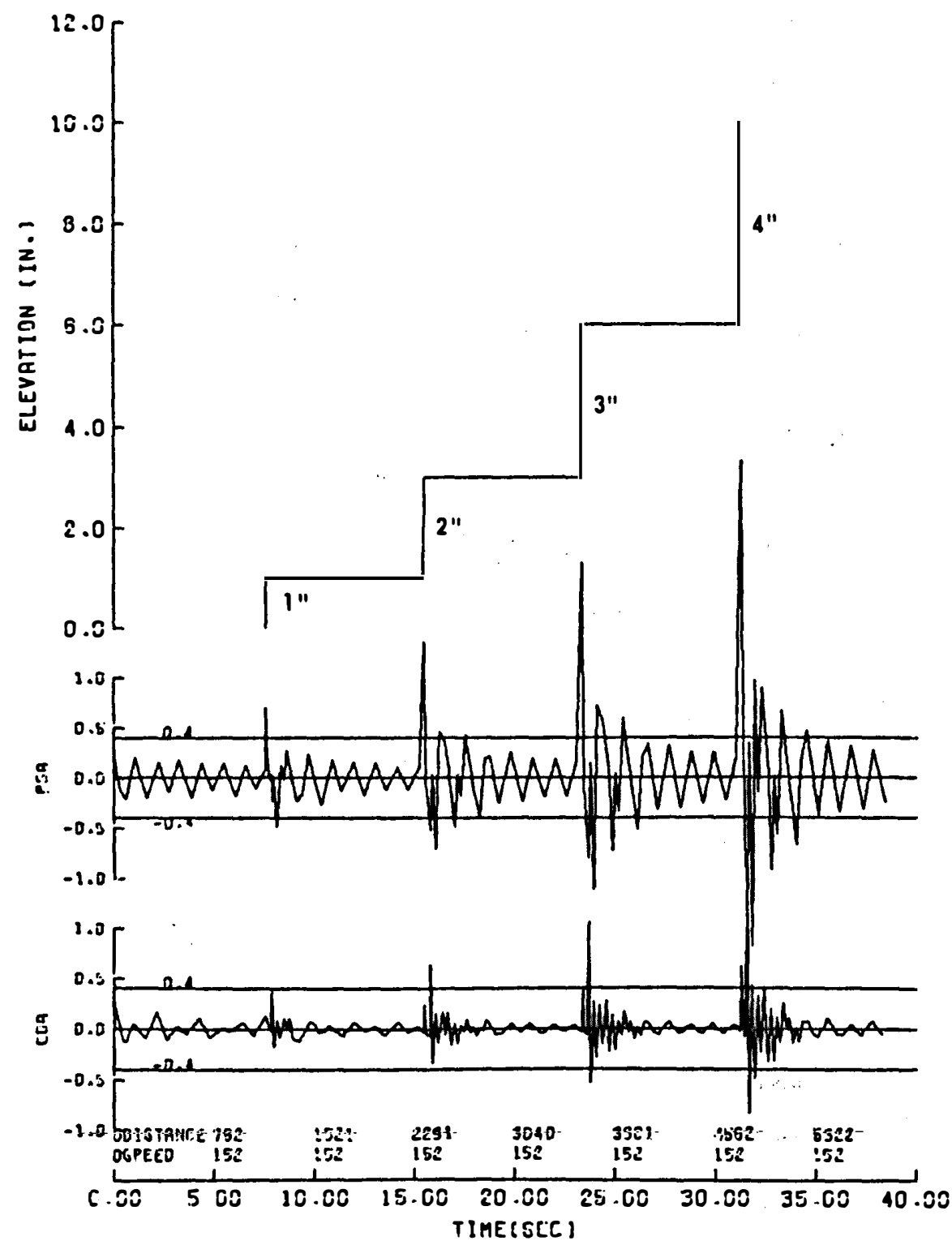

Figure 32. Aircraft acceleration response-time history; $\mathrm{B}-52 \mathrm{H}$ taxiing at 90 knots; step functions of $1,2,3$, and 4 in. 

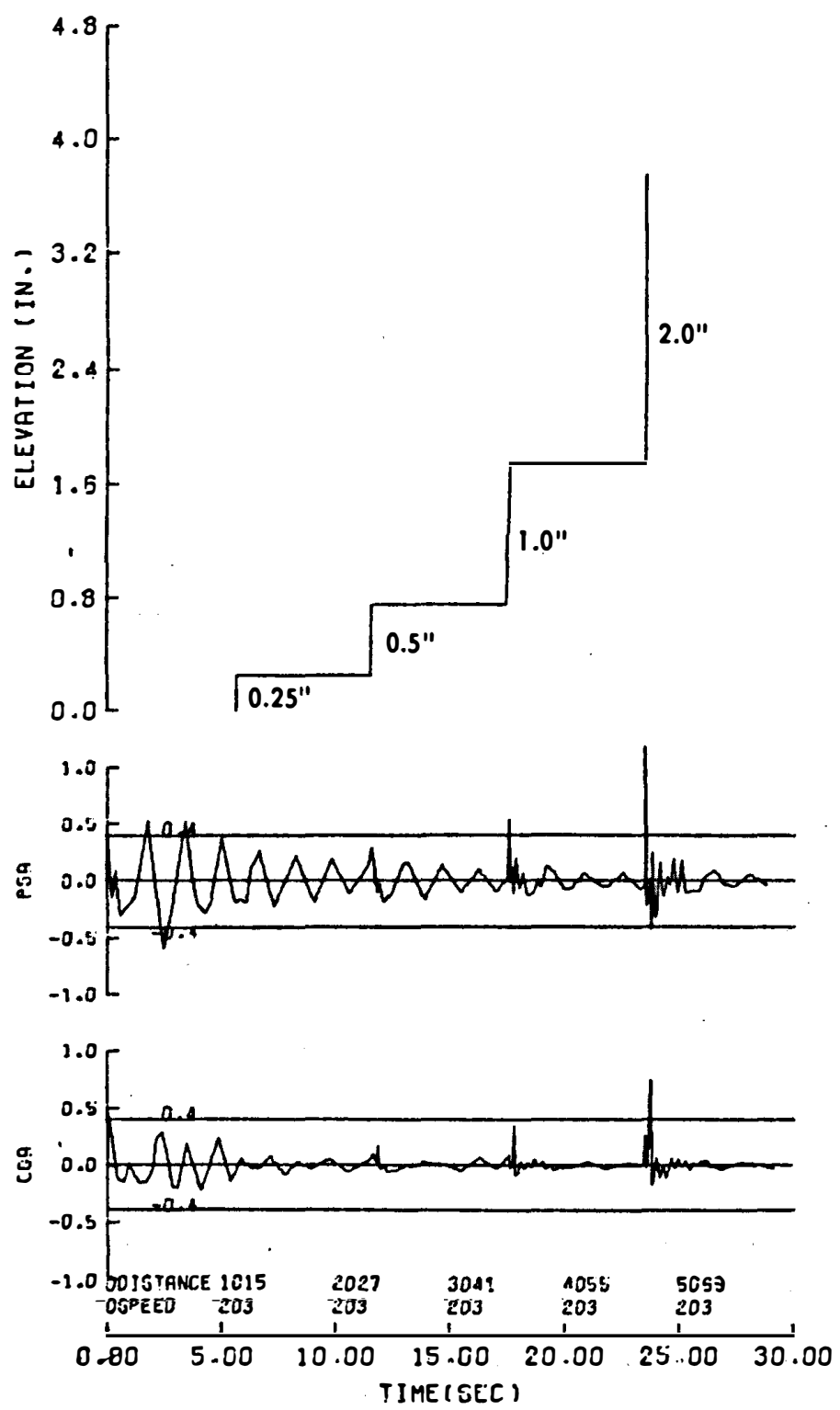

Figure 33. Aircraft acceleration responsetime history; $\mathrm{B}-52 \mathrm{H}$ taxilng at 120 knots 


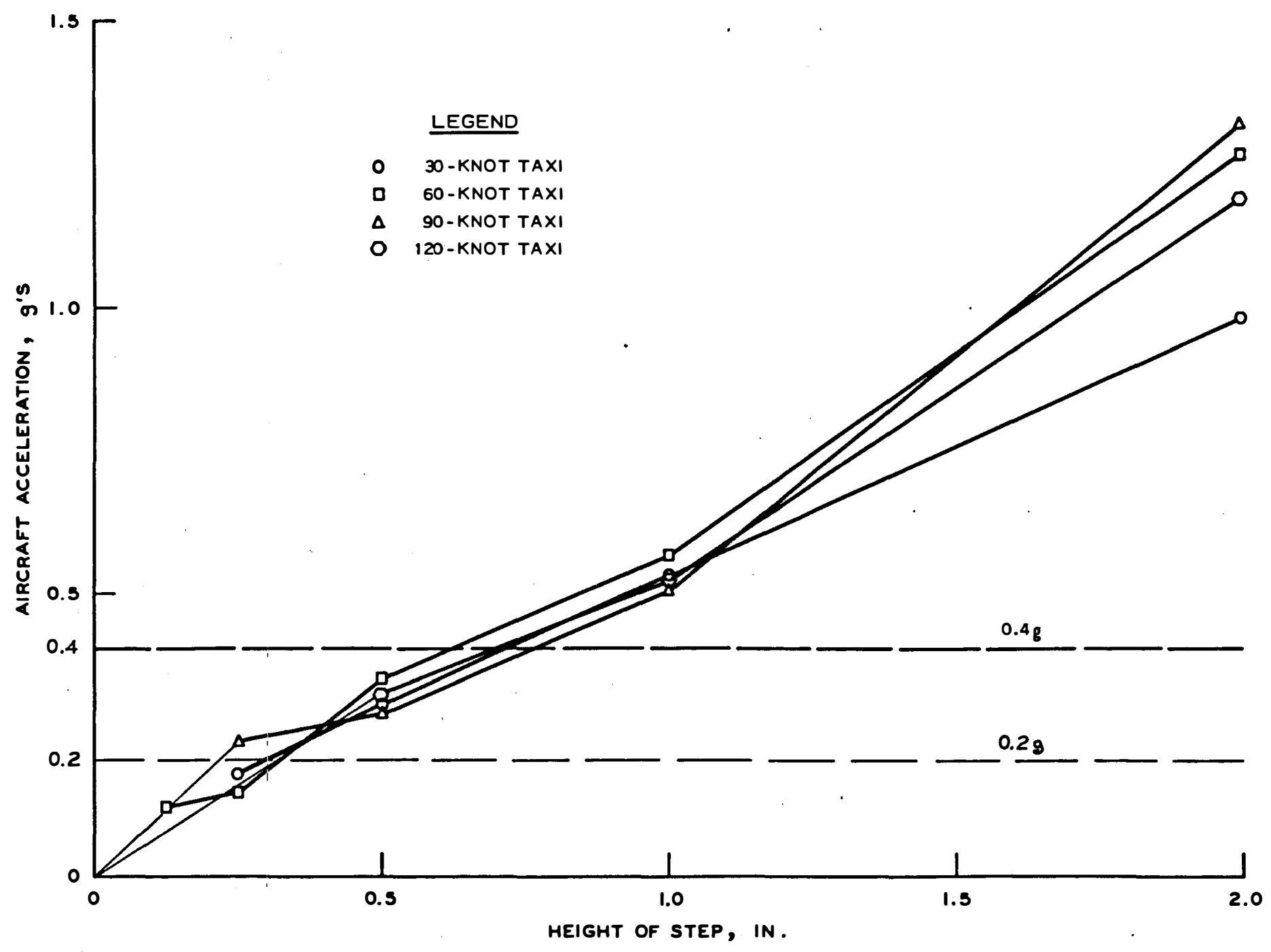

Figure 34. Maximum B-52H aircraft response at pilot station as function of amplitude of pavement roughness 


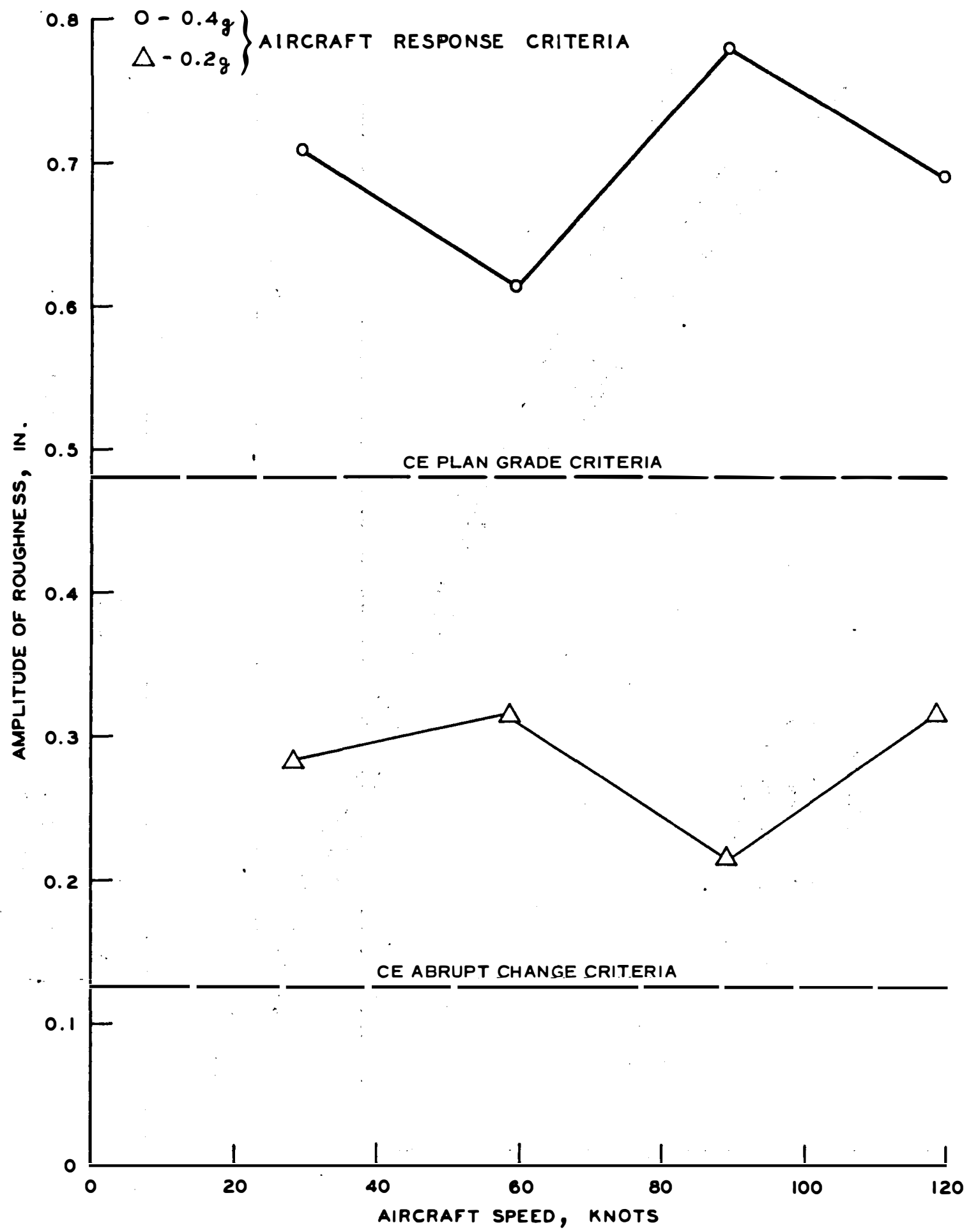

Figure 35. Summary of single-encounter step function analysis 


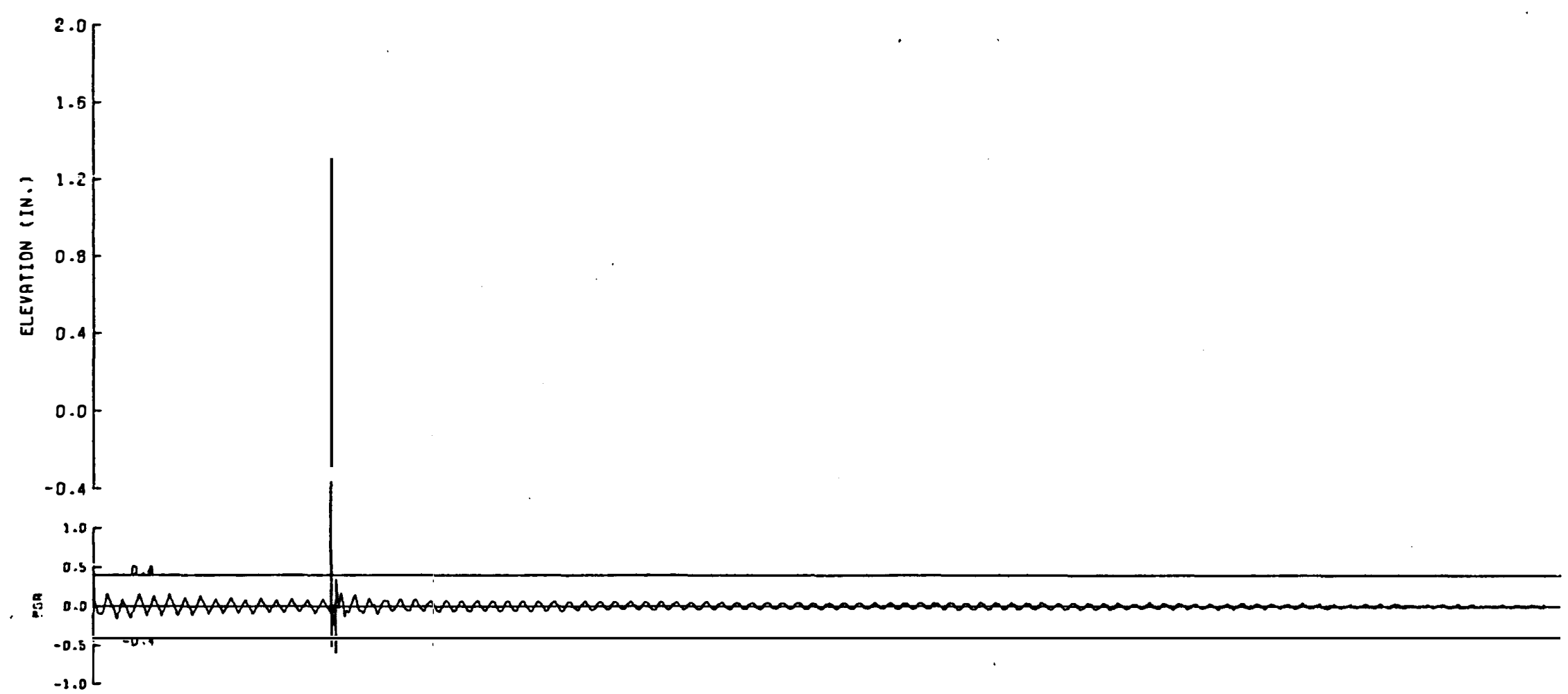

$-1.0$

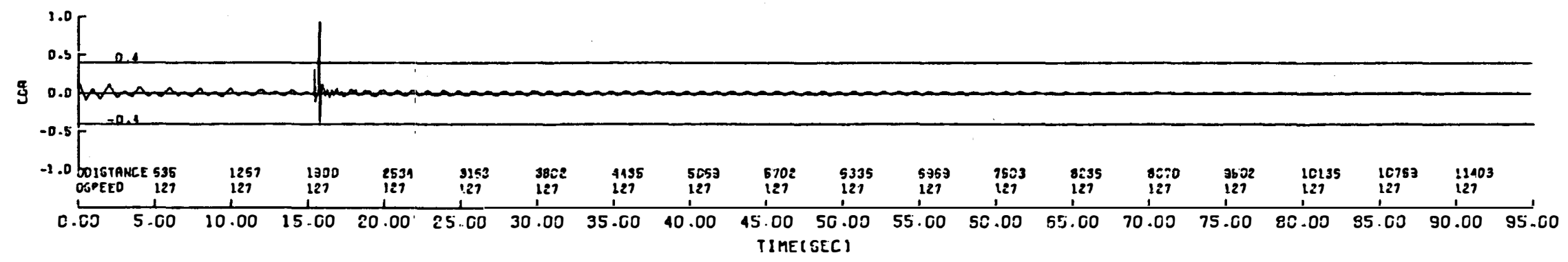

Figure 36. B-52H aircraft response to impulse profile; aircraft taxiling at 75 knots 


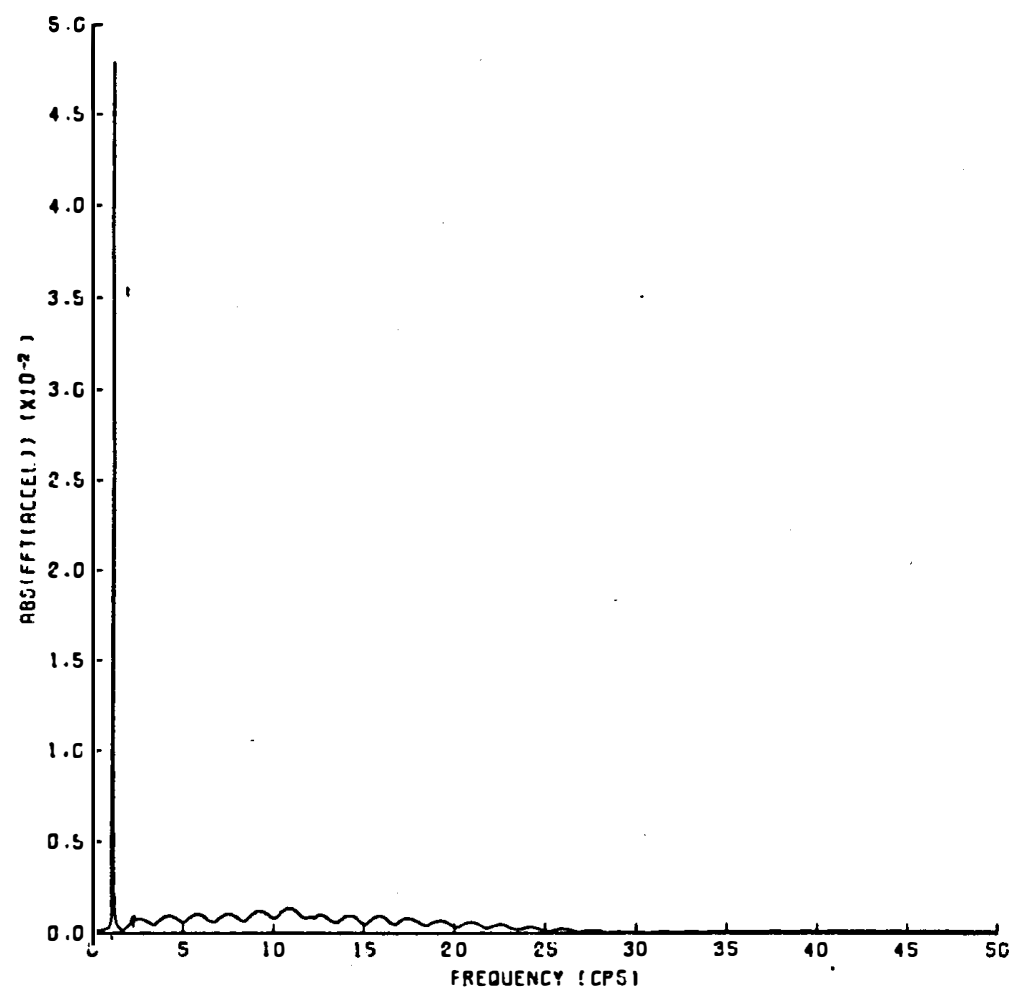

Figure 37. Fast Fourier transform of B-52H aircraft response to impulse function profile; aircraft taxiing at 75 knots 


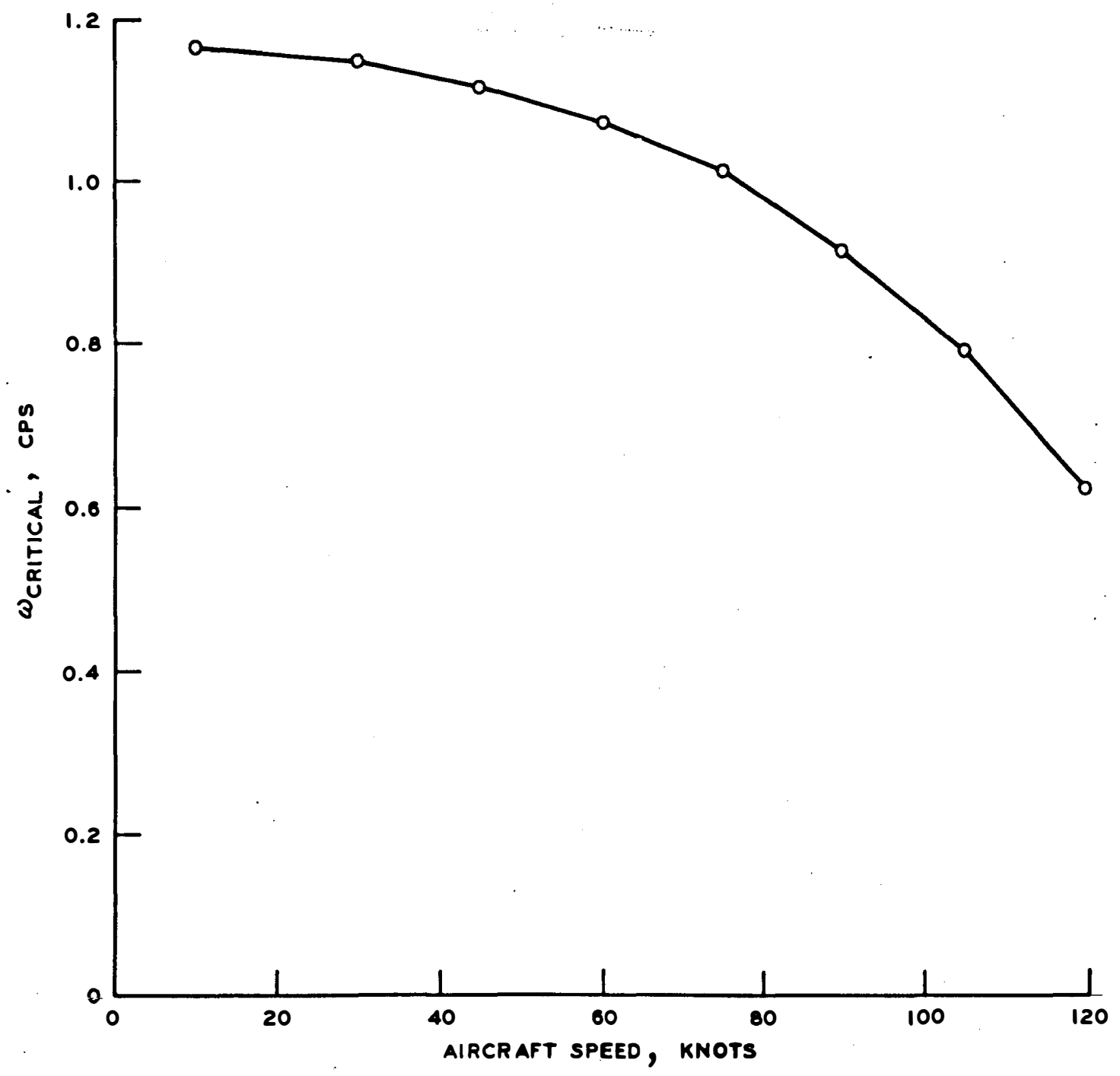

Figure 38. Critical frequency of $\mathrm{B}-52 \mathrm{H}$ response as a function of aircraft speed 


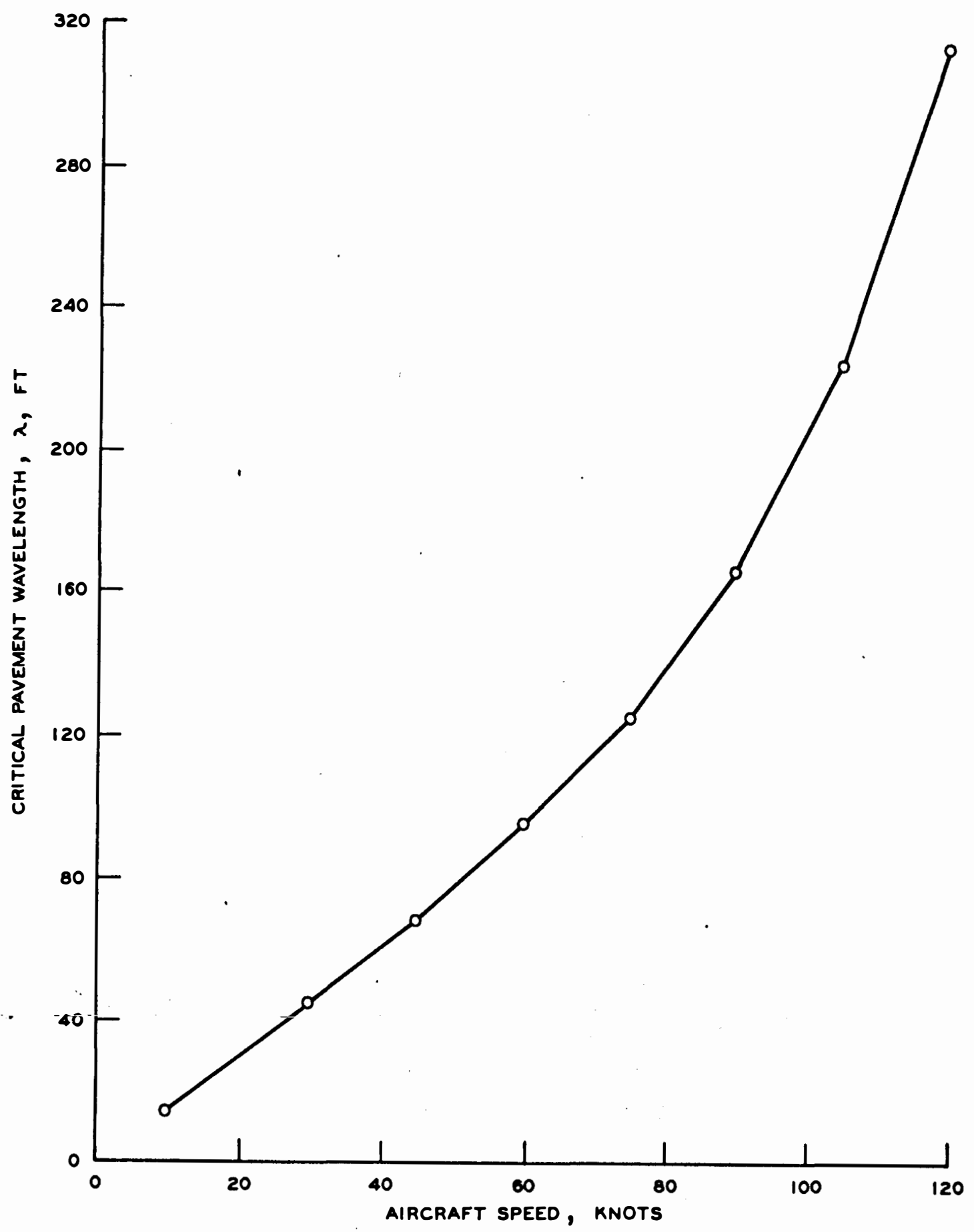

Figure 39. Critical pavement wavelength as a function of aircraft speed 


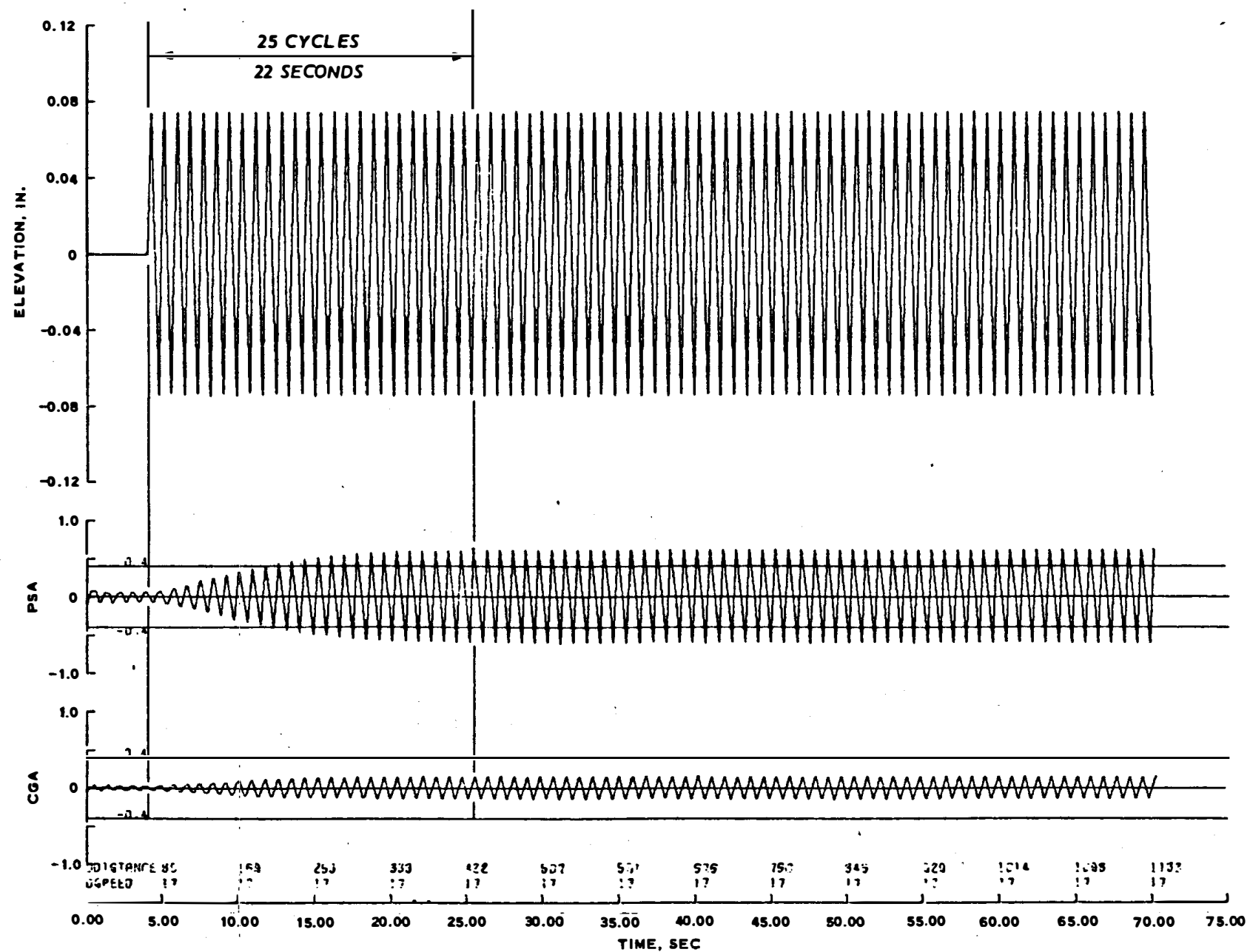

Figure 40. B-52H aircraft response to sinusoidal profile; aircraft taxiing at 10 knots; critical pavement wavelength of $14.5 \mathrm{ft}$; waveform amplitude of $0.075^{\circ} \mathrm{in}$. 


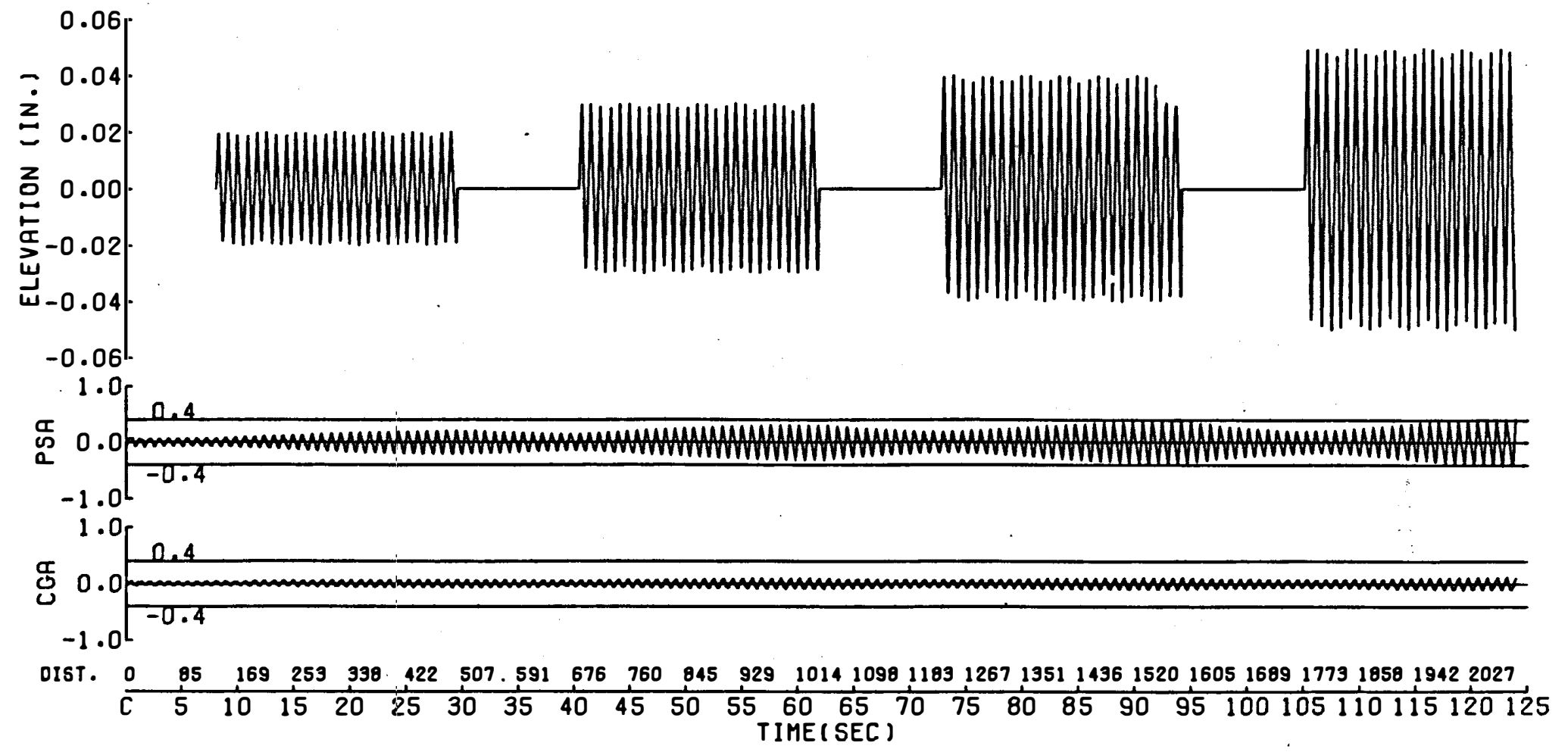

Figure 4l. B-52H aircraft response to sinusoidal waveform; taxi speed = 10 knots; critical pavement wavelength $=14.52 \mathrm{ft}$; waveform amplitude $=0.02,0.03,0.04$, and 0.05 in. 


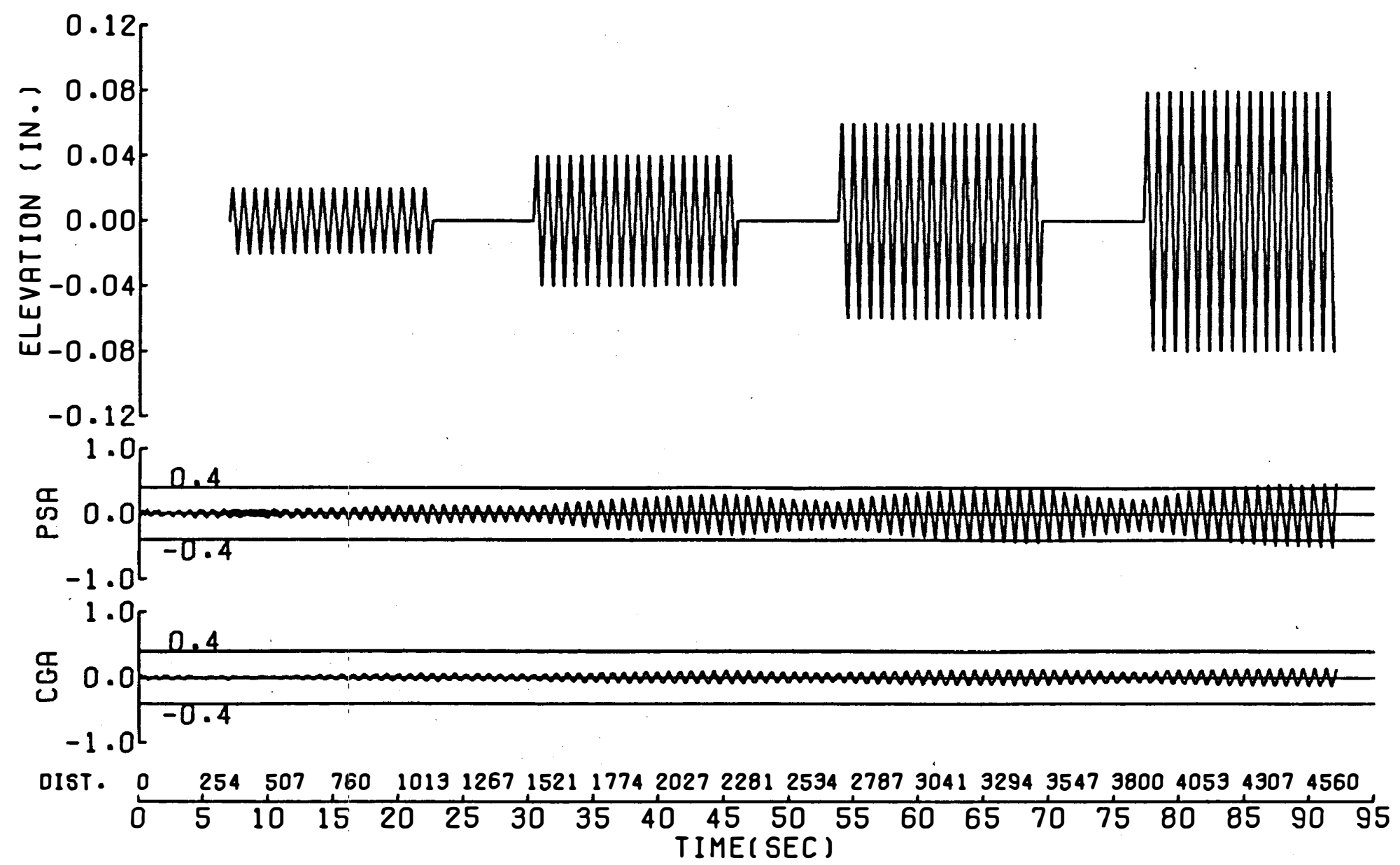

Figure 42. B-52H aircraft response to sinusoidal waveform; taxi speed $=30$ knots; critical pavement wavelength $=44.14 \mathrm{ft}$; waveform amplitude $=0.02,0.04,0.06$, and $0.08 \mathrm{in.}$ 

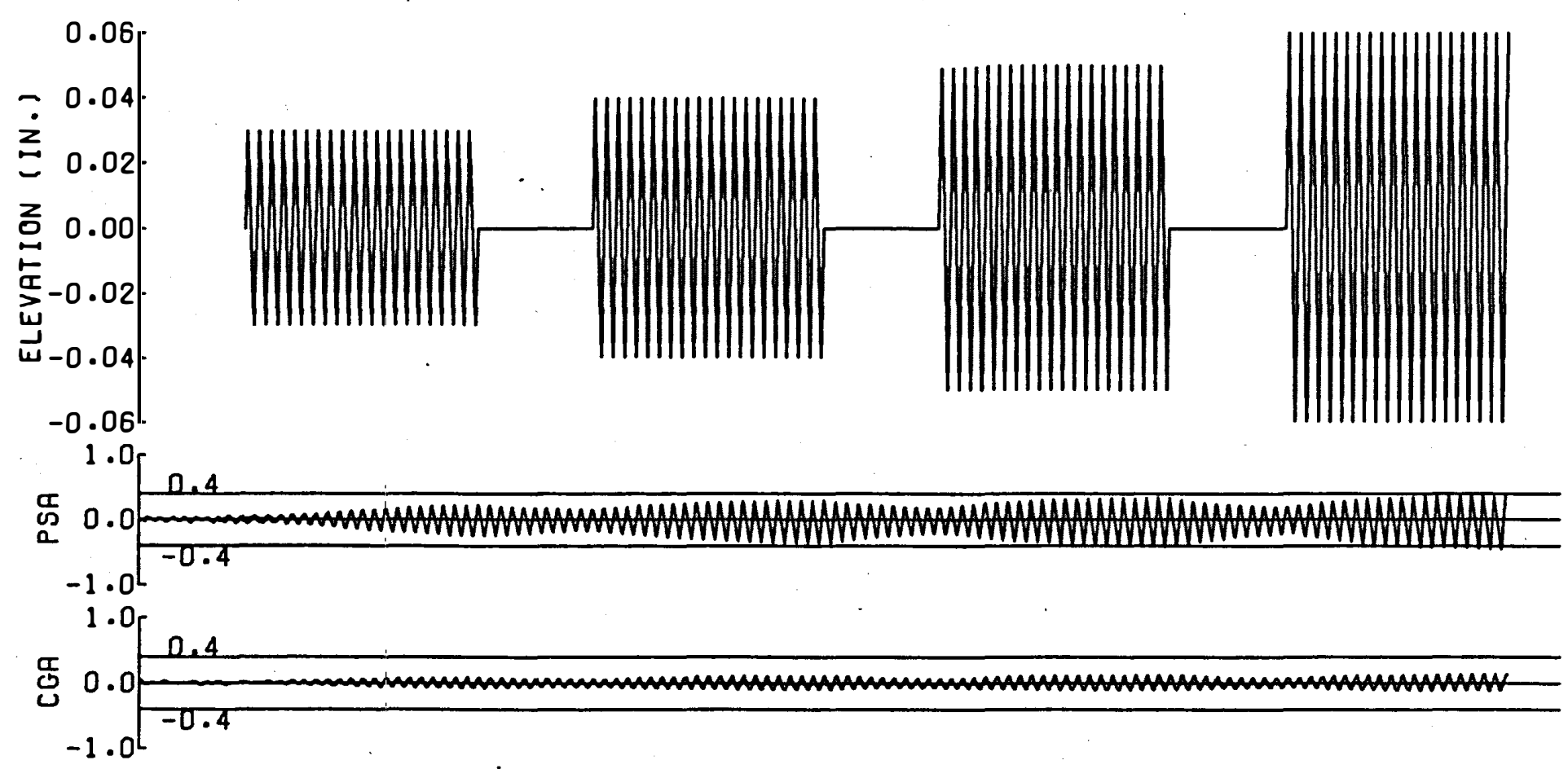

DIST. $0 \quad 381760 \quad 1140152019012281266130413421380141814561494153215700608064606840722075997979$

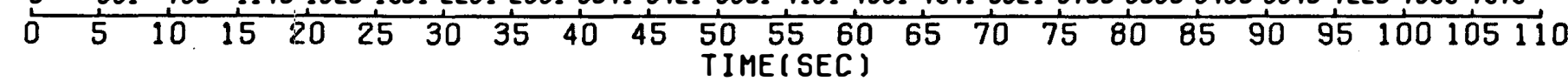

Figure 43. B-52H aircraft response to sinusoidal waveform; taxi speed $=45$ knots; critical pavement wavelength $=68.005 \mathrm{ft}$; waveform amplitude $=0.03,0.04,0.05$, and $0.06 \mathrm{in}$. 


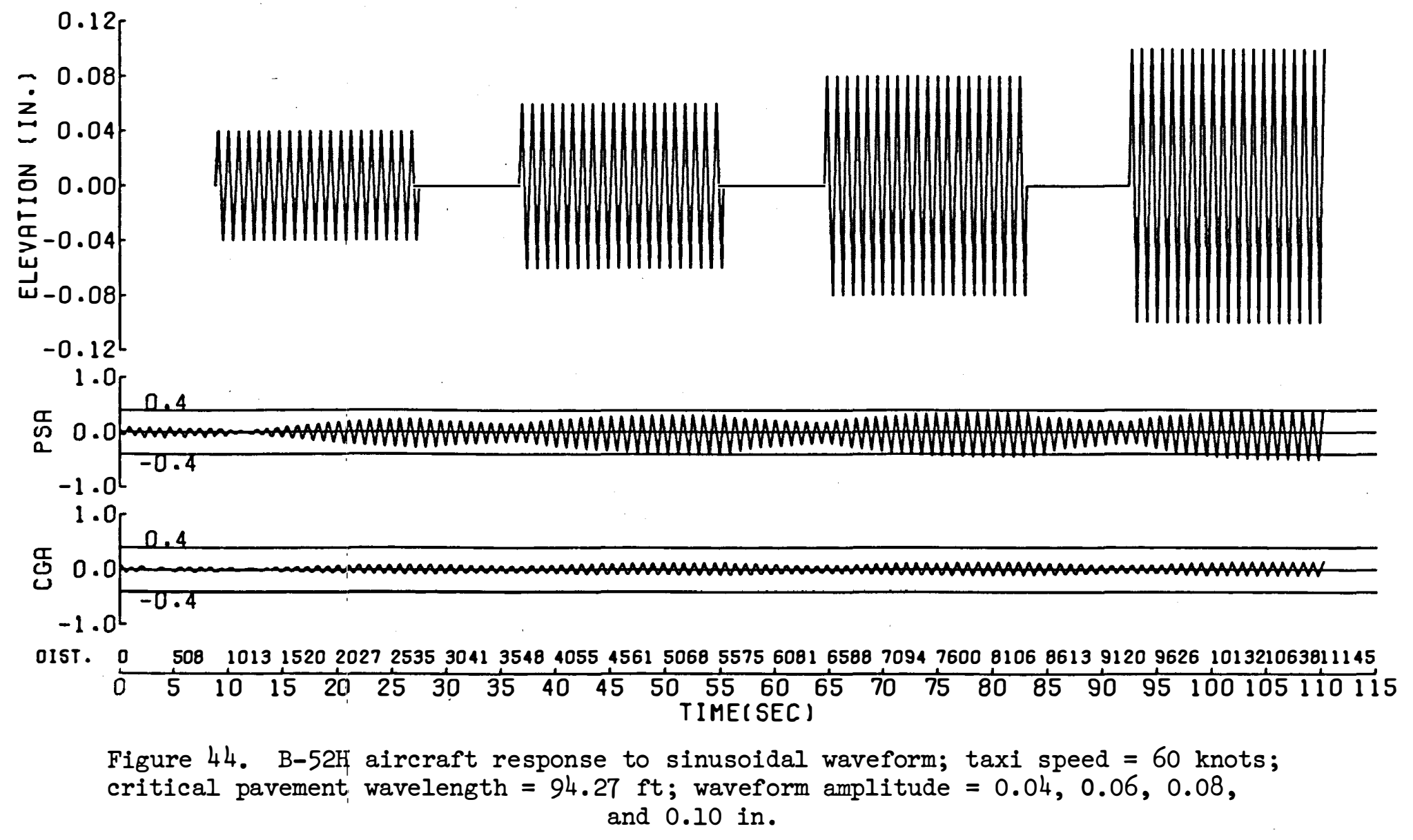




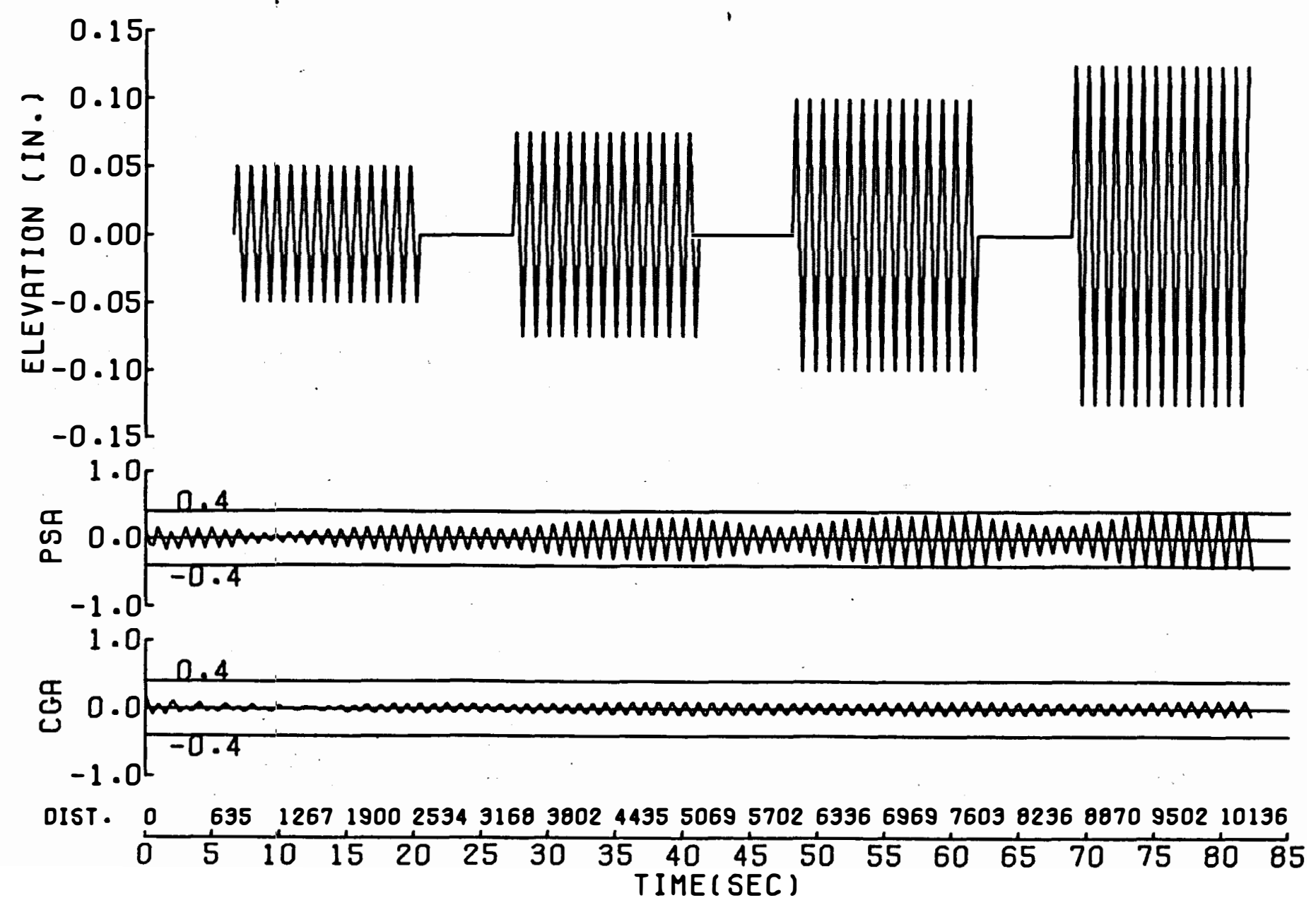

Figure 45. B-52H aircraft response to sinusoidal waveform; taxi speed $=75$ knots; critical pavement wavelength $=125.3 \mathrm{ft}$; waveform amplitude $=0.05,0.075,0.10$, and 0.125 in. 


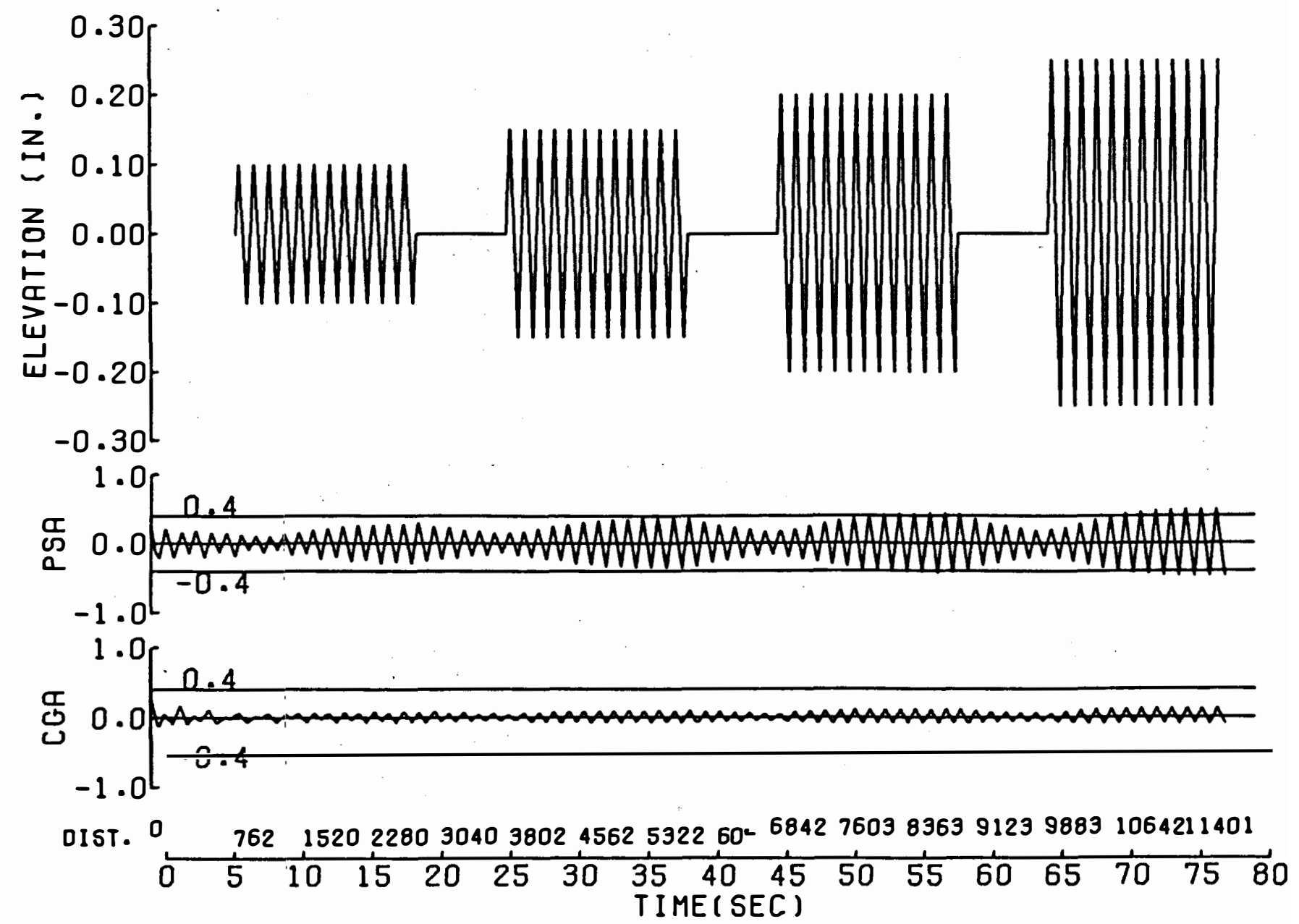

Figure 46. B-52H aircraft response to sinusoidal waveform; taxi speed $=90 \mathrm{knots}$; critical pavement wavelength $=166.15 \mathrm{ft}$; waveform amplitude $=0.1,0.15,0.2$, and 0.25 in. 


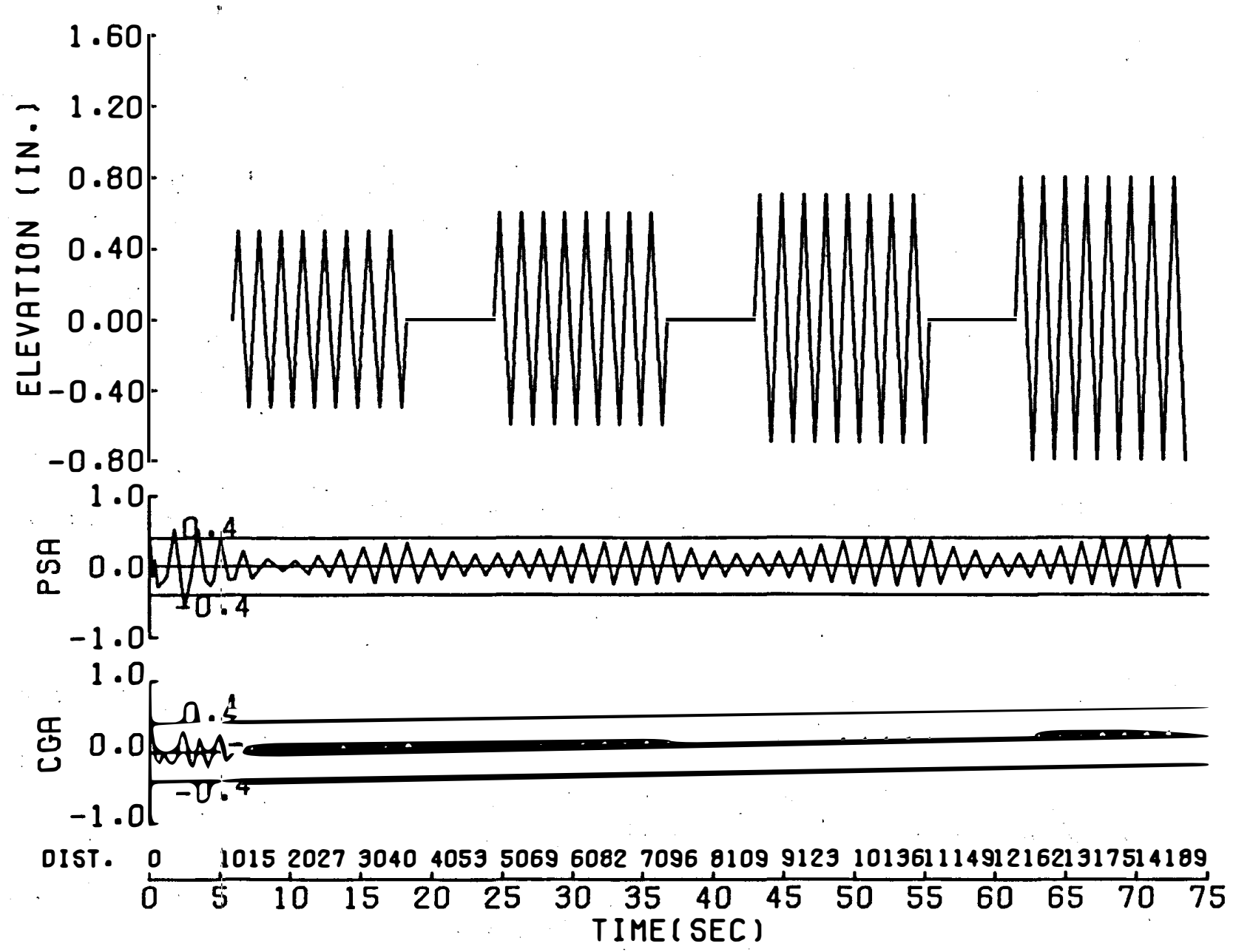

Figure 47. B-52H aircraft response to sinusoidal waveform; taxi speed $=120 \mathrm{knots}$; critical pavement wavelength $=312.8 \mathrm{ft}$; waveform amplitude $=0.5,0.6,0.7$, and $0.8 \mathrm{in}$. 


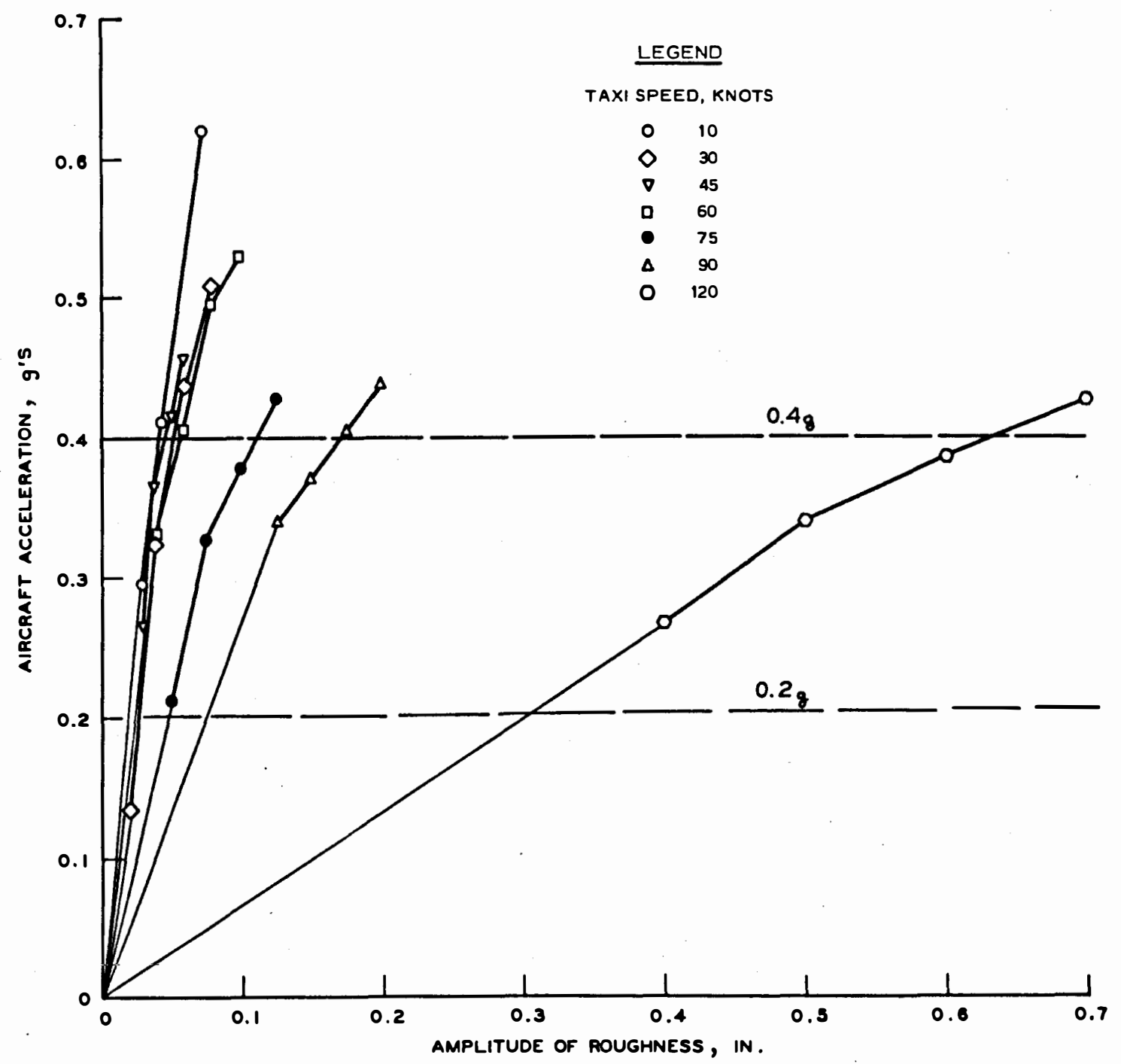

Figure 48. Sinusoidal roughness summary; B-52H 


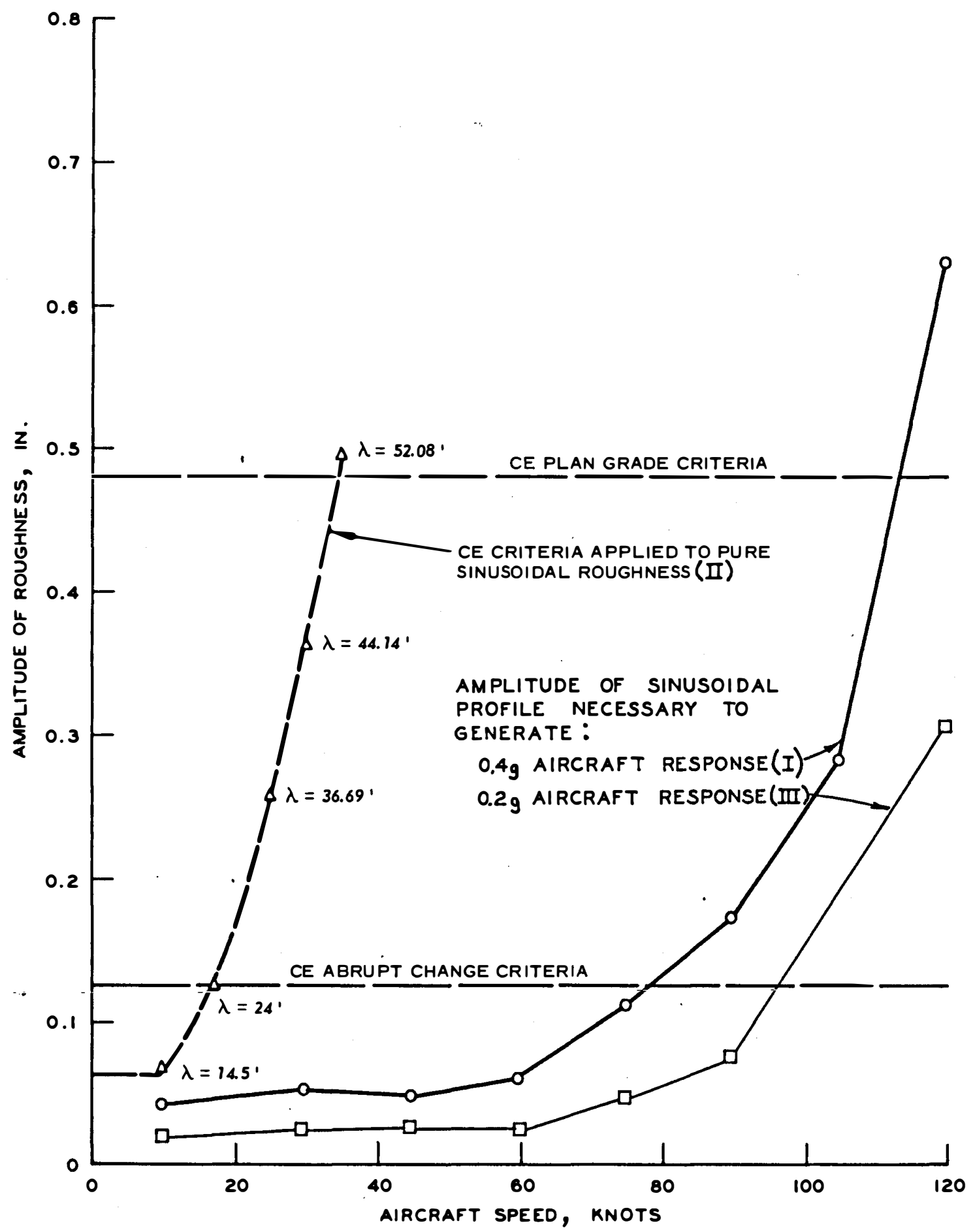

Figure 49. Summary of results for the sinusoidal waveform 


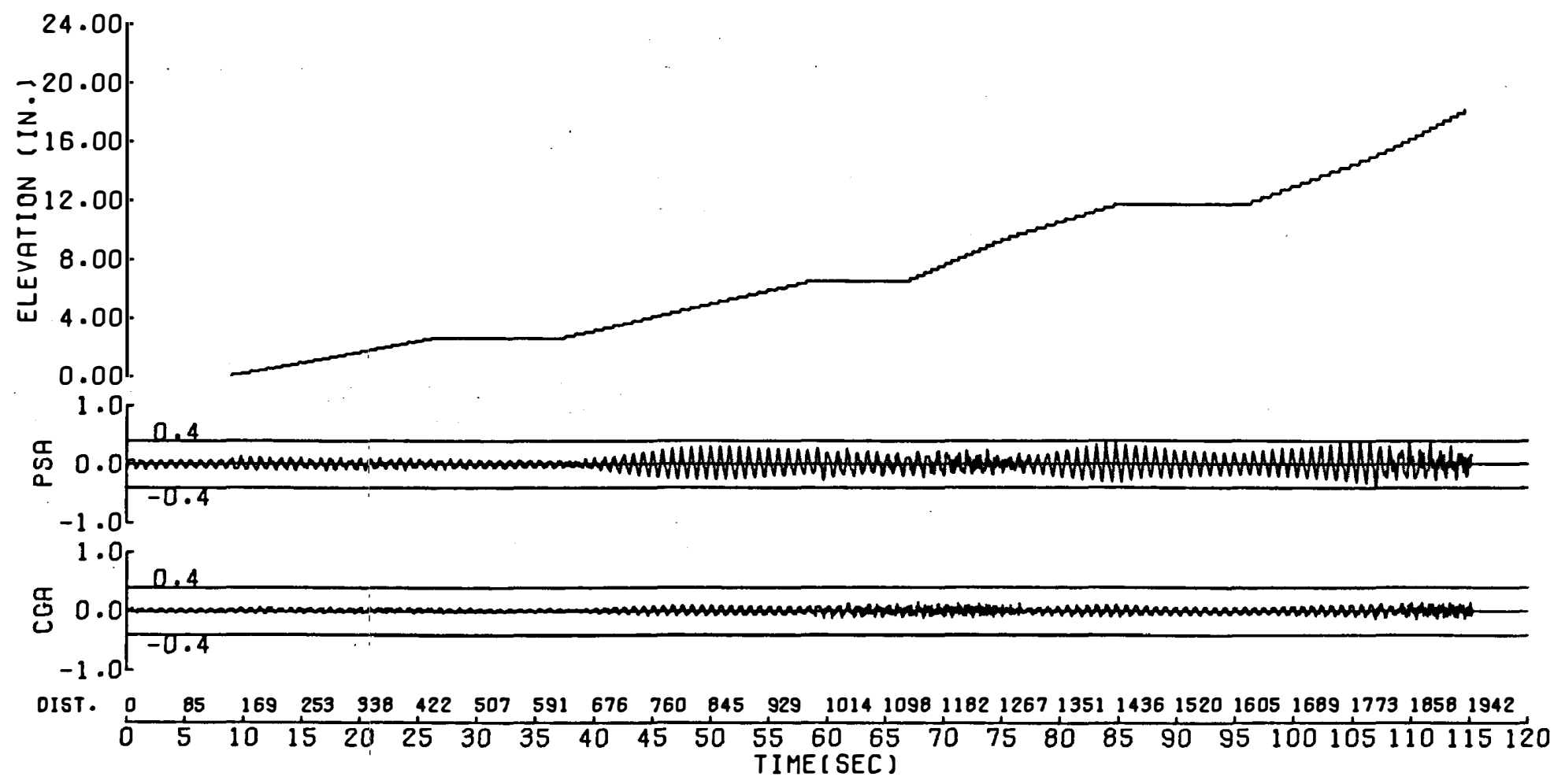

Figure 50. B-52H aircraft response to multiple-step waveform; taxi speed = $10 \mathrm{knots;} \mathrm{critical}$ pavement wavelength $=14 \mathrm{ft}$; waveform amplitude $=0.1,0.15,0.20$, and 0.25 in. 


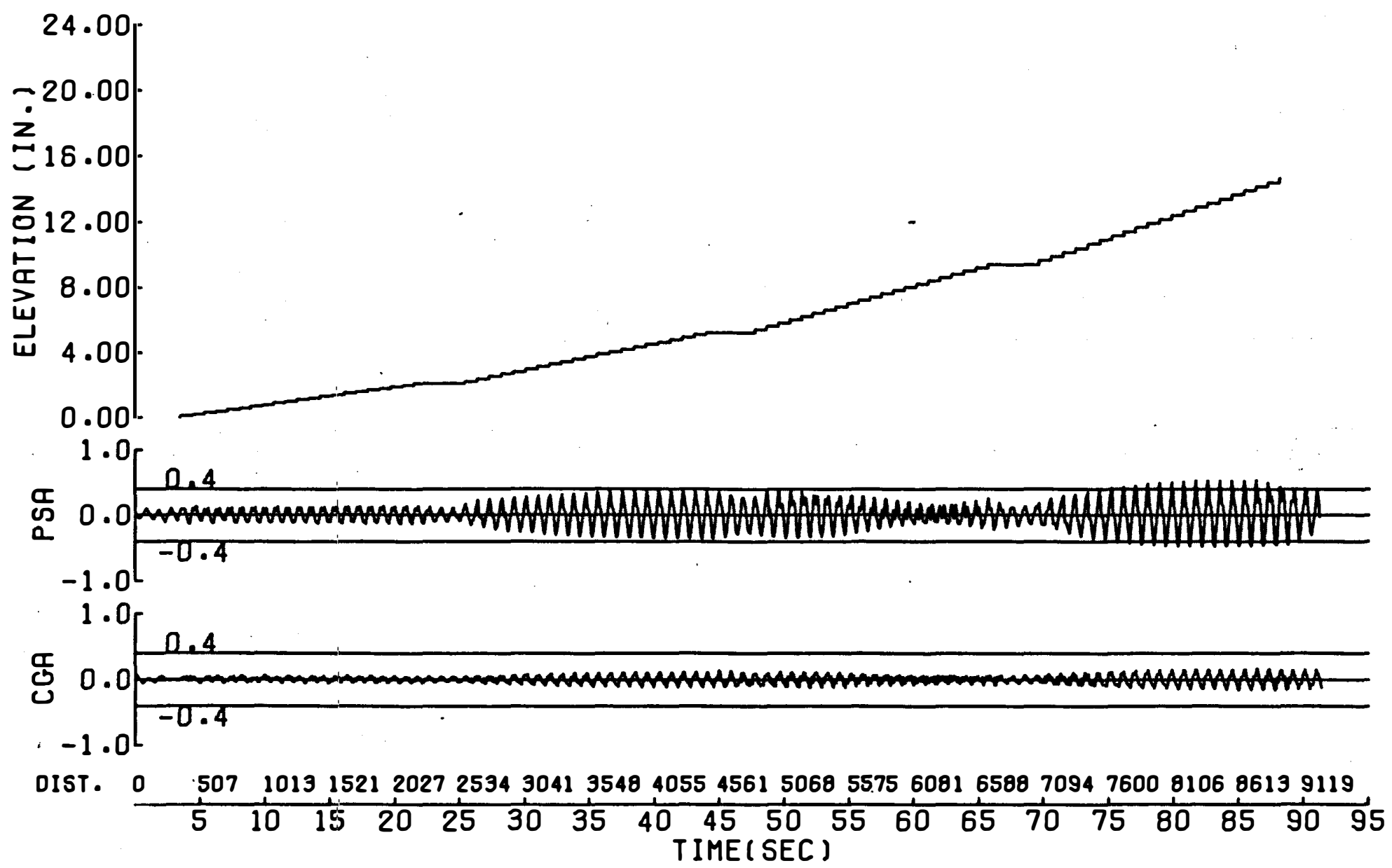

Figure 51. B-52H aircraft response to multiple-step waveform; taxi speed = $60 \mathrm{knots}$; critical pavement wavelength $=94 \mathrm{ft}$; waveform amplitude $=0.1,0.15,0.2$, and $0.25 \mathrm{in}$. 


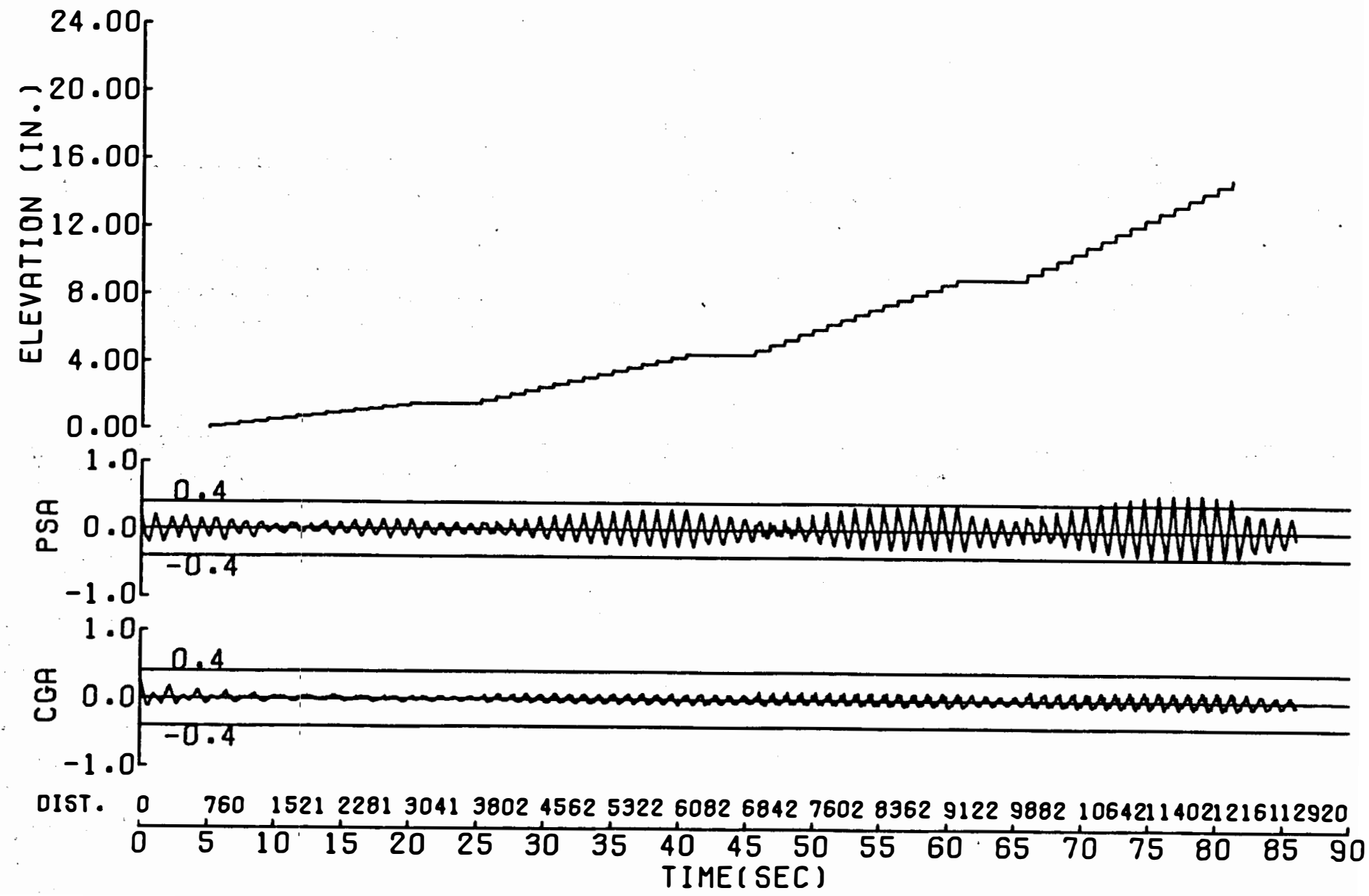

Figure 52. B-52H aircraft response to multiple-step waveform; taxi speed = $90 \mathrm{knots}$; critical pavement wavelength $=166 \mathrm{ft}$; waveform amplitude $=0.1,0.2,0.3$, and $0.4 \mathrm{in}$. 


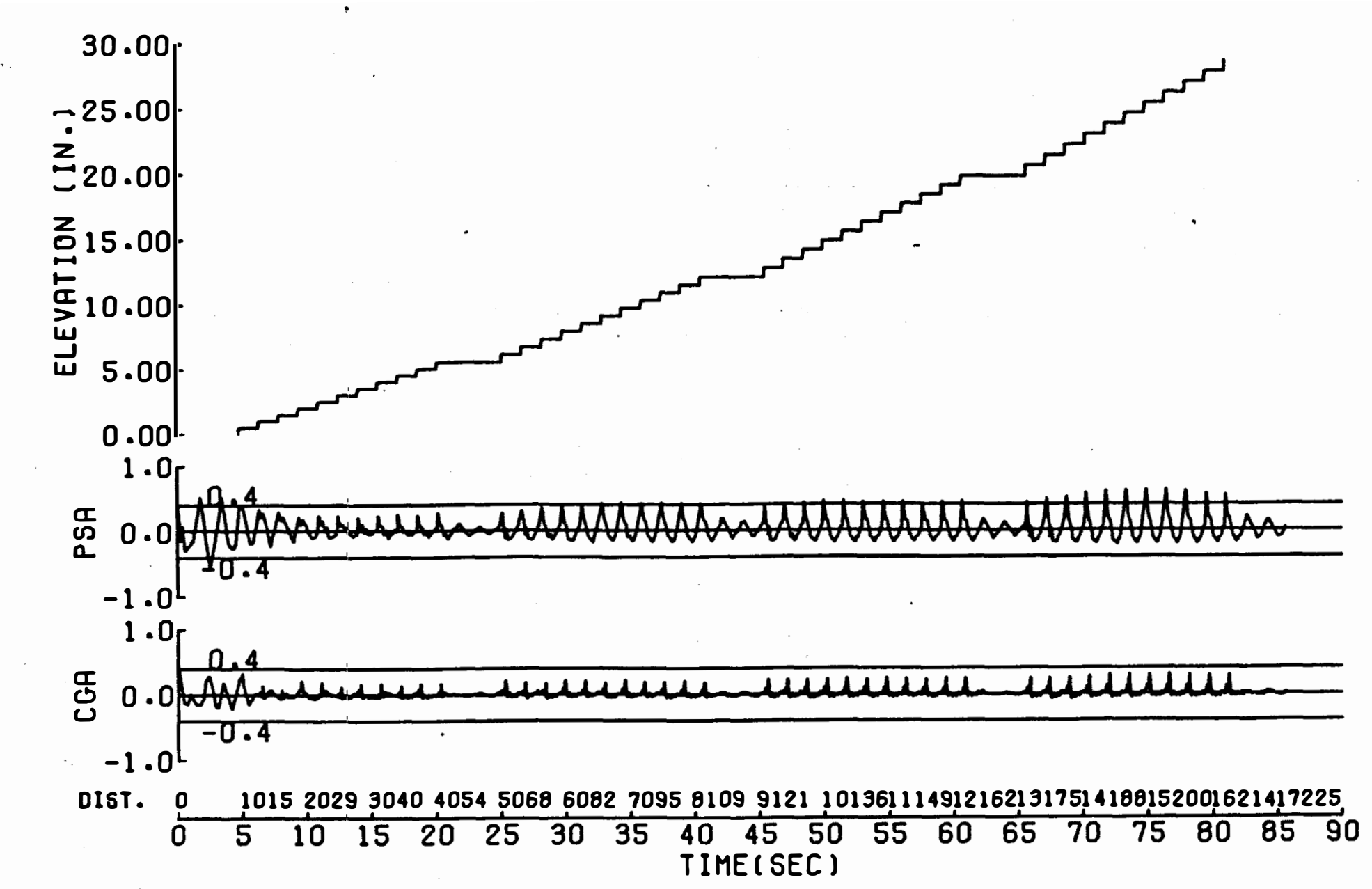

Figure 53. B-52H aircraft response to multiple-step waveform; taxi speed = $120 \mathrm{knots}$; critical pavement wavelength $=312 \mathrm{ft}$; waveform amplitude $=0.5,0.6,0.7$, and $0.8 \mathrm{in}$. 


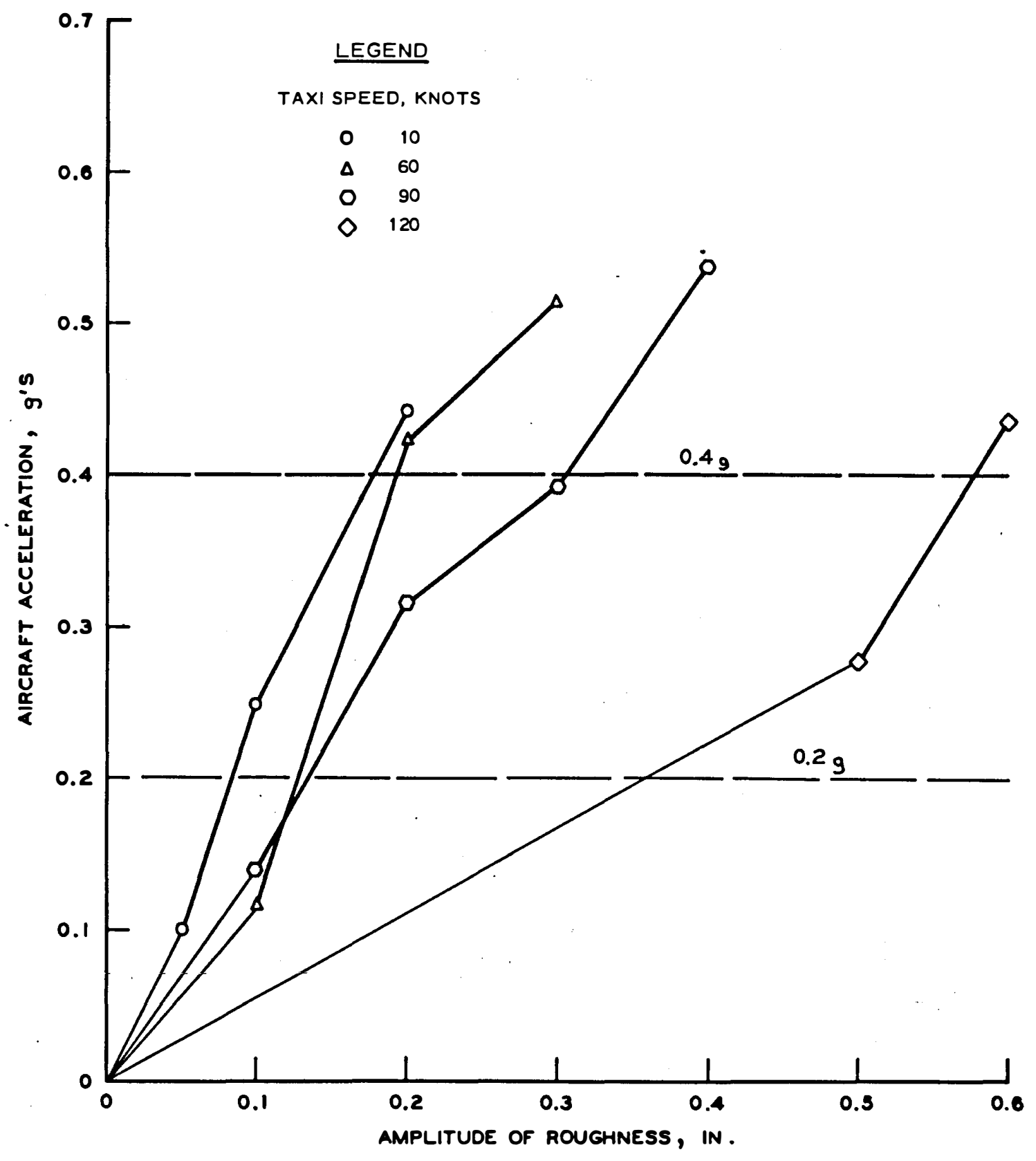

Figure 54. Summary of multiple-step function analysis 


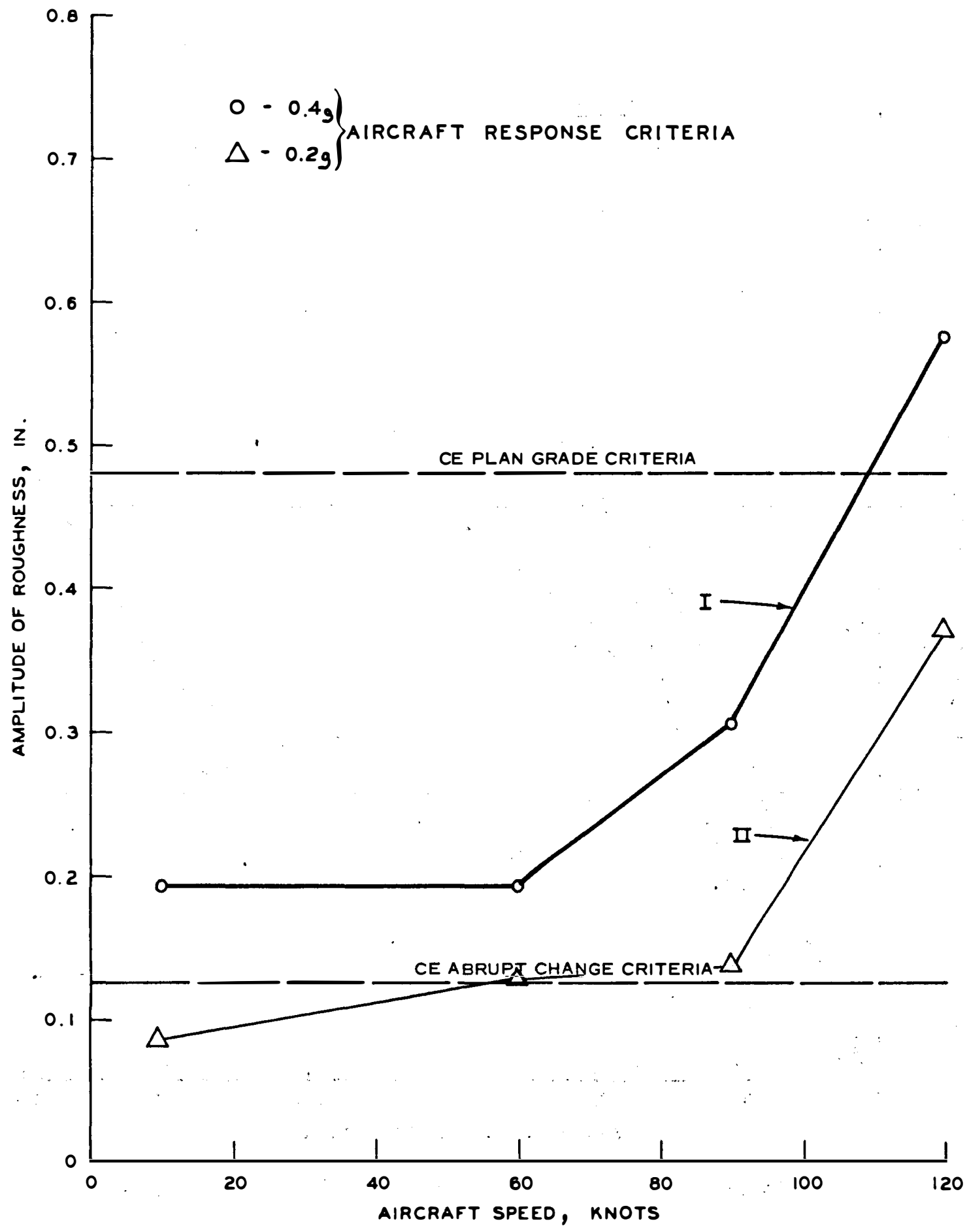

Figure 55. Summary of results for the multiple-step waveform 


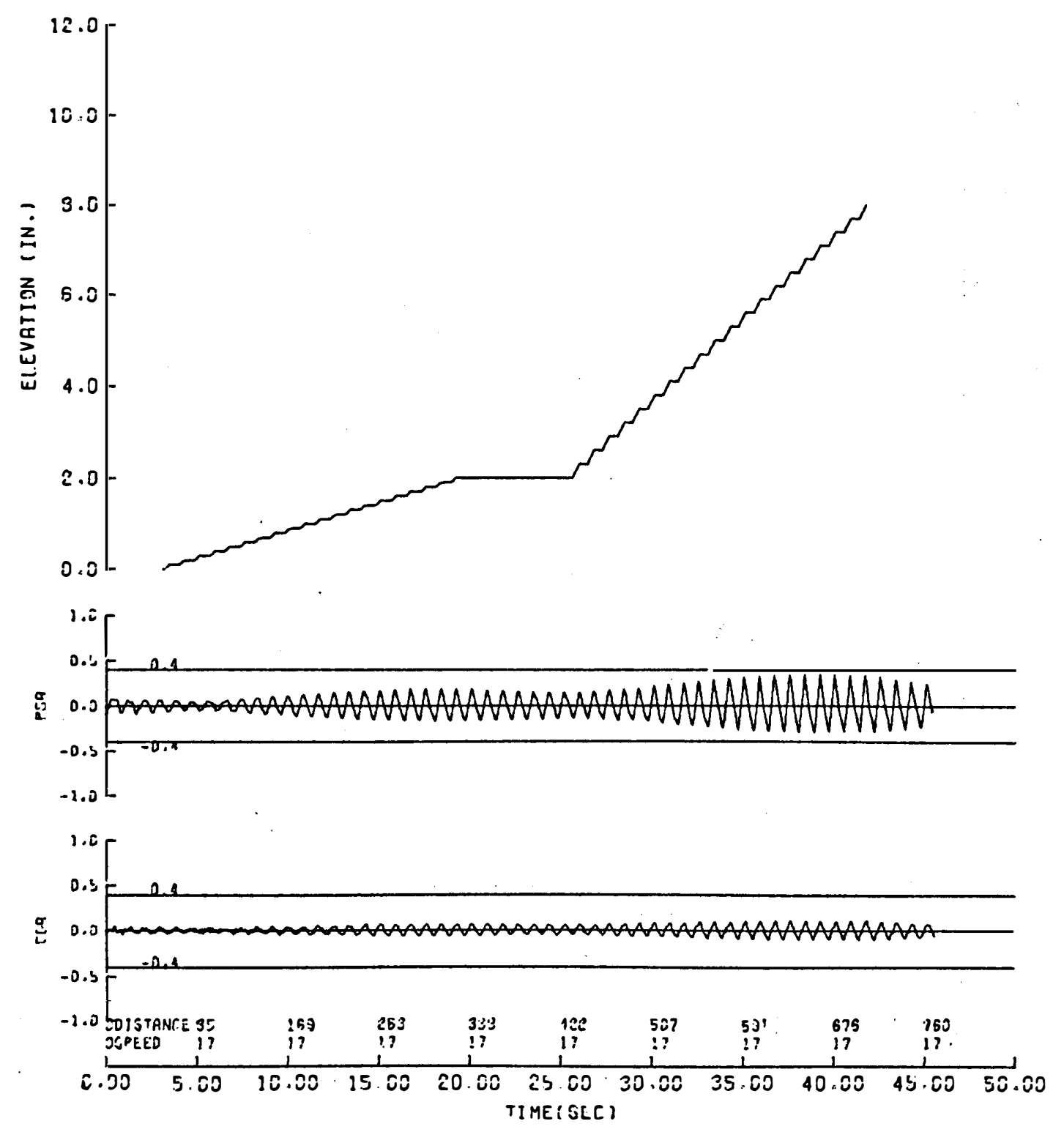

Figure 56. B-52H aircraft response to multi-ramp 1 waveform; taxi speed $=10$ knots; critical pavement wavelength $=14 \mathrm{ft}$; waveform amplitude $=0.1$ and $0.3 \mathrm{in}$. 


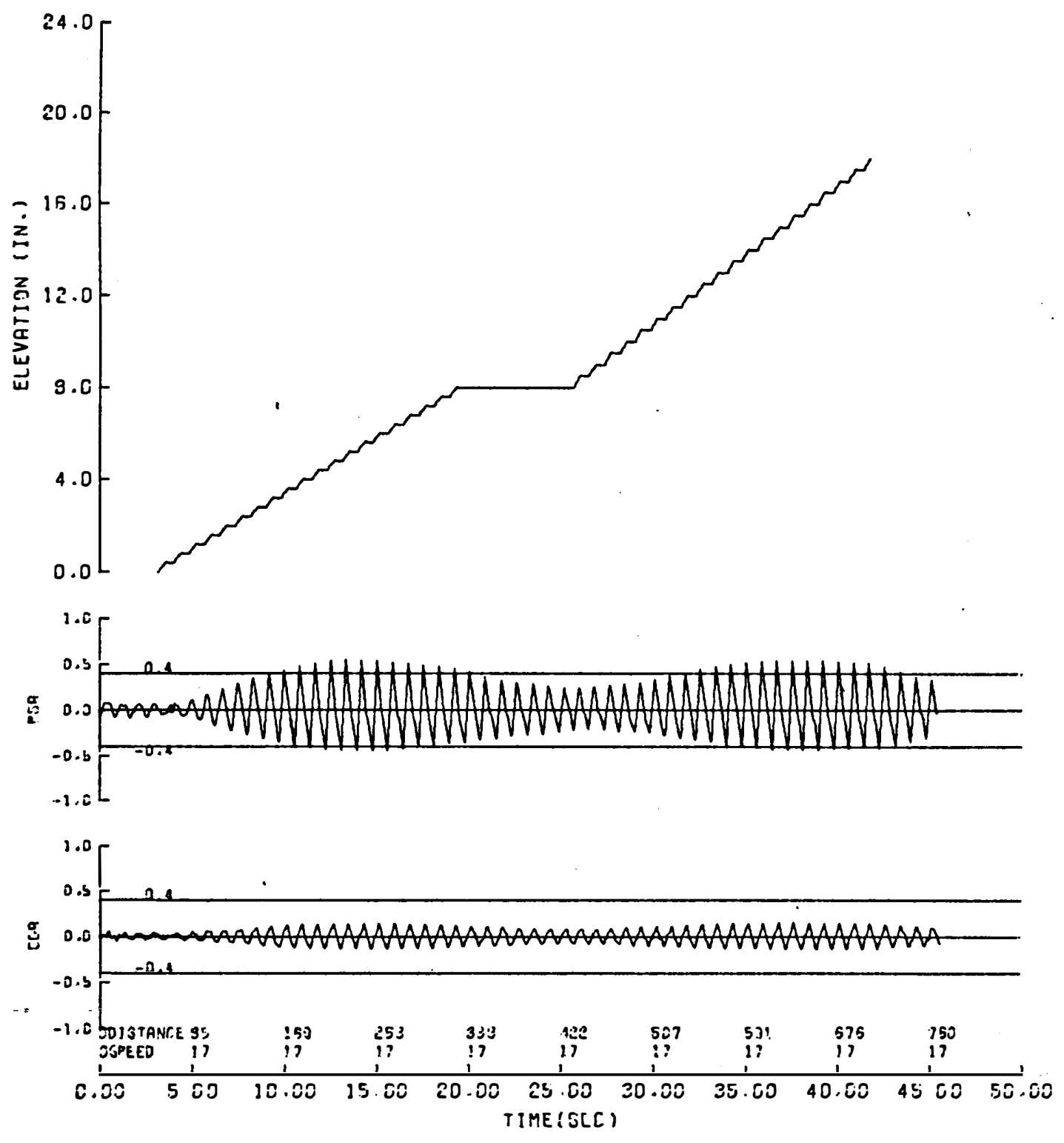

Figure 57. B-52H aircraft response to multi-ramp 1 waveform; taxi speed $=10$ knots; critical pavement wavelength $=14 \mathrm{ft}$; waveform amplitude $=0.4$ and $0.5 \mathrm{in}$. 


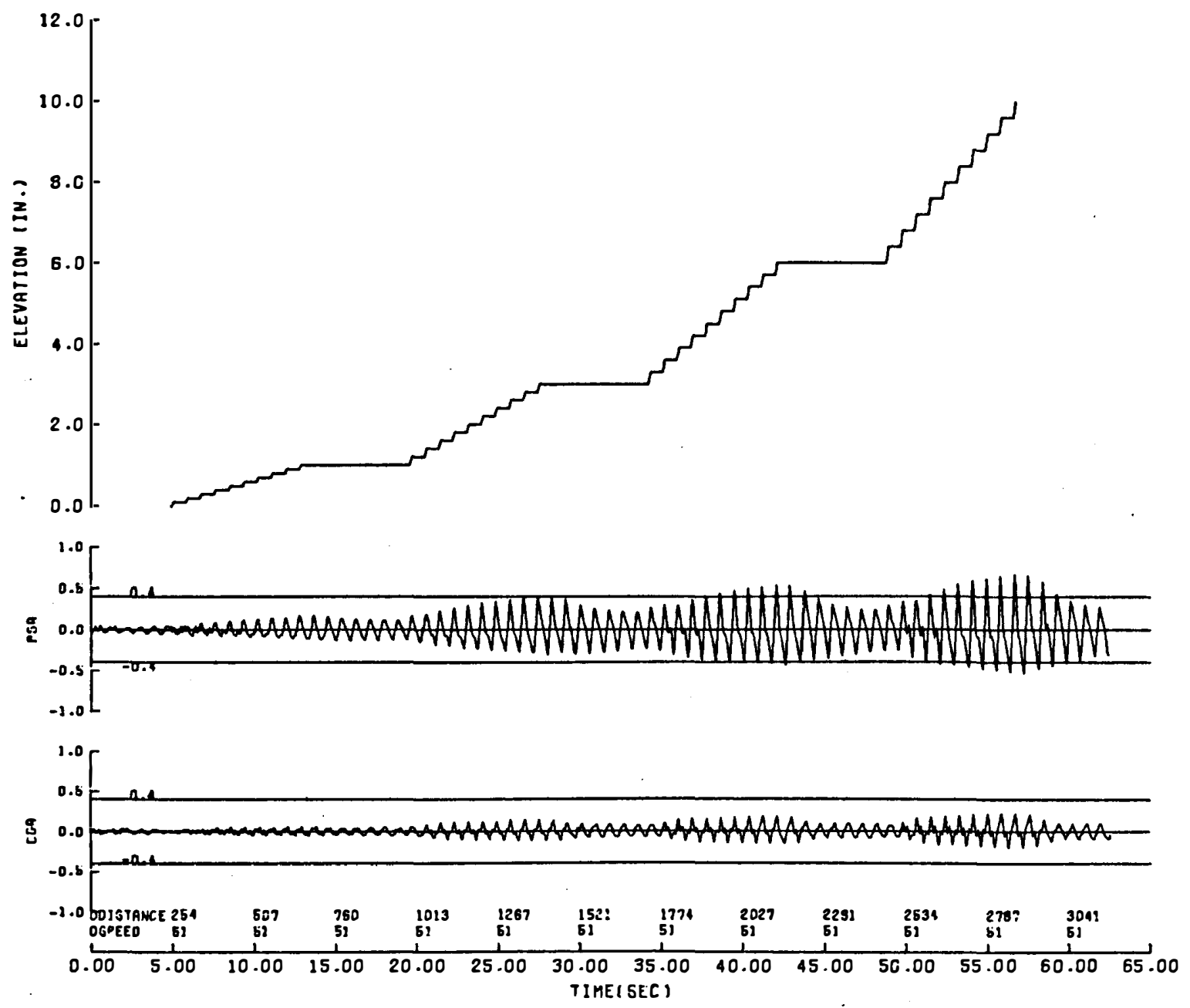

Figure 58. B-52H aircraft response to multi-ramp 1 waveform; taxi speed $=30$ knots; critical pavement wavelength $=44 \mathrm{ft}$; waveform amplitude $=0.1,0.2,0.3$, and $0.4 \mathrm{in}$. 


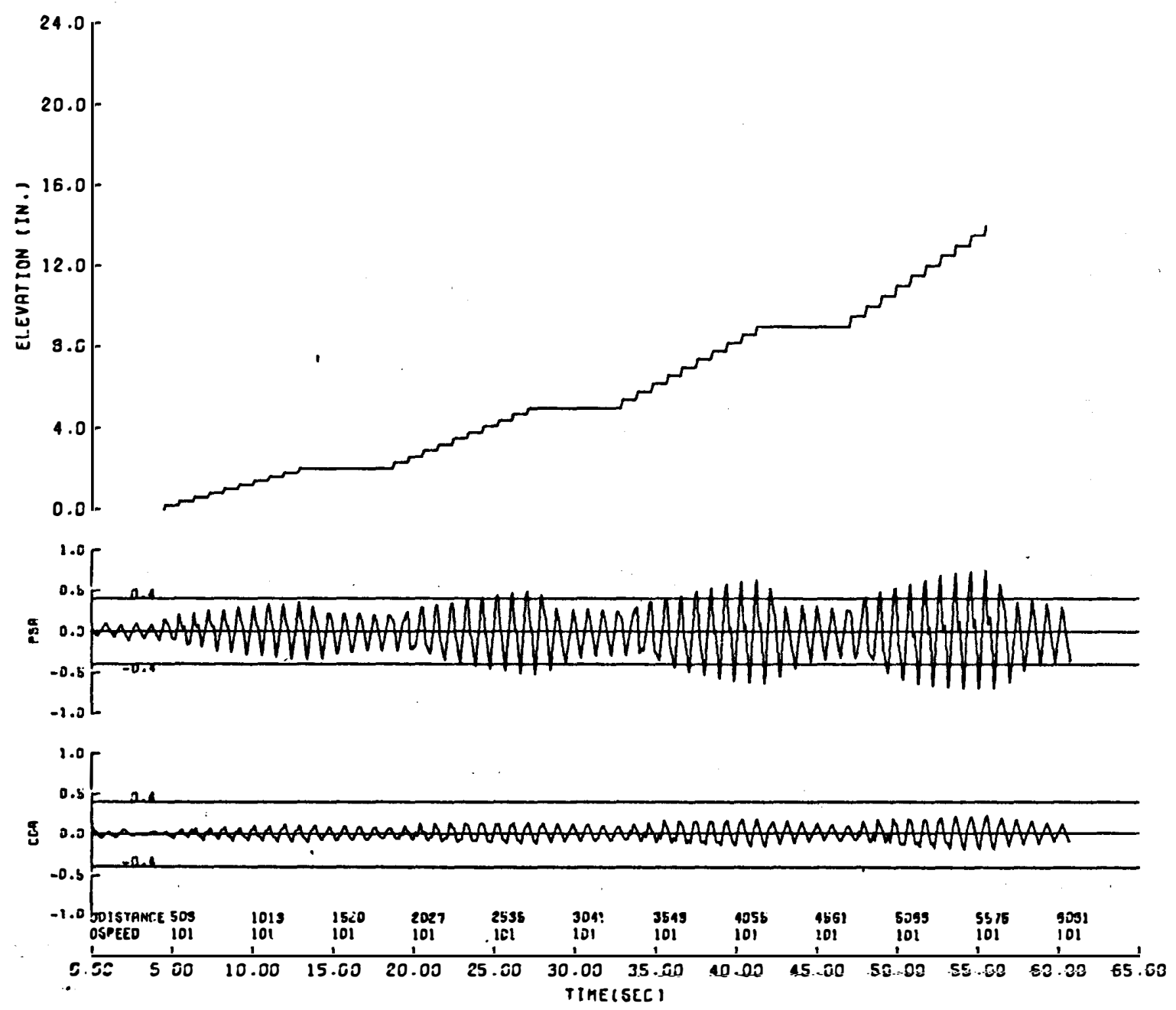

Figure 59. B-52H aircraft response to multi-ramp 1 waveform; taxi speed $=60$ knots; critical pavement wavelength $=94 \mathrm{ft}$; waveform amplitude $=0.2,0.3,0.4$, and $0.5 \mathrm{in}$. 


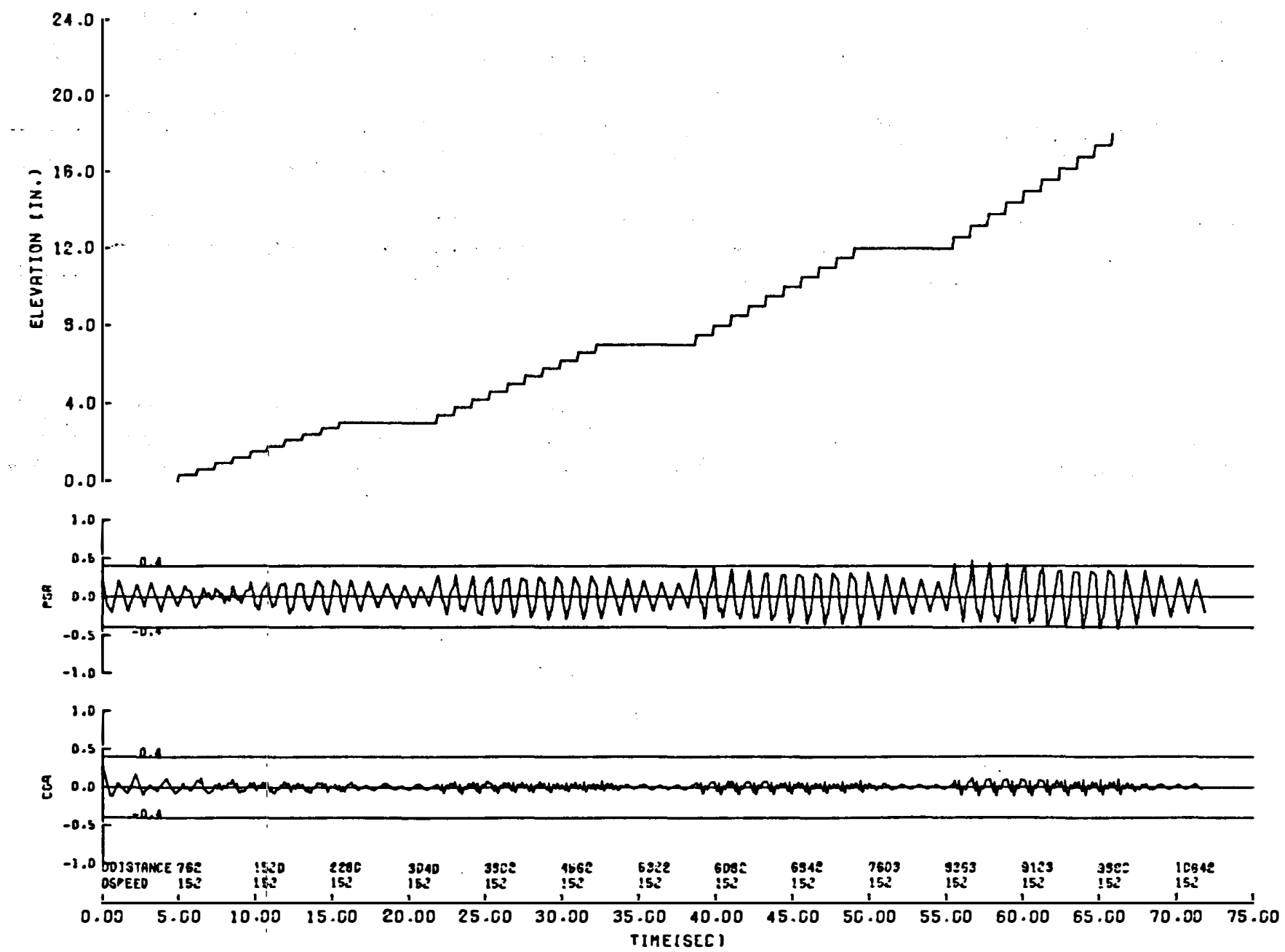

Figure 60. B-52H aircraft response to multi-ramp 1 waveform; taxi speed = $90 \mathrm{knots}$; critical pavement wavelength $=175 \mathrm{ft}$; waveform amplitude $=0.3,0.4,0.5$, and 0.6 in. 


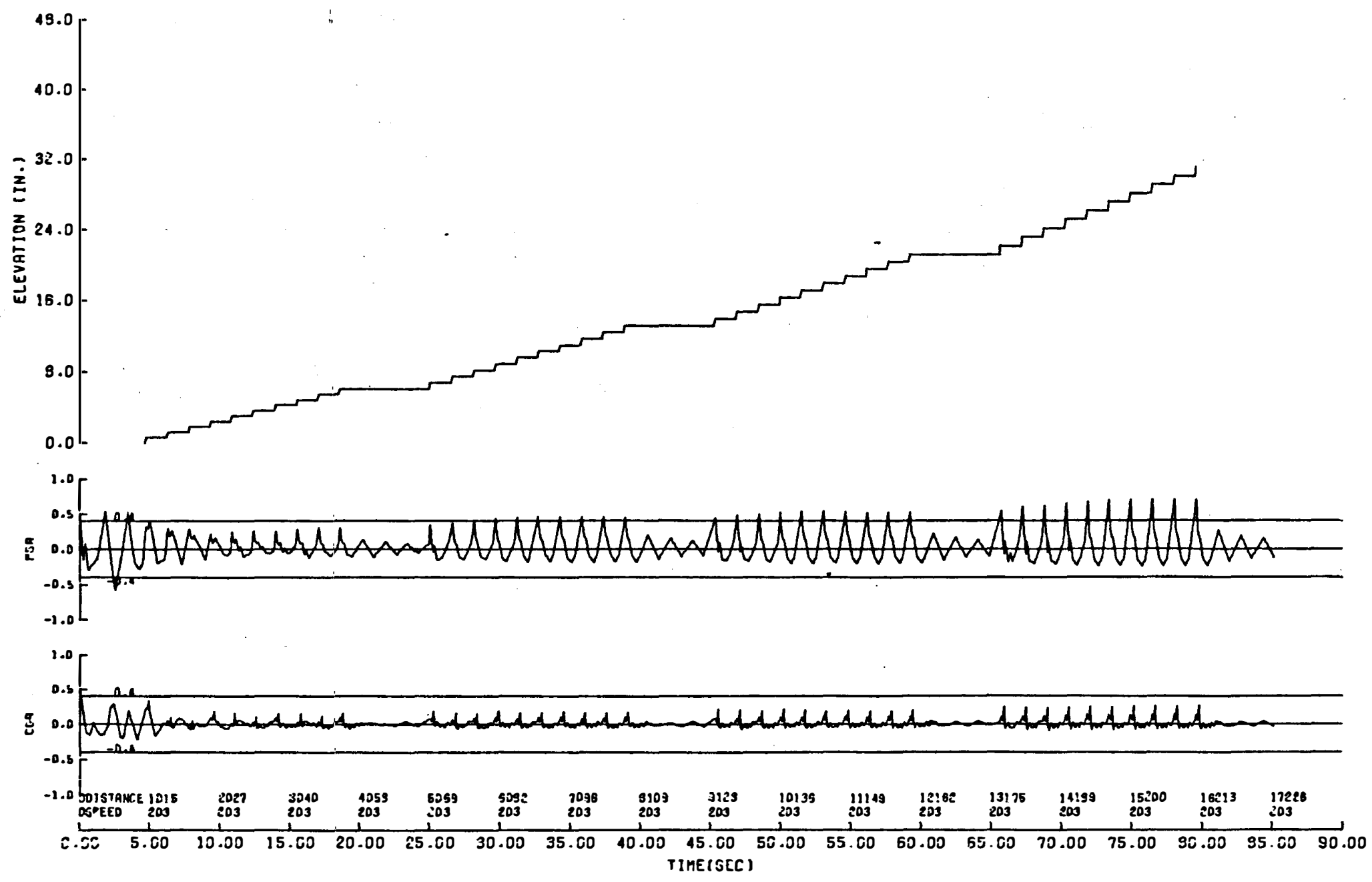

Figure 61. B-52H aircraft response to multi-ramp 1 waveform; taxi speed = $120 \mathrm{knots}$; critical pavement wavelength $=312 \mathrm{ft}$; waveform amplitude $=0.6,0.7,0.8$, an $1.0 \mathrm{in}$. 


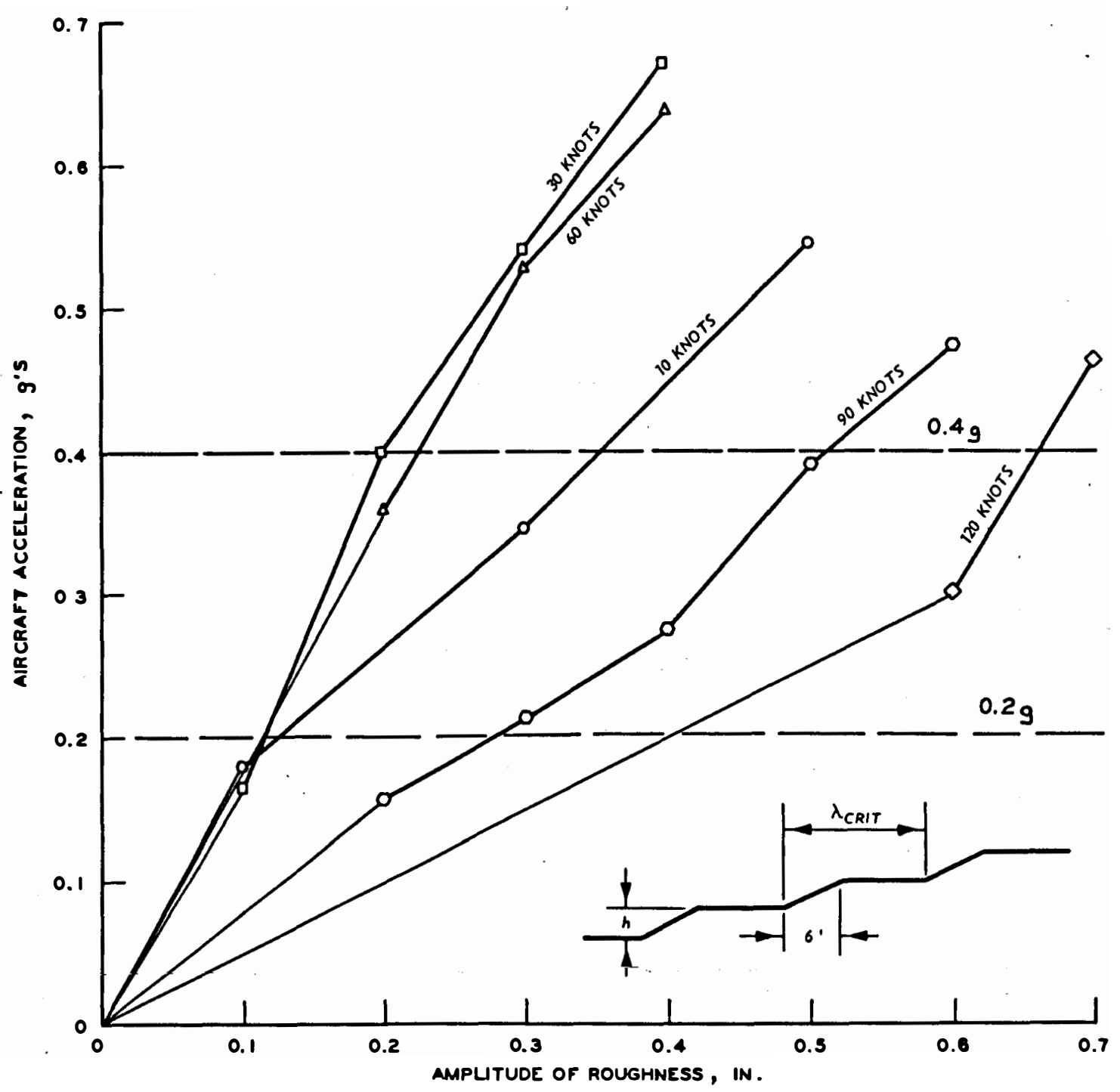

Figure 62. Multi-ramp I roughness summary; B-52H 


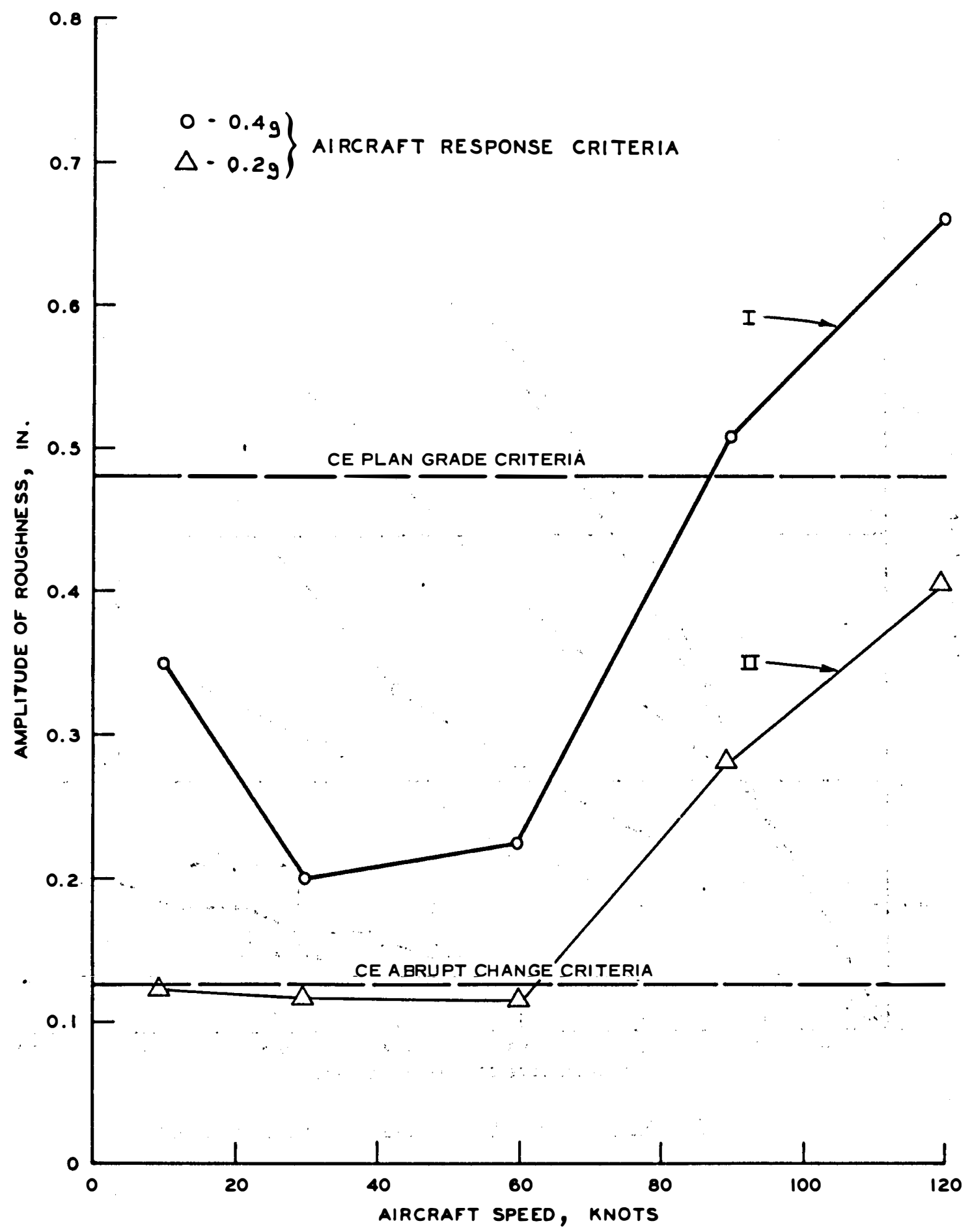

Figure 63. Summary of multi-ramp 1 results 


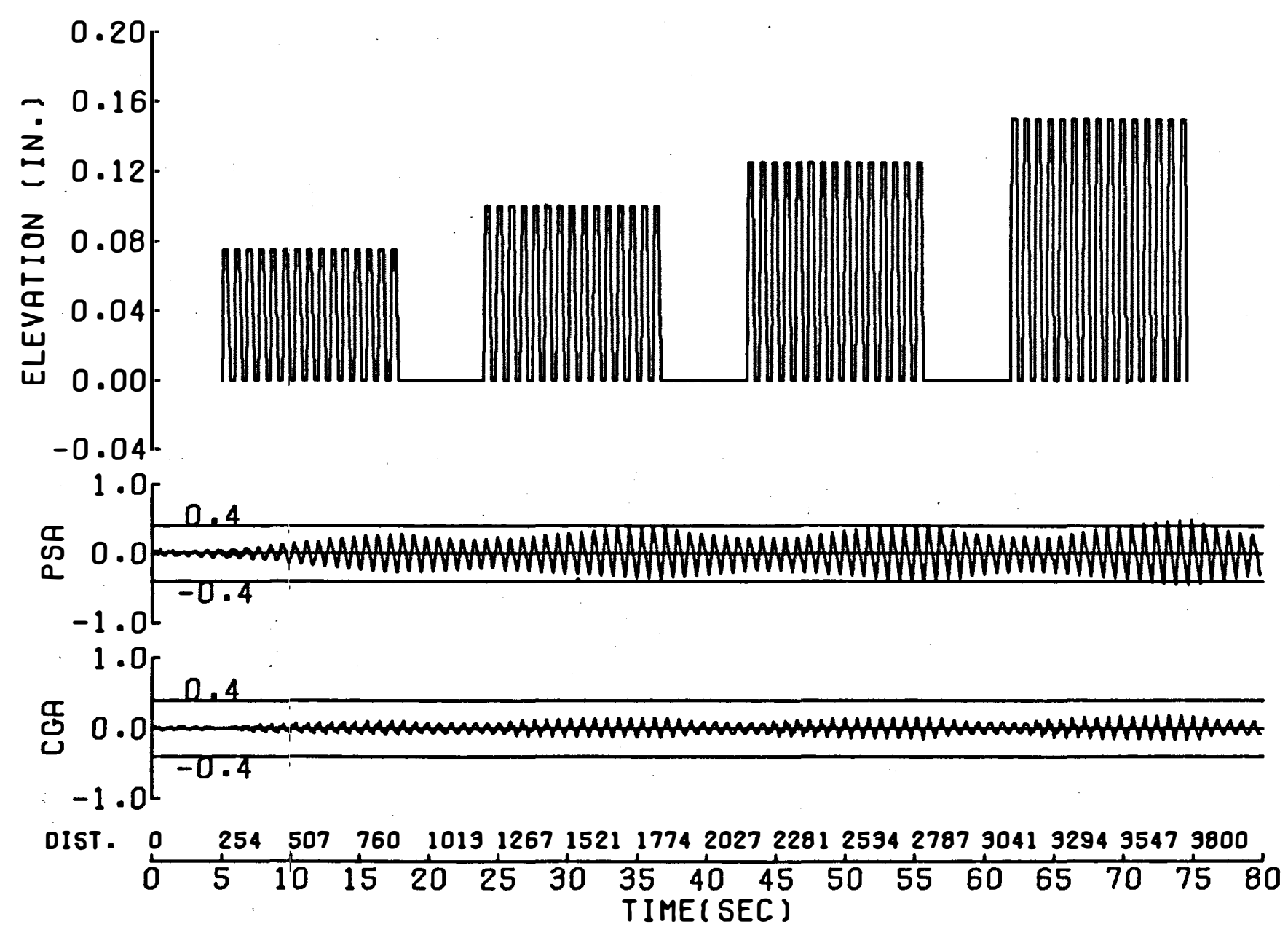

Figure 64. B-52H aircraft response to multi-ramp 2 waveform; taxi speed = $30 \mathrm{knots}$; critical pavement wavelength $=44 \mathrm{ft}$; waveform amplitude $=0.075,0.100,0.125$, and $0.150 \mathrm{in}$. 


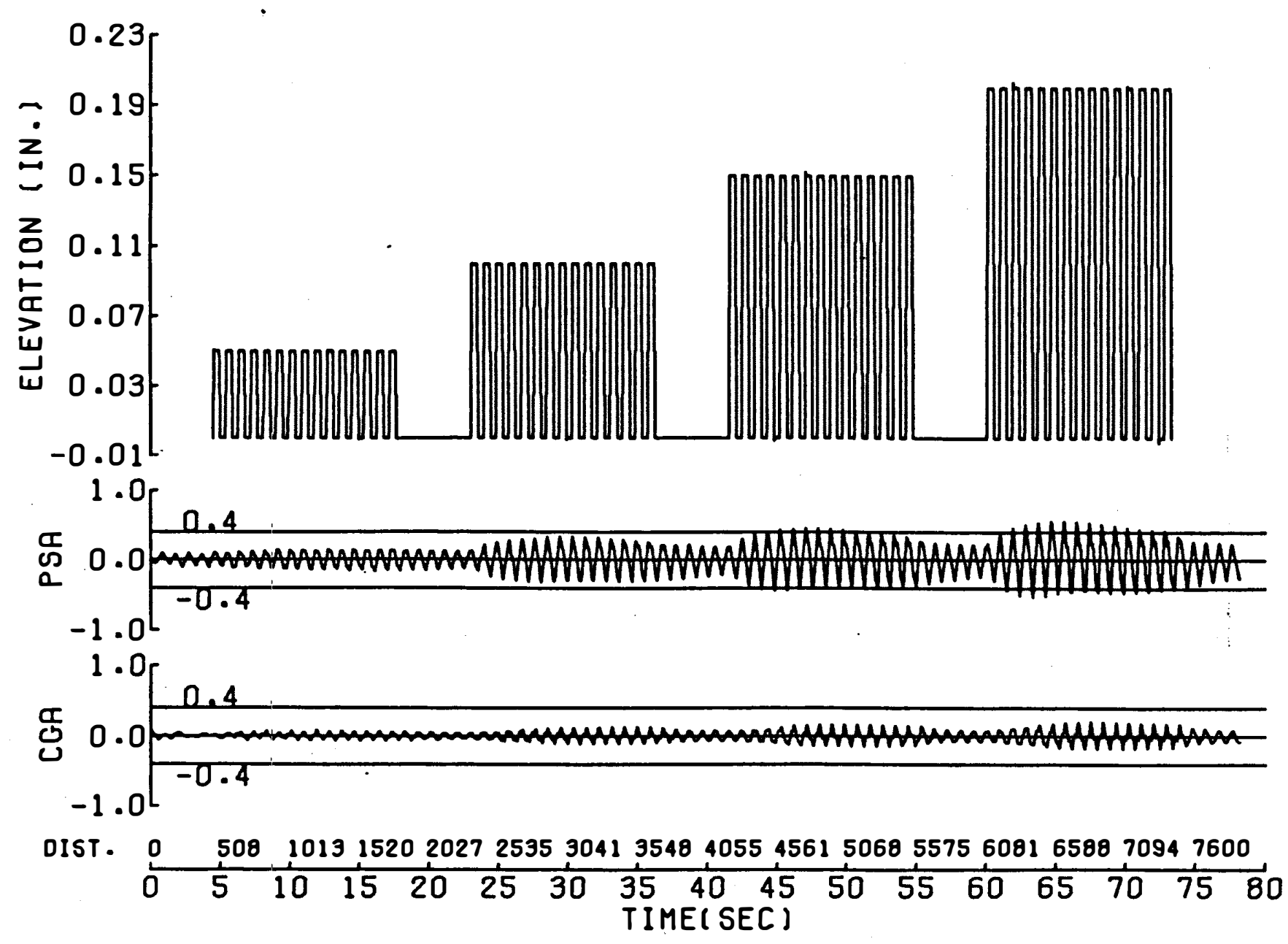

Figure 65. B-52H aircraft response to multi-ramp 2 waveform; taxi speed $=60 \mathrm{knots}$; critical pavement wavelength $=92 \mathrm{ft}$; waveform amplitude $=0.05,0.10,0.15$, and

$0.20 \mathrm{in}$. 


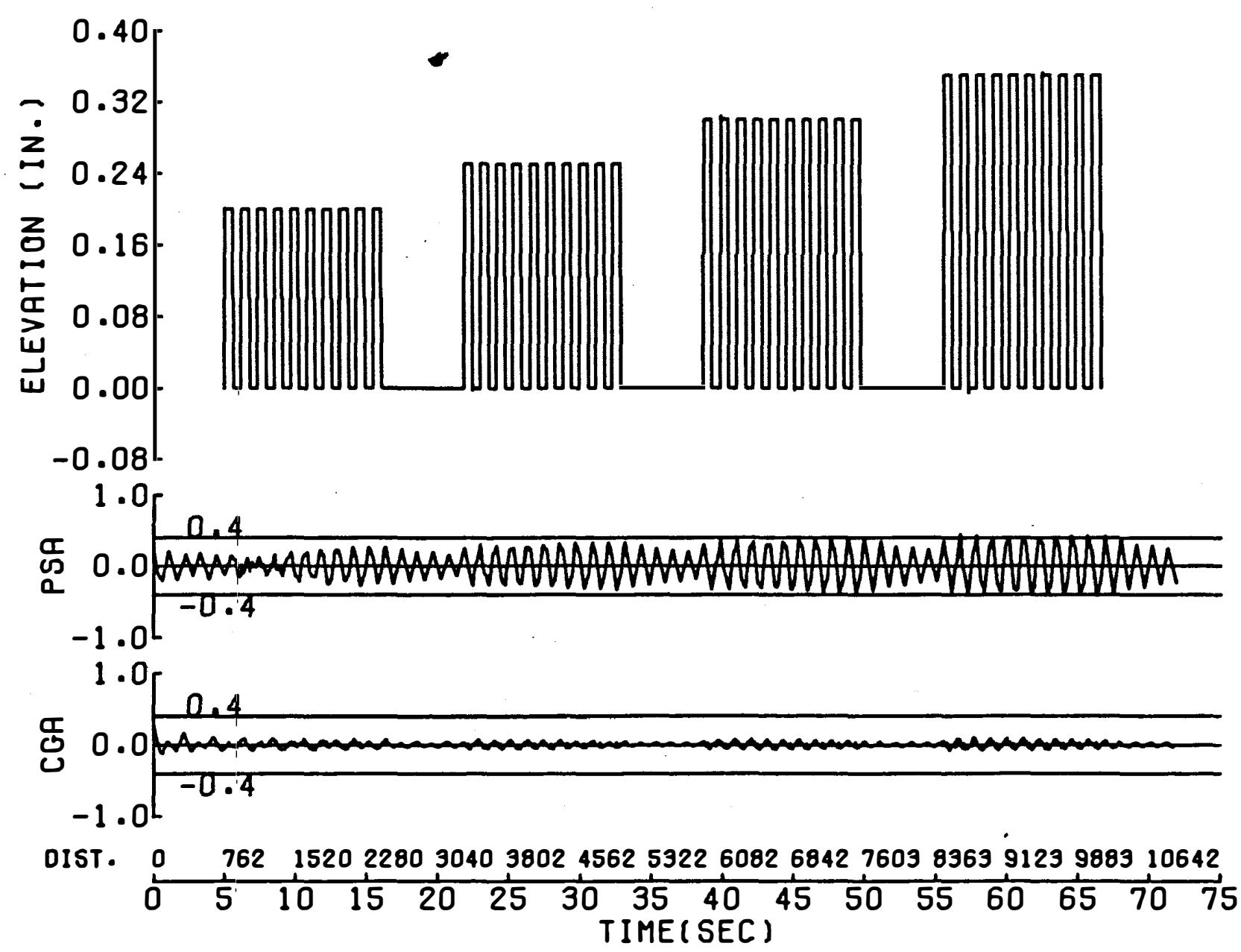

Figure 66. B-52H aircraft response to multi-ramp 2 waveform; taxi speed = $90 \mathrm{knots}$; critical pavement wavelength $=176 \mathrm{ft}$; waveform amplitude $=0.20,0.25,0.30$, and $0.35 \mathrm{in}$. 


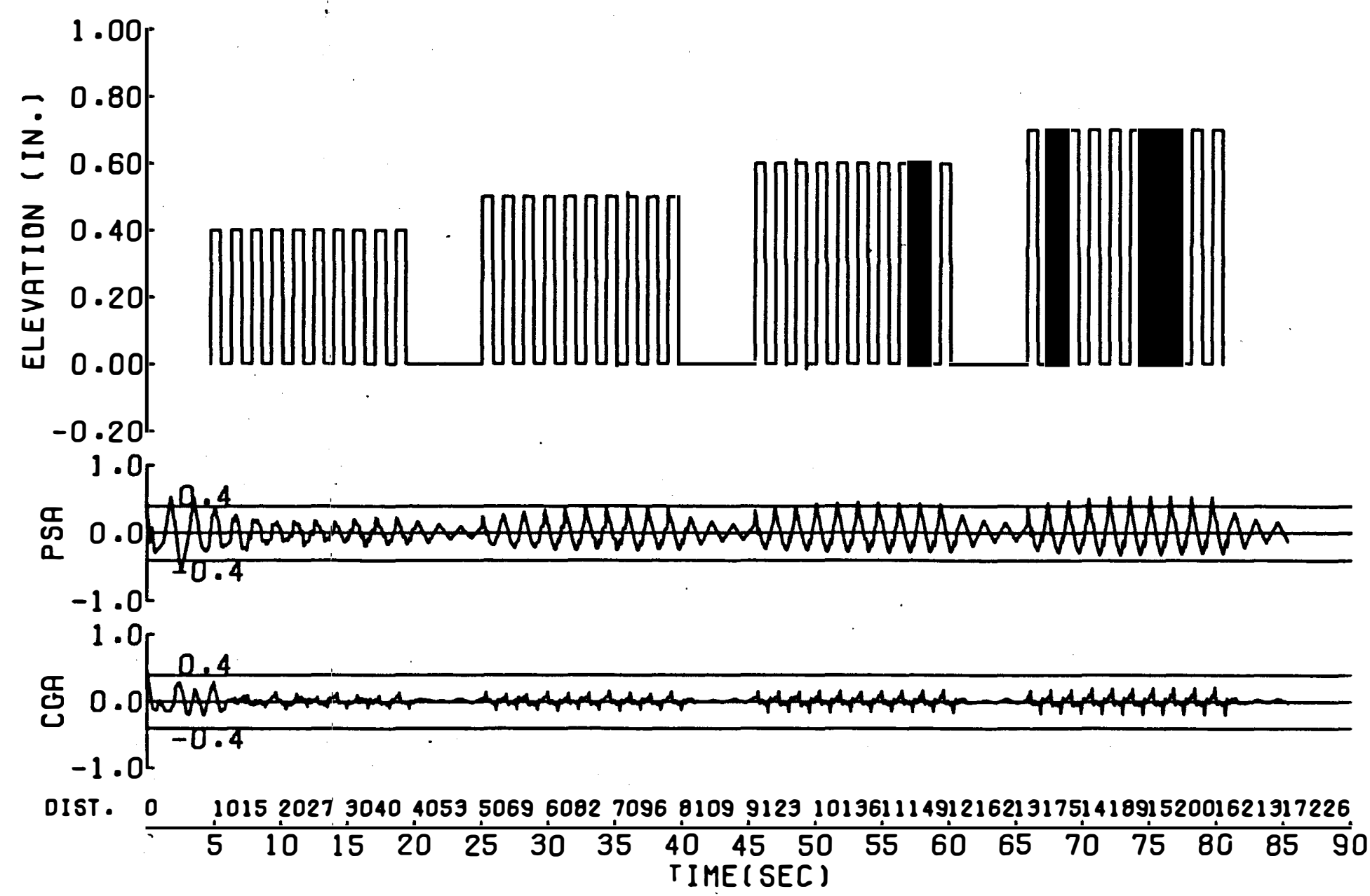

Figure 67. B-52H aircraft response to multi-ramp 2 waveform; taxi speed $=120 \mathrm{knots}$; critical pavement wavelength $=312 \mathrm{ft}$; waveform amplitude $=0.4,0.5,0.6$, and $0.7 \mathrm{in}$. 


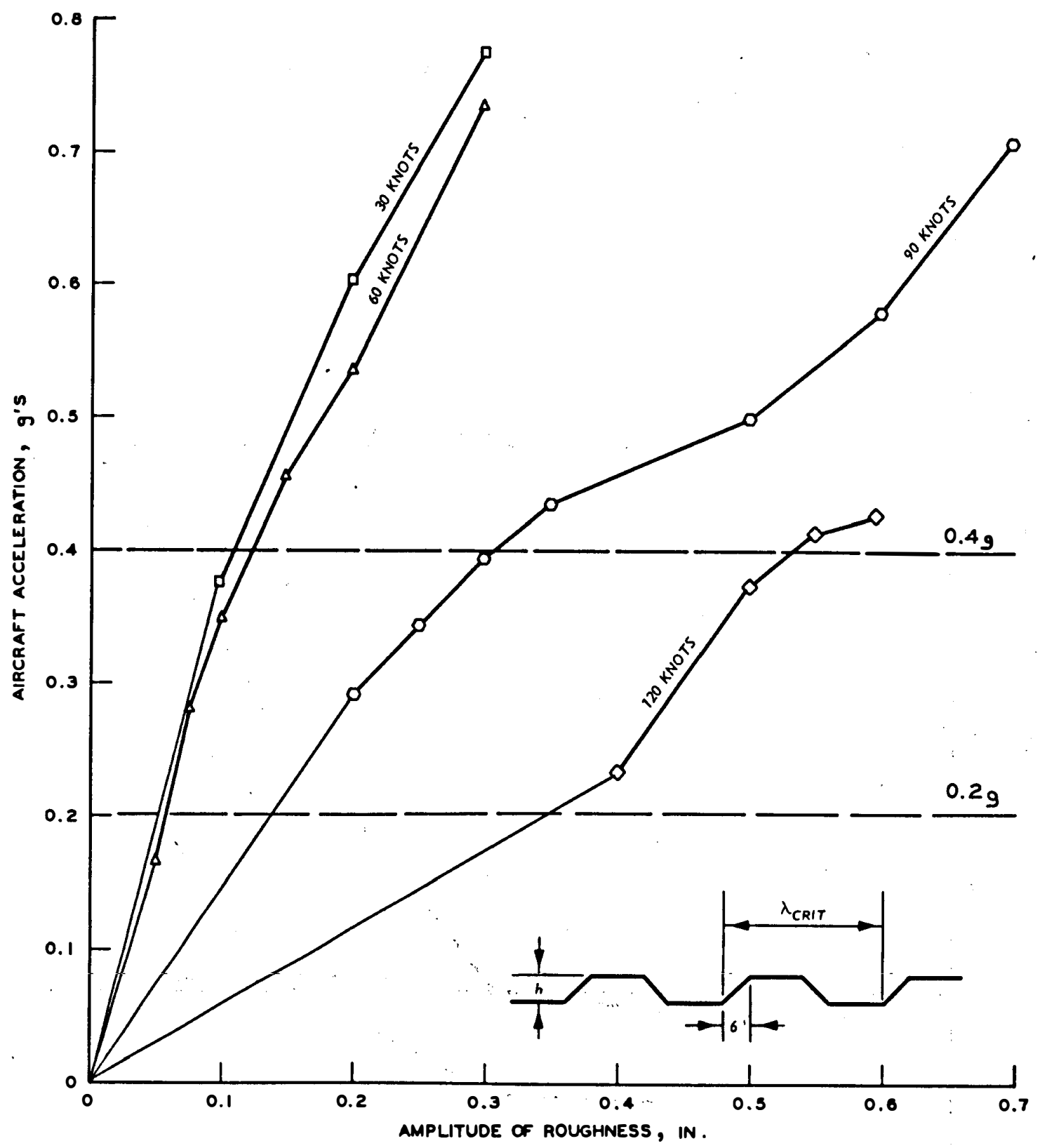

Figure 68. Multi-ramp 2 roughness summary; B-52H 


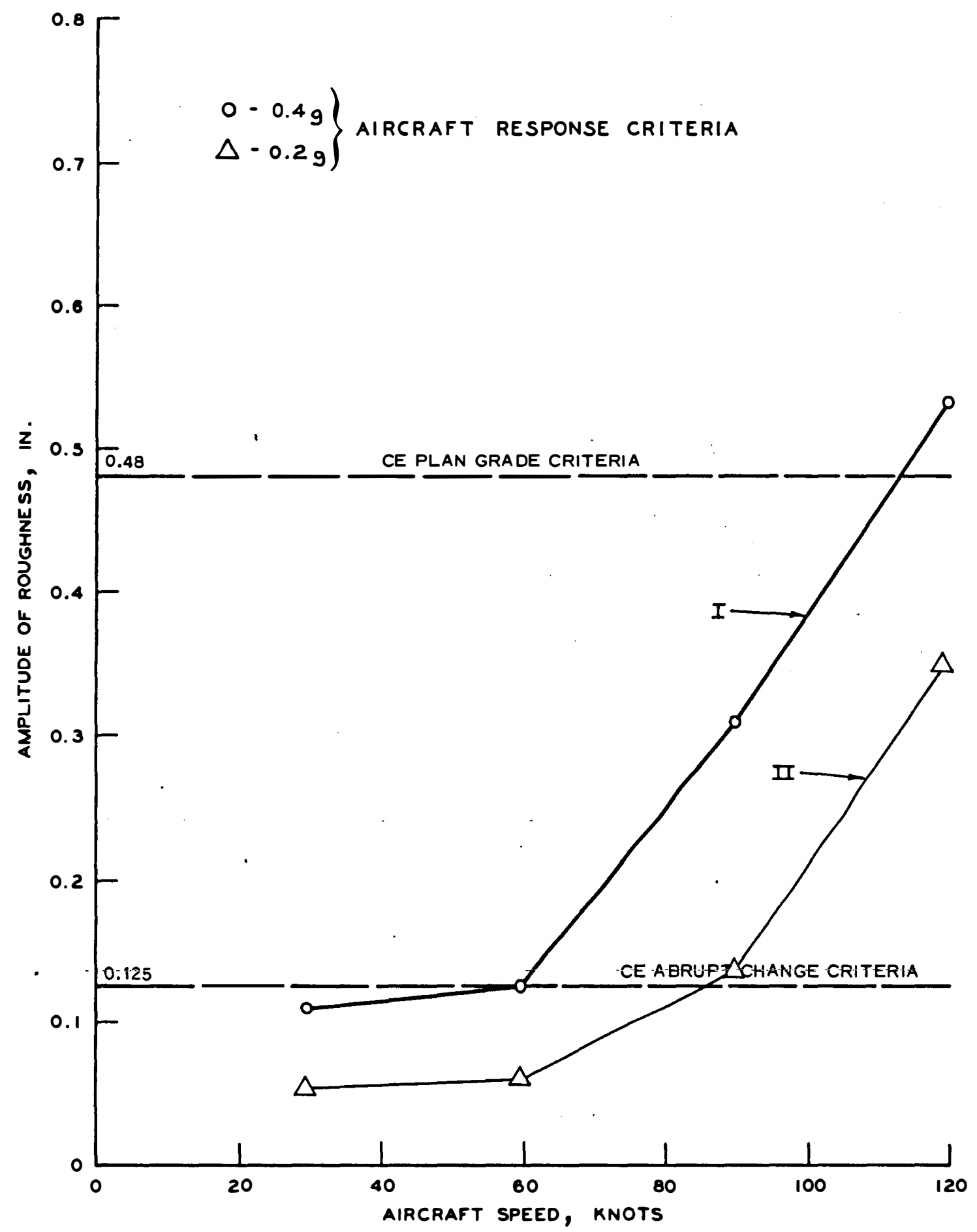

Figure 69. Summary of multi-ramp 2 response data 


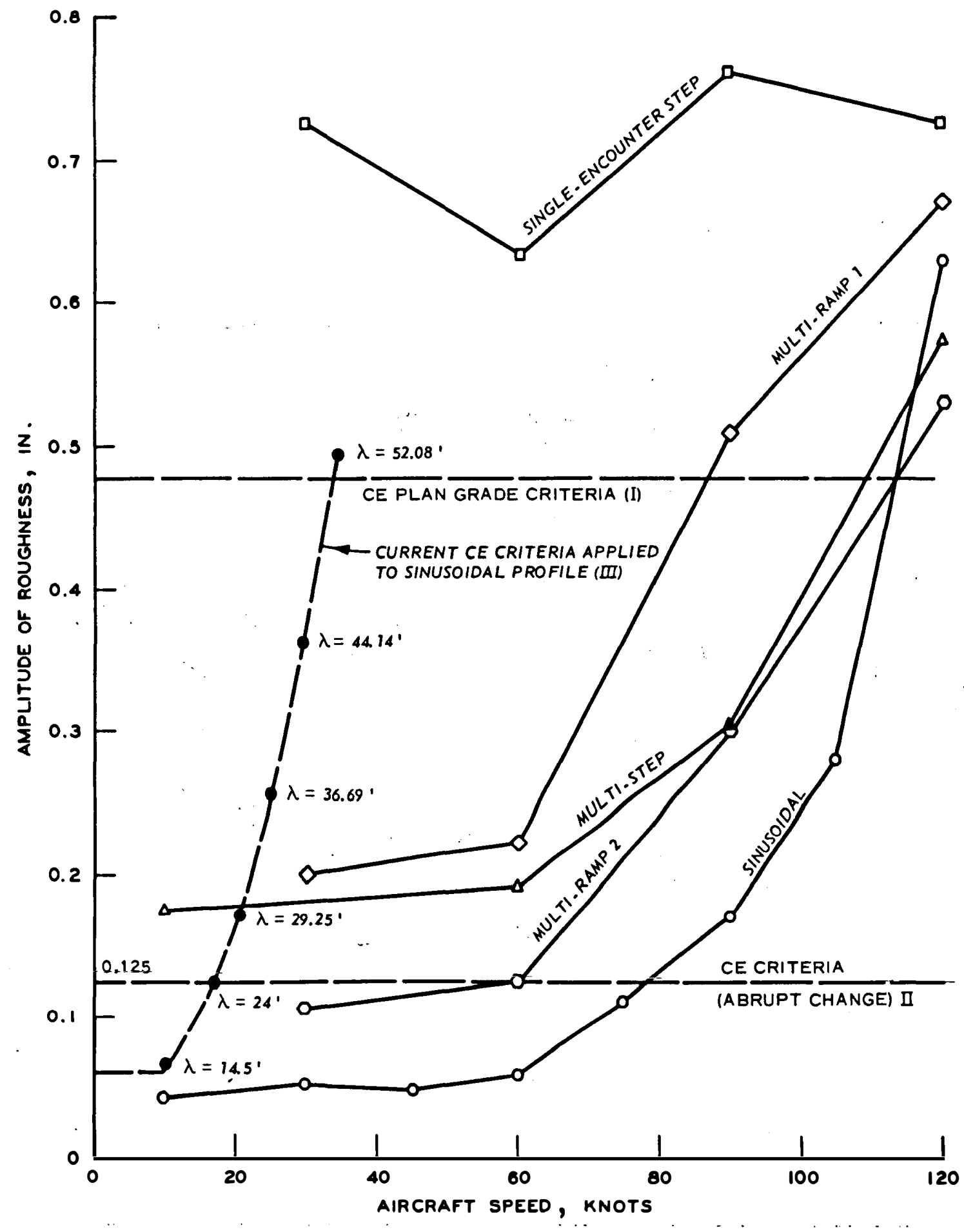

Figure 70. Sumnary of results of parametric study for an acceptable aircraft vertical acceleration of $0.4 \mathrm{~g}$ 


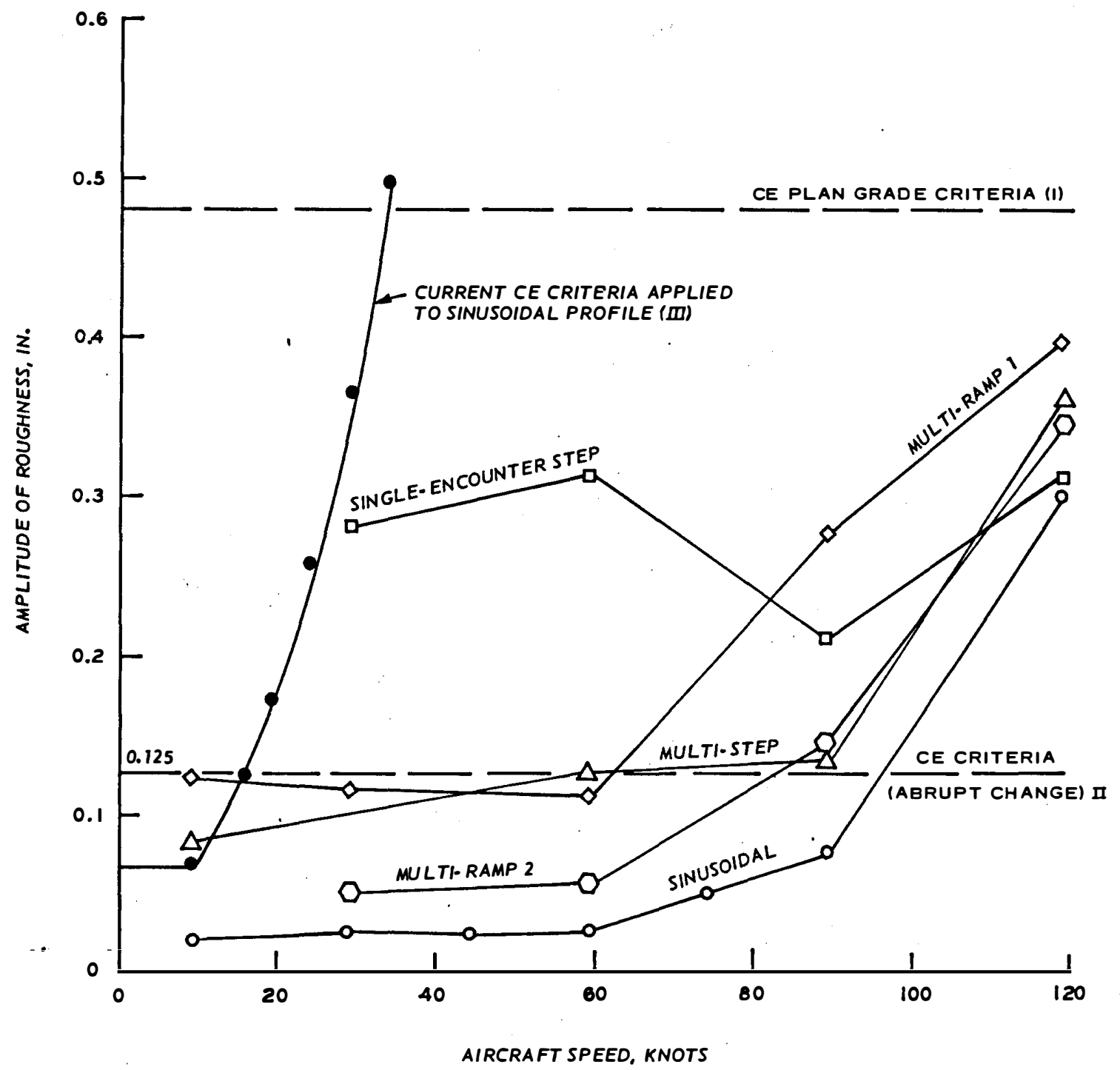

Figure 71. Summary of results of parametric study for an acceptable aircraft vertical acceleration of $0.2 \mathrm{~g}$ 